\title{
Seismic Behavior of Innovative Hybrid CLT-steel Shear Wall for Mid-Rise Buildings.
}

\section{Tulio Carrero Enrique ( $\nabla$ tecarrero@uc.cl)}

Pontificia Universidad Católica de Chile: Pontificia Universidad Catolica de Chile https://orcid.org/0000-0001-8324-0226

Jairo Montaño

Pontificia Universidad Católica de Chile: Pontificia Universidad Catolica de Chile

\section{Sebastián Berwart}

Pontificia Universidad Católica de Chile: Pontificia Universidad Catolica de Chile Hernán Santa María

Pontificia Universidad Católica de Chile: Pontificia Universidad Catolica de Chile

\section{Pablo Guindos}

Pontificia Universidad Católica de Chile: Pontificia Universidad Catolica de Chile

\section{Research Article}

Keywords: hybrid shear wall, connections, cyclic test, seismic design, cross laminated timber, ductility

Posted Date: February 17th, 2021

DOl: https://doi.org/10.21203/rs.3.rs-237940/v1

License: (c) (i) This work is licensed under a Creative Commons Attribution 4.0 International License. Read Full License

Version of Record: A version of this preprint was published at Bulletin of Earthquake Engineering on August 20th, 2021. See the published version at https://doi.org/10.1007/s10518-021-01204-y. 


\title{
Seismic behavior of innovative hybrid CLT-steel shear wall for mid-rise buildings.
}

\author{
Tulio Carrero ${ }^{\mathrm{a}, \mathrm{b}^{*}}$, Jairo Montaño ${ }^{\mathrm{b}}$, Sebastián Berwart ${ }^{\mathrm{b}}$, Hernán Santa María ${ }^{\mathrm{a}, \mathrm{b}}$, Pablo Guindos ${ }^{\mathrm{a}, \mathrm{b}^{*}}$ \\ a Department of Structural and Geotechnical Engineering, Pontificia Universidad Católica de Chile, \\ Av. Vicuña Mackenna, Santiago 6904411, Chile. E-mail: tecarrero@uc.cl, hsm@ing.puc.cl, \\ pguindos@ing.puc.cl \\ b UC Center for Wood Innovation (CIM), Pontificia Universidad Católica de Chile, Av. Vicuña \\ Mackenna, Santiago 6904411, Chile. E-mail: jamontano@uc.cl, siberwart@uc.cl \\ *Corresponding author at: Department of Structural and Geotechnical Engineering, Pontificia Universidad \\ Católica de Chile, Av. Vicuña Mackenna, Santiago 6904411, Chile.
}

\begin{abstract}
This paper examines the seismic behavior of CLT-steel hybrid walls at six-and ten-story heights to increase seismic force resistance compared to a conventional wooden wall. The ultra-strong shear walls proposed in this paper are called Framing Panel Shear Walls (FPSW), which are based on a robust articulated steel frame braced with CLT board panels and steel tendons. Timber structures are well-known for their ecological benefits, as well as their excellent seismic performance, mainly due to high strength-to-weight ratio compared to steel and concrete ones, flexibility, and redundancy. However, in order to meet the requirements regarding the maximum inter-story drifts prescribed in seismic design codes, a challenging engineering problem emerges, because sufficiently resistant, rigid and ductile connections and lateral assemblies are not available for timber to meet both the technical and economical restrictions. Therefore, it is a necessity to develop strong and cost-effective timber-based lateral systems, in order to become a real alternative to mid- and high-rises, especially in seismic countries. In this investigation, the dynamic response of cross-laminated timber (CLT) combined with hollow steel profiles has been investigated in shear wall configuration. After experimental work, an investigation was also carried out into numerical modelling for simulating the cyclic behavior of a hybrid FPSW wall and the spectral modal analysis of a six- and a ten-story buildings with FPSW. A FPSW shear wall can double the capacity and stiffness.
\end{abstract}

Keywords: hybrid shear wall; connections; cyclic test; seismic design; cross laminated timber; ductility.

\section{Introduction}

In some seismic-prone countries, such as Chile, typical wood shear wall configurations may not have enough vertical strength for mid- and high-rise timber buildings. In Chile, the structural design standard (Instituto Nacional de Normalización 2009) was developed in timber constructions for low-rise buildings. Currently, around the world, two predominant structural systems are used in wood construction: platform frame construction (light-frame timber building, LFTB) and cross laminated timber (CLT) construction. Nowadays, mid-height timber buildings are designed using the Special Design Provisions for Wind and Seismic standard (SDPWS) with Commentary (2015) standard for the USA and European Committee for Standardization (2016) as the European Standard. The Chilean code for seismic design of buildings states that CLT walls can have a seismic reduction factor of $\mathrm{R}=2$, which in practical terms implies that CLT buildings respond as elastic material with negligible ductility. Therefore, it is important to develop new designs with larger ductility that can have a higher $\mathrm{R}$ value.

Light platform wood-frame construction is currently the most used type of construction for wood buildings up to six stories in many countries, because of its economic viability. There are other construction systems such as mass timber shear walls, glued laminated timber braced frames and post-and-beam systems, among others. These systems generally make economic sense for the construction of buildings over seven stories high in earthquake-prone areas, especially with seismic protection systems (see Montaño et al. (2020) for supplemental damping mechanisms in wood-framed shear walls). Tables 1 and 2 summarize the results of some recent tests of shear walls for the two current wood construction systems, as well as some tested hybrid walls that represent some new designs.

The CLT system is becoming a more popular and more effective technology for the construction of prefabricated mid-rise buildings. Examples of experimental tests on the load-bearing capacity of CLT walls are presented in Ceccotti et al. (2006) and Gavric et al. (2015). According to Dujic et al. (2006), the importance of properly taking into account the boundary conditions and the influence of the type of vertical and horizontal loading is evident from the comparison of the behavior of differently tested panels. An important finding was that the vertical joints of the walls with gravity loads showed lower deformation 
capacity and initial stiffness of the walls (Gavric et al. 2013) when compared to those without gravity loads. Others, such as Shahnewaz et al. (2018), studied the strength and stiffness of CLT walls subjected to lateral loads. The results showed that the strength and stiffness of CLT walls increase significantly with an increasing number of connectors that are able to take the loads. The lateral load-bearing capacity of CLT walls does not change if the area of openings is up to $30 \%$ of the total size of the wall, but with openings of 50\% the resistance decreases considerably (Dujic et al. 2015). In general, it is assumed that a timber shear wall can suffer three deformation mechanisms in series (see Fig. 1), including rigid body rotation or overturning, rigid body translation and in-plane shear deformation Casagrande et al. (2016).

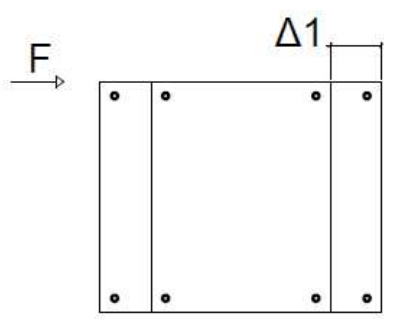

(a) $\Delta_{\text {Rigid body }}=\Delta 1$

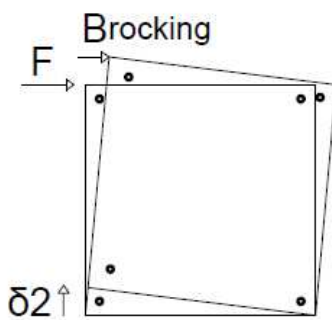

(b) $\Delta_{\text {bending }}=\Delta_{2}=L * \theta=L \frac{\delta_{2}}{B_{\text {rocking }}}$

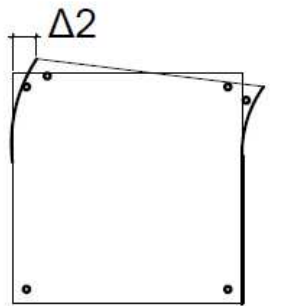

(c) $\Delta_{\text {shear }}=\Delta_{3}=\frac{\delta_{3}}{\cos \left(\theta_{3}\right)}$

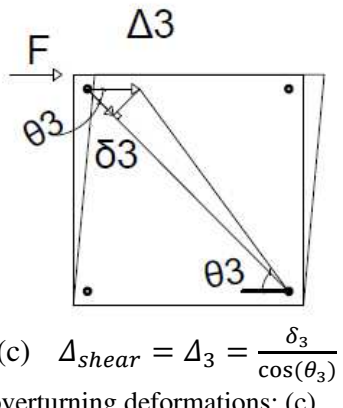

Fig. 1. (a) Lateral displacement due to rigid body; (b) Lateral displacement due to ben
Lateral displacement due to shear deformations.

The influence of the connections is of vital importance in the structural behavior of a timber building. Therefore, the essential requirement for increased ductility of CLT construction (and therefore greater value of the reduction R-factor) is the use of dissipative connectors for shear walls (Carrero et al. 2020). A number of studies have been carried out to determine the response reduction factors (Estrella et al. 2019, Amini et al. 2018, Dechent et al. 2016). Having adequate R-factors for CLT construction can lead to the design of CLT buildings with lower seismic design forces (Guindos 2020).

Solutions that include use of post-tensioned steel cables and dissipative connections with mass timber walls have emerged recently (Priestley et al. 1999), (Iqbal et al. 2015). These new technologies allow for enhanced damage-free behavior of mass timber structures in high seismic zones. These walls use energy dissipation devices such as U-Shaped Flexural Plates (UFPs) between the wall panels in coupled walls, thus providing the energy dissipation. These systems avoid generating any damage and permanent deformations to the walls. Devices such as post-tensioned bars and UFPs have shown good hysteretic behavior with no evidence of loss of stiffness, or any problem regarding the rocking effect (Priestley et al. 1999). There are a few seismic tests on post-tensioned systems around the world, for example in the United States (Pei et al. 2019), Italy (Di Cesare et al. 2017) and New Zealand (Newcombe et al. 2010).

Some hybrid solutions aim to solve the problem of the overturning effect and, consequently, the problem of large inter-story displacements that occur during earthquakes. One case is the use of tendons that is presented in the patent application AU2015367279 (A1) (Murray-Parkes, J 2016), where a connection system for walls stacked along the height of a building is described, allowing post-tensioning walls. This system uses CLT and a series of arrangements by means of steel hollow sections and ATS bars that have the characteristic of providing resistance to lateral forces (wind and earthquakes). The system solves the problem of rocking or overturning of CLT panels but does not quantify how much it improves ductility. On the other hand, patent US9765510 (B2) (Clark Isaac Miller 2017) describes a system of structural panels for use in light construction, up to two stories. Although the described panels are hybrid, with an interior frame made of wood or metal covered by wooden plates on each side, connected by screw-type connectors, the system is limited to two stories because of the small thickness of the material, the structuring of the frame and mainly the weak connections. Also, the most important disadvantage is that it is quite an elaborate system; therefore, it requires to manufacture many special pieces that may be quite expensive if they are meant to be used in a building that is located in a high-seismicity area.

In order for timber buildings to target taller heights in a highly seismic country like Chile, it is mandatory to obtain a substantial enhancement of the lateral force resisting system performance in terms of lateral strength, stiffness and ductility, to decrease the cost of the structure and increase production feasibility. That is why it is necessary to carry out further research regarding the development of elements that can provide those mechanical requirements. The hypothesis of this investigation is that hybrid frame-platform type walls similar to usual wooden frame but combining a steel frame with CLT stiffening plates better seismic behavior than conventional timber shear walls. The main objective is to develop resistance systems 
hybrid structures with CLT for mid-rise buildings in Chile. At this time there is a pending patent that includes the type of wall developed in this research (Guindos et al. 2019).

\subsection{Solutions for structural timber wall systems}

An analysis of experimental results of eleven walls subjected to cyclic tests by several researchers is presented in this section, in order to understand the mechanical properties and behavior of timber walls with different typologies in terms of ultimate load, ductility, vertical strength, stiffness, deformation characteristics, energy dissipation, damping, yield load and yield displacement. Unit strengths and stiffness were evaluated to compare the results obtained by different authors (see Tables 1 and 2). The walls include LFTB system, CLT walls, CLT with steel or timber frame, and plywood panels with steel frame. The wall with plywood panels and steel frame had the largest ductility and highest lateral load capacity ( $242 \mathrm{kN})$. The hysteretic response of CLT walls changes depending on the vertical load and the type of bottom slab (Hummel 2016). Hold-down connections in LFTB generally offer high deformation capacity but little energy dissipation, while angle brackets tolerate less deformation, but offer significantly higher dissipation, Durham et al. (2001).

Table 1. Summary of shear wooden wall tests regarding dimensions, thickness, vertical load applied, and lateral load strength.

\begin{tabular}{|c|c|c|c|c|c|c|}
\hline \multicolumn{2}{|c|}{ Tested Wall } & \multirow{2}{*}{$\begin{array}{c}\text { Length x } \\
\text { Height } \\
\text { [mm x mm] }\end{array}$} & \multirow{2}{*}{$\begin{array}{c}\text { Type } \\
\text { [-] }\end{array}$} & \multirow{2}{*}{$\begin{array}{c}\text { Thickness } \\
{[\mathrm{mm}]} \\
\end{array}$} & \multirow{2}{*}{$\begin{array}{c}\text { Vertical } \\
\text { load } \\
{[\mathrm{kN} / \mathrm{m}]}\end{array}$} & \multirow{2}{*}{$\begin{array}{c}\text { Lateral } \\
\text { strength } \\
\text { Pmax }[k N]\end{array}$} \\
\hline [Reference] & [Wall] & & & & & \\
\hline (Guiñez et al. 2019) & C240-10-02 & $2400 \times 2400$ & LFTB & 160 & 0 & 77.5 \\
\hline (Branco et al. 2017) & $\mathrm{DHC}$ & $1250 \times 1950$ & LFTB & 237 & 0 & 34.26 \\
\hline \multirow{5}{*}{ (Popovski et al. 2011) } & CA-SN-00 & \multirow{5}{*}{$2300 \times 2300$} & \multirow{5}{*}{ CLT } & \multirow{5}{*}{94} & 0 & 88.47 \\
\hline & CA-SN-02 & & & & 10 & 87.24 \\
\hline & CA-SN-03 & & & & 20 & 91.64 \\
\hline & CA-RN-04 & & & & 20 & 99.97 \\
\hline & CA-S2-06 & & & & 20 & 92.61 \\
\hline (Pozza et al. 2014) & Wall A & $2950 \times 2950$ & CLT & 85 & 18.5 & 100 \\
\hline \multirow{2}{*}{ (Hummel et al. 2016) } & W-CLT-St-10 & $2500 \times 2500$ & CLT+Steel base & 105 & 10 & 87.3 \\
\hline & W-CLT-Ti-10 & $2500 \times 2500$ & CLT+Timber base & 105 & 10 & 63.2 \\
\hline (Kho et al. 2018) & Wall 8 & $3600 \times 2400$ & $\begin{array}{c}\text { Steel moment } \\
\text { frame+infill plywood }\end{array}$ & 254 & 0 & 242 \\
\hline
\end{tabular}

Table 2. Summary of shear wooden wall tests regarding ductility, stiffness, unit load capacity, yield and ultimate displacement.

\begin{tabular}{|c|c|c|c|c|c|c|c|c|}
\hline Teste & d wall & Stiffness & $\begin{array}{c}\text { Stiffness } \\
\text { for length }\end{array}$ & $\begin{array}{l}\text { Unit } \\
\text { load }\end{array}$ & $\begin{array}{l}\text { Equivalent } \\
\text { viscous }\end{array}$ & $\begin{array}{c}\text { Yielding } \\
\text { displacement }\end{array}$ & $\begin{array}{c}\text { Ultimate } \\
\text { displacement }\end{array}$ & $\begin{array}{r}\text { Ductility } \\
(\Delta \mathbf{u} / \Delta \mathbf{y})\end{array}$ \\
\hline [Reference] & [Wall] & $\begin{array}{c}\text { Ko } \\
{[\mathrm{kN} / \mathbf{m m}]}\end{array}$ & $\begin{array}{c}\text { Ko } \\
{[\mathrm{kN} / \mathrm{mm} / \mathrm{m}]}\end{array}$ & $\begin{array}{c}v \exp \\
{[\mathrm{kN} / \mathrm{m}]}\end{array}$ & $\xi(\%)$ & $\Delta y[\mathbf{m m}]$ & $\Delta \mathbf{u}[\mathbf{m m}]$ & $\mu$ \\
\hline $\begin{array}{l}\text { (Guiñez et } \\
\text { al. 2019) }\end{array}$ & C240-10-02 & 2.85 & 1.19 & 32.30 & 10.00 & 22.00 & 89.00 & 4.10 \\
\hline $\begin{array}{l}\text { (Branco et } \\
\text { al. 2017) }\end{array}$ & DHC & 0.69 & 0.55 & 27.41 & 27.19 & 45.57 & 65.45 & 1.44 \\
\hline & CA-SN-00 & 3.16 & 1.37 & 38.46 & 16.59 & 25.59 & 64.08 & 2.50 \\
\hline & CA-SN-02 & 4.41 & 1.92 & 37.93 & 14.00 & 17.88 & 66.80 & 3.74 \\
\hline et al 2011) & CA-SN-03 & 4.19 & 1.82 & 39.84 & 13.64 & 20.03 & 64.39 & 3.21 \\
\hline & CA-RN-04 & 6.28 & 2.73 & 43.46 & 10.15 & 14.29 & 55.24 & 3.87 \\
\hline & CA-S2-06 & 4.84 & 2.11 & 40.27 & 12.62 & 16.33 & 46.39 & 2.84 \\
\hline $\begin{array}{c}\text { (Pozza et al. } \\
2014)\end{array}$ & Wall A & 4.76 & 1.61 & 33.90 & 10.57 & 17.83 & 90.00 & 4.48 \\
\hline (Hummel et & $\begin{array}{c}\text { W-CLT-St- } \\
10\end{array}$ & 4.40 & 1.76 & 34.92 & 10.30 & 17.80 & 54.00 & 3.03 \\
\hline al. 2016) & $\begin{array}{c}\text { W-CLT-Ti- } \\
10 \\
\end{array}$ & 3.90 & 1.56 & 25.28 & 8.40 & 14.30 & 78.50 & 5.49 \\
\hline $\begin{array}{c}\text { (Kho et al. } \\
\text { 2018) }\end{array}$ & Wall 8 & 6.60 & 1.83 & 67.22 & - & 21.20 & 160.00 & 7.60 \\
\hline
\end{tabular}

Test results show that CLT walls behave almost as rigid bodies during lateral load testing. Although slight shear deformations in the panels have been measured (Popovski et al. 2011), most of the panel deflections (35\% to $83 \%$ of the total deflection (Hummel 2016) occurred as a result of the deformation of the wall in the foundation joints; this is called the rocking effect. At the same time, deformations in the panel-framing joints also made a significant contribution to the overall wall deflection. Another fact that is important 
depends on the higher withdrawal resistance in CLT walls using ring nails, which exhibited higher resistance, although the ductility behaves differently (Popovski et al. 2011).

\section{Hybrid shear wall proposal}

\subsection{Connections for hybrid walls}

In the first phase of this research project, hybrid unions are defined to obtain behaviors related to each corresponding effect. For more information and details see Carrero et al. (2020). The connection that best behaved at different damage states such as the pinching effect, stiffness degradation and strength degradation, was the CLT-Steel connection shown in Fig. 2. All the information regarding the CLT grade C24 according to the European Committee for Standardization (2016) and its manufacture see in Carrero et al. (2020). It is important to know that different types of specimens were manufactured to test, including combinations of CLT with reinforced concrete (CLT-RCwo) and with post-tensioned concrete (CLT$\mathrm{RCw}$ ), CLT with hollow structural steel profiles (CLT-steel) and CLT with wood. strand rolled (LSL). The lateral resistance, ductility and high dissipation capacity of the CLT-Steel connection was better than the others tested and then the conventional wooden connections. The effect that this type of structure designs on walls would benefit the construction on site, increases the prefabrication in the manufacturing industry.

Table 3. Summary of the monotonic mechanical properties of the tested hybrid connections (Carrero et al. 2020)

\begin{tabular}{ccccc}
\hline Parameter & CLT-Steel & CLT-LSLs & CLT-LSLn & CLT-LSLd \\
\hline $\mathrm{K}(\mathrm{kN} / \mathrm{mm})$ & 2.30 & 0.76 & 0.86 & 1.13 \\
$\mathrm{~F}_{\mathrm{y}}(\mathrm{kN})$ & 5.3 & 7.6 & 3.0 & 4.2 \\
$\Delta_{\mathrm{y}}(\mathrm{mm})$ & 2.98 & 10.0 & 3.48 & 6.4 \\
$\mathrm{~F}_{\max }(\mathrm{kN})$ & 8.20 & 9.0 & 6.22 & 7.32 \\
$\Delta_{\mathrm{u}}(\mathrm{mm})$ & 26.5 & 21.5 & 30 & 26.3 \\
$\mu$ (unitsless) & 8.89 & 2.15 & 8.62 & 4.11 \\
\hline
\end{tabular}

The mechanical seismic parameters obtained from the averaged monotonic tests are summarized in Table 3; all connections are high-ductility class according to European Committee for Standardization (2016). It must be clear that the CLT-LSLs connections are with self-tapping screws, the CLT-LSLn connections with annular ring nails, and the CLT-LSLd joints with dowels. The CLT-steel connection using steel selfdrilling dowels as connectors gave the highest stiffness and ductility results, Carrero et al. (2020), in comparison to the other connections tested. Full details of the hybrid CLT-steel connection design are presented in previous research (Carrero et al. 2020). Characteristic values of strength and elastic properties in $\mathrm{N} / \mathrm{mm}^{2}$ and density in $\mathrm{kg} / \mathrm{m}^{3}$ for CLT comprising timber layers derived from the properties of the timber laminations can be found in Brandner et al. (2018).

After obtaining the results of the seismic parameters of the connections, we are interested in finding the verification of the shear wall lateral capacity and see the difference that exists by varying the separation between connector and the thickness of the CLT panel (Table 4). Therefore, there is a comparison, with regards to the load-carrying capacity, with a $200-\mathrm{mm}, 150-\mathrm{mm}, 100-\mathrm{mm}$, and 50-mm self-tapping dowel spacing for each material and different panel thicknesses, between CLT with steel, concrete and LSL (see Table 5). These results were calculated using a non-linear model in the MCASHEW program (see section 5 for more information). On the other hand, a CLT-Designer program is used to analyze the panel shear capacity for various panel thicknesses. For the admissible capacity of the CLT-steel wall with 150-mm spacing for pre-design, the lateral strength for panel shear capacity at $60 \mathrm{~mm}$ is verified. As the hypothesis of this analysis was the consideration of ductility implemented for this type connection, it showed a good resistance behavior.

Table 4. Shear capacity expected

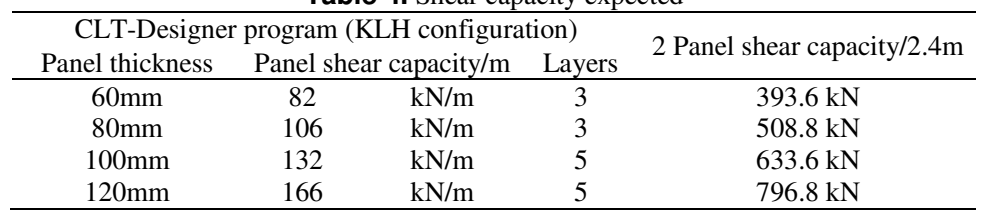

Table 5. Different load-carrying capacity configurations in previous research

\begin{tabular}{|c|c|c|c|c|c|}
\hline \multicolumn{6}{|c|}{ Load-carrying capacity } \\
\hline \multirow[b]{2}{*}{ Material } & Panel & Sel & tapping d & owel spac & \\
\hline & $\begin{array}{l}\text { thickness } \\
\text { (mm) }\end{array}$ & $200 \mathrm{~mm}$ & $150 \mathrm{~mm}$ & $100 \mathrm{~mm}$ & $50 \mathrm{~mm}$ \\
\hline
\end{tabular}




\begin{tabular}{cccccc}
\hline & 60 & 229.04 & 278.72 & 412.27 & 793.71 \\
CLT- & 80 & 229.22 & 278.81 & 412.84 & 792.26 \\
steel & 100 & 229.18 & 278.79 & 413.19 & 791.17 \\
& 120 & 229.26 & 278.75 & 413.41 & 790.35 \\
\hline \multirow{3}{*}{ CLT- } & 60 & 229.15 & 278.88 & 412.85 & 792.78 \\
Rcwo & 100 & 229.29 & 278.76 & 413.4 & 791.08 \\
& 120 & 229.21 & 278.73 & 413.65 & 789.91 \\
& 60 & 229.3 & 278.7 & 413.85 & 789.15 \\
\hline \multirow{2}{*}{ CLT- } & 80 & 229.35 & 278.87 & 413.59 & 789.84 \\
LSLd & 100 & 229.27 & 278.73 & 413.97 & 788.22 \\
& 120 & 229.24 & 278.82 & 414.29 & 786.13 \\
\hline
\end{tabular}

\subsection{Discussion of CLT-steel connection results}

It is important to understand that behind the CLT-steel there is twice the energy dissipation of the other types of connectors, see in Carrero et al. (2020). They also generate stiffer, high-strength connections compared to conventional (wood-wood) connections. In relation to details of the failures that occurred in the tests, see Carrero et al. (2020) (Fig. 3).

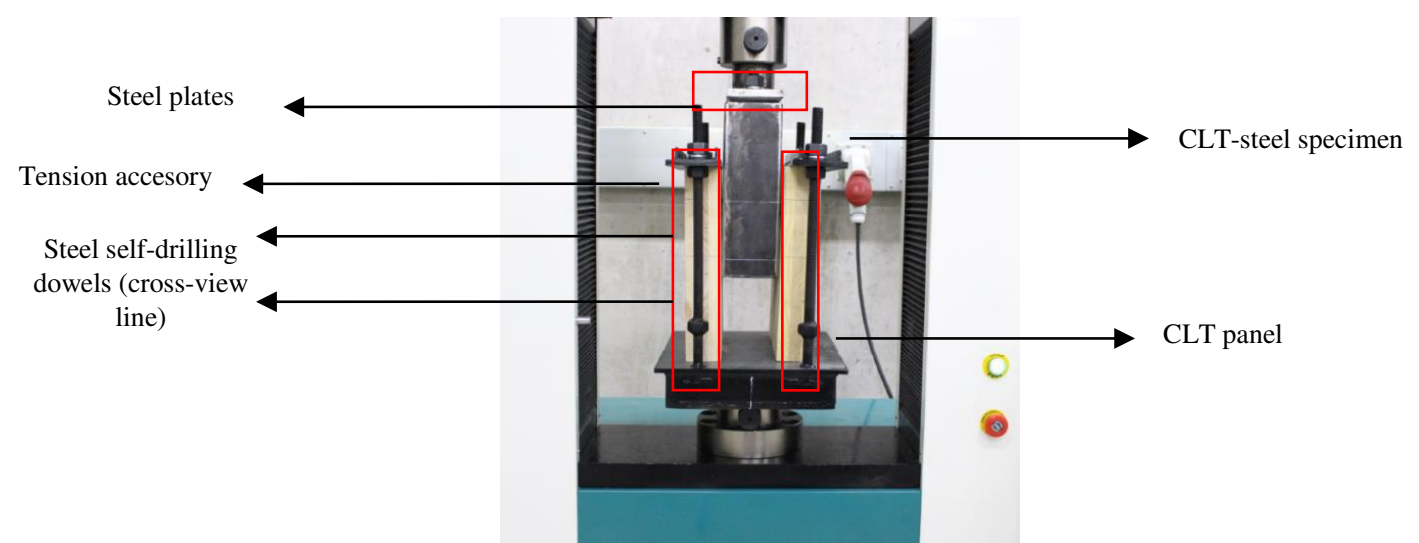

Fig. 2. Mechanical testing of the connection according to EN 12512, including the layout for the CLT-steel connection during cyclic testing (Carrero et al. 2020).
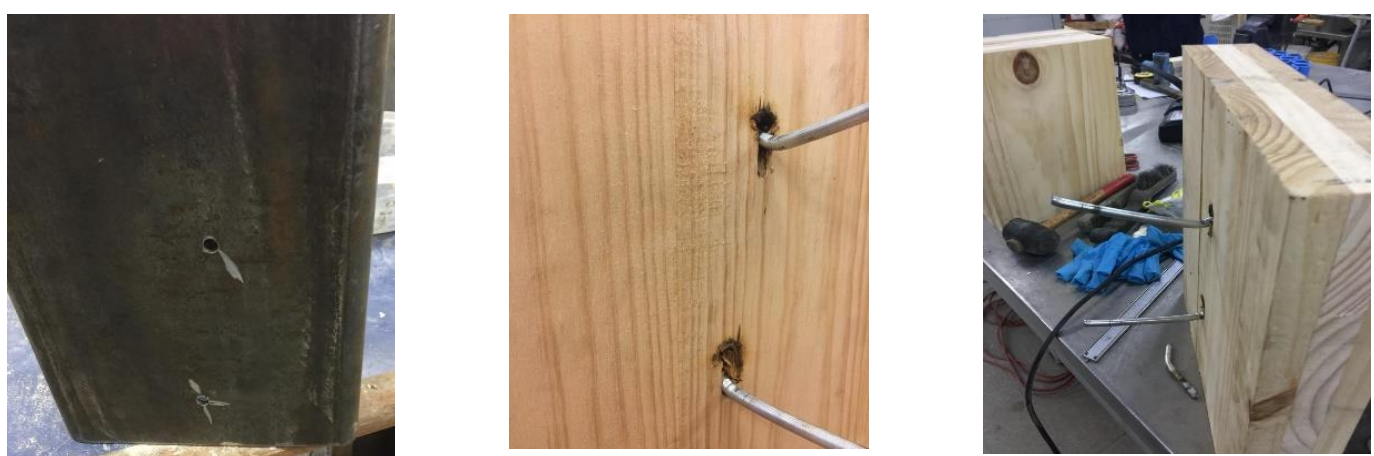

Fig. 3. Ductile failure after fatigue of the dowels in the CLT-steel connection (Carrero et al. 2020).

\subsection{Development of hybrid FPSW solution}

The need for a system of shear walls that allows to construct medium-height wooden buildings in highly seismic areas is evident, and can be achieved by increasing the reduction factor of seismic design R for construction with wood; consequently, increasing the axial load capacity with respect to conventional wooden walls through the use of steel will allow to considerably reduce the number of necessary shear walls and significantly reduce construction costs.

The strong shear walls proposed in this paper (Framing CLT panel shear walls, FPSW), consist of a robust, fully articulated steel frame braced with CLT panels and vertical steel tendons. The hybrid shear wall 
described in Fig. 4 comprises an interior frame (100) with hinged nodes (110) for the connection between columns (120) and beams (130), to which exterior massive wood panels (200) are attached on both faces by means of individual CLT hybrid energy-dissipating connectors (300); the frame (100) comprises posttensioned self-centering tendons (400), as can be seen in Fig. 4. For more details see the pending patent in Guindos et al. (2019).
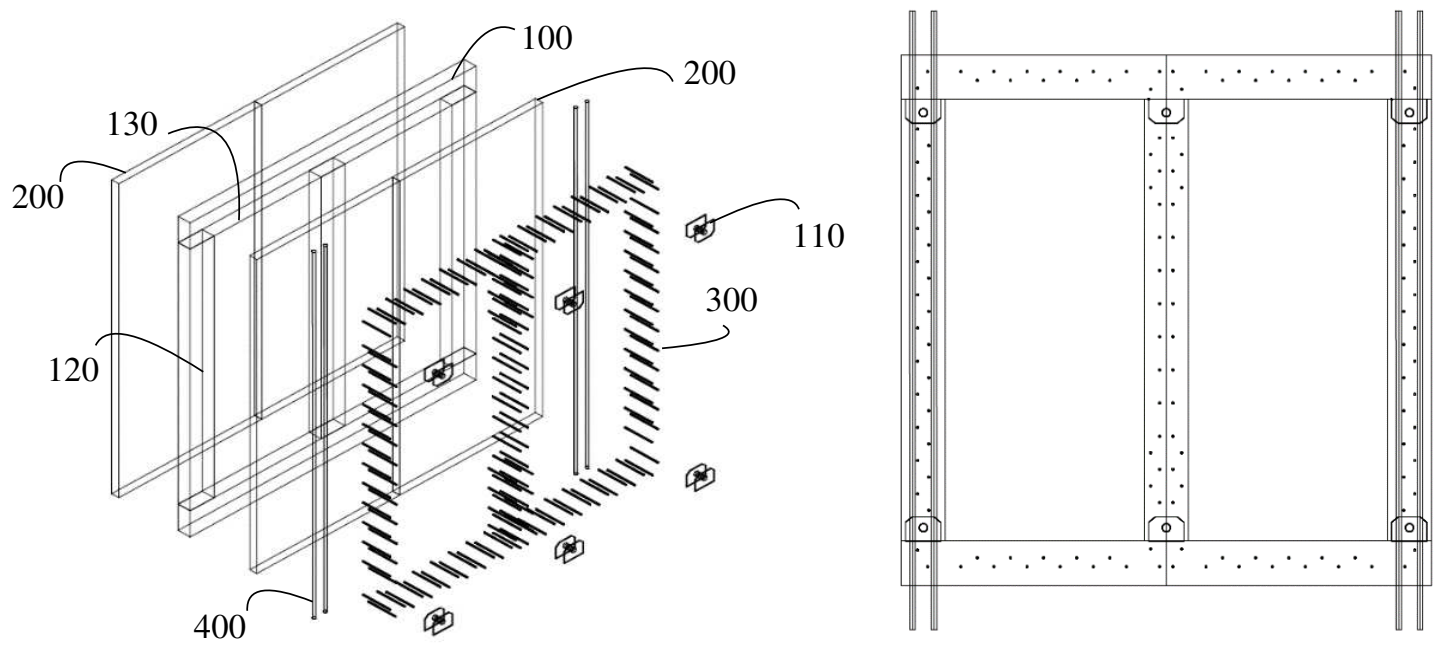

Fig. 4. Schematic isometry of Robust framing CLT, Frame-Panel Shear Wall (FPSW) by Guindos et al. (2019).

Another objective of the invention (FPSW) is to provide a shear wall system that has high ductility concentrated in a high energy-dissipation effect of the system, allowing the load to be uniformly distributed along the entire perimeter of the shear wall. The final and main objective is to provide a shear wall system that allows a significant reduction of the overturning effect, avoiding the lifting and displacement of the walls, which translates into greater rigidity and reduction of the maximum value of the drift. Another aim is to provide a shear wall system that allows to reduce rehabilitation costs after the seismic event, ensuring that the integrity is not compromised when the gravitational load-bearing elements are damaged.

The mechanical joints between the beams and columns are articulated node-type assemblies, consisting of a normally pivoting mechanical joint that allows an assembly with relative movement on a plane. By having this type of joints in the structure of the interior frame, the stiffness and lateral resistance of the wall are dominated by the CLT panels (see Fig. 5). The articulated joints remain in an elastic regime, limiting the displacements of the rigid body. Thus, the predominant deformation for non-slender walls is clearly shear, so that the capacity and stiffness can be assumed to be proportional to the length of the wall. As the frames are made of hollow steel profiles, the mechanical connection consists of articulated nodes, preferably containing a pair of rigid steel support plates, parallel to each other and crossed by a transverse pin connection. The self-tapping dowel connectors are individual elements, which are installed around the perimeter of the CLT panel. The function of the connectors is to brace the frame with respect to the seismic shear force. The connectors are the weak point of the structure, so the failure occurs intentionally there, allowing a lot of ductility until the ultimate failure is reached. This allows accurate prediction of stress in the components and especially in the joints, so that the structural design and its experimental response can be easily predicted with great precision. 


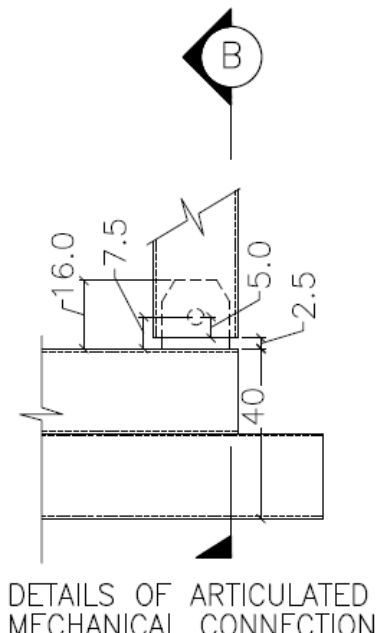

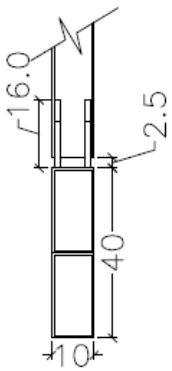

$B-B^{\prime}$

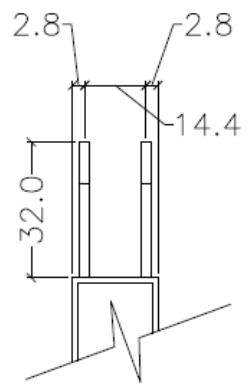

METAL PLATES

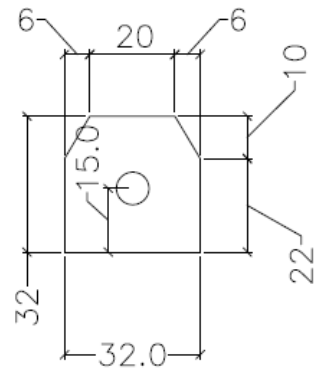

METAL PLATES - $16 \times 16 \times 1.0 \mathrm{~cm}$ AMOUNT OF $=12$ UNITS. PERFORATION $\phi=3.8 \mathrm{~cm}$

Fig. 5. Test details from mechanical articulated connection (lengths in millimeters).

The fastening spacing in the CLT was set according to the European Committee for Standardization (2005). The minimum required thicknesses of members were verified to ensure ductile failure modes in all connections, because this failure mode is preferred. The hybrid system should be designed taking advantage of each material. The different results of the numerical and experimental test might be analyzed for a final response to the study. This will indicate if we can validate the experimental response with numerical modeling (MCASHEW) by Pang et al. (2007), obtaining the optimization of the system. We will also be able to know the load capacities (shear resistance) and capacities of lateral displacement (drift).

The proposed wall is based on five well-known principles. First, when bracing a hinged frame (without rotational stiffness at the connections of the frame members) with wooden boards (CLT), its stiffness and lateral resistance are governed by the board-frame joints. This implies that it is possible to significantly increase the stiffness and lateral resistance of the wall by increasing the size of the connectors and decreasing their spacing. Second, it is possible to obtain ductile failure modes (Johansen, K.W 1949, mode IV according to Norma Chilena Oficial "NCh 1198" 2014) in slender connectors of large dimensions, as long as the minimum thickness (resistance) provided by the frame and the board is sufficient. Third, the structural redundancy and the ductility of a wooden wall increase substantially by increasing the number of connectors (reducing dowel spacing). On the other hand, it is possible to anchor a timber wall to the rigid body tipping movement (lifting or rocking) using steel cables (ATS). Thus, in addition, the wooden posts will only be applied to compression, never to tension, so that the design resistance of the same can be assumed to be much higher. Furthermore, the wooden walls that are anchored to the floor, and whose rigidity and lateral resistance are governed by the panel-frame connectors, present a rigidity and lateral resistance that are linearly proportional to the length, because the dominant deformation is shear. This generates a very predictable seismic response that can be calculated with simple models.

\section{Experimental tests}

This section provides a description of the test specimens and testing procedures. A discussion of the materials, construction details, instrumentation, and data acquisition system is included. The study is focused on improving the lateral behavior of shear walls in the platform frame system with hybrid shear walls, applied to buildings from six to ten stories high.

\subsection{Test set up}

The test setup is shown in Figures 6 and 7. The test specimen consists of a wall $2400 \mathrm{~mm}$ long and 2400 $\mathrm{mm}$ high. The lower and upper hollow steel beams of the test specimen are connected to three hollow steel columns of the transvers area of each frame $(200 \mathrm{~mm}$ x $100 \mathrm{~mm})$ with a 6-mm thickness each, using a steel self-tapping dowel WS of $7 \mathrm{~mm}$ in diameter and $233 \mathrm{~mm}$ in length, alternated every $150 \mathrm{~mm}$ center to center (Fig. 8). No vertical load was applied to the wall during the test. 


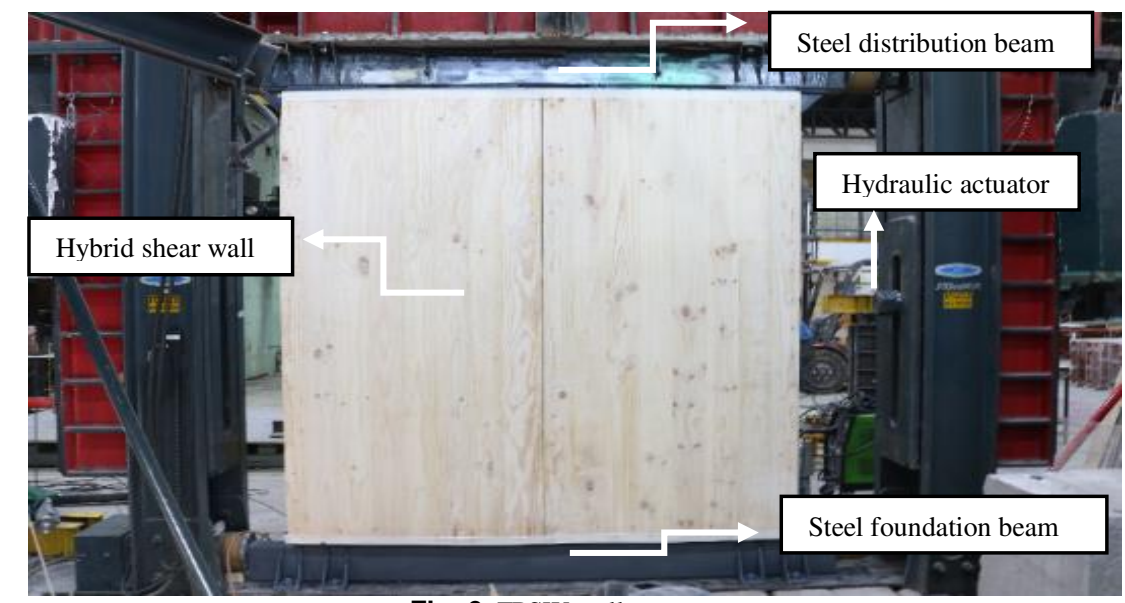

Fig. 6. FPSW wall test setup.

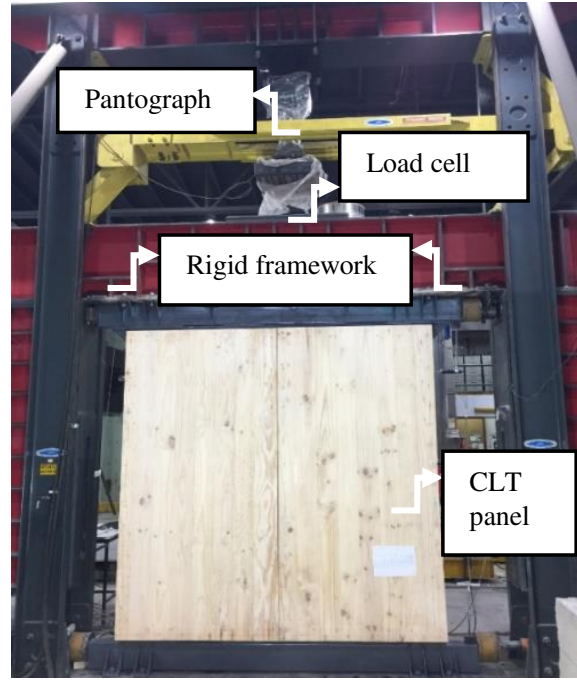

(a)

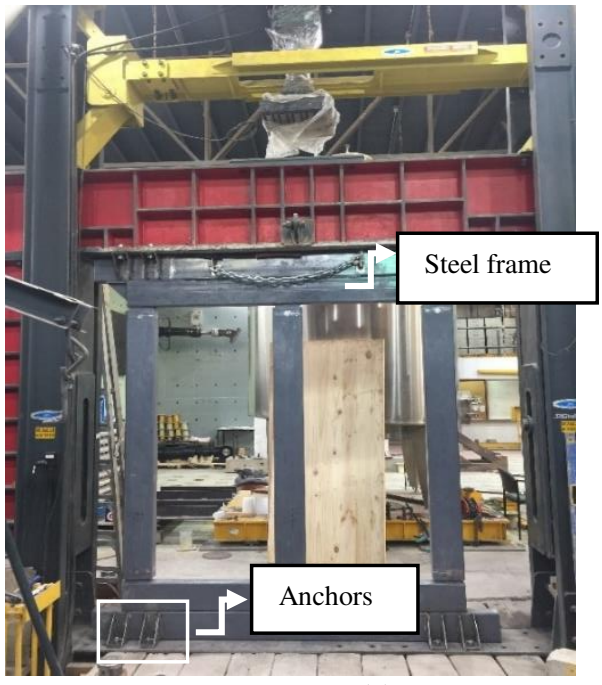

(b)

Fig. 7. Details from FPSW configuration: (a) CLT panel assembly; (b) hollow steel frame assembly.

The wood is mechanically classified as an MGP10-grade Pinus radiata. As can be seen in Figures 6 and 7 , the anchors used with the bars of the ATS system were not included in the configuration of this test for simplicity of implementation. The ATS bars were not included in the test because it was difficult to match the position of the ATS bars within the loading frame with the exact location of the pre-existing anchor grid (every $500 \mathrm{~mm}$ x $500 \mathrm{~mm}$ ) in the lower reaction slab in the laboratory of the Pontificia Universidad Católica de Chile. Instead, steel mechanism and eight 38-mm diameter bolts were used to resist tension forces of $458 \mathrm{kN}$ at each edge stud. Under the beams are bolts and steel teeth to allow the wall to move laterally on its plane in a free form. Vertical studs are spaced at $1200 \mathrm{~mm}$.

The hydraulic actuator has a capacity of $500 \mathrm{kN}$ and a travel range of $\pm 200 \mathrm{~mm}$. It was secured between the support and the distribution beams by hinged connections, as shown in Figures 8 and 9. The hinged connections are present to release any moment. Hydraulic jacks were placed at the foundation beam to restrict sliding of the wall obtaining only a shear deformation.
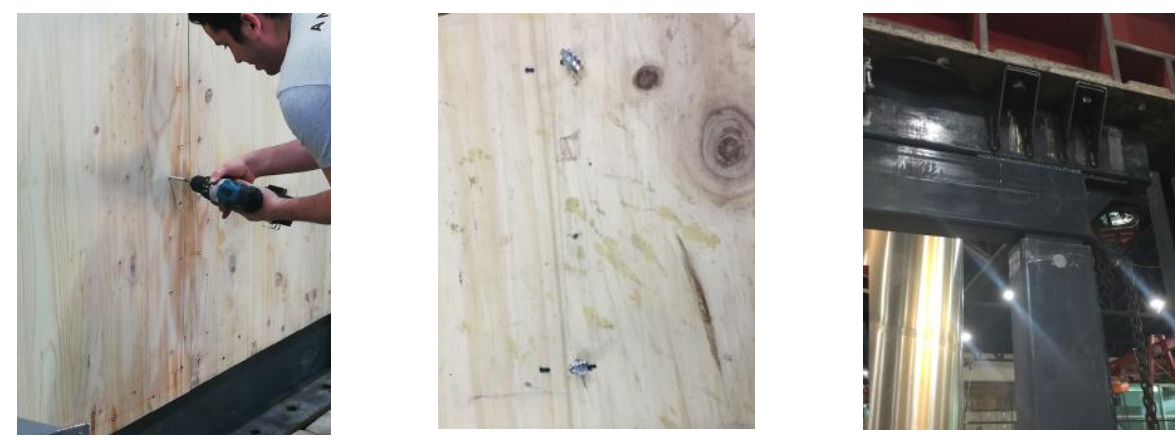
Fig. 8. Test setup procedure: (a) drilling the CLT panels; (b) pins

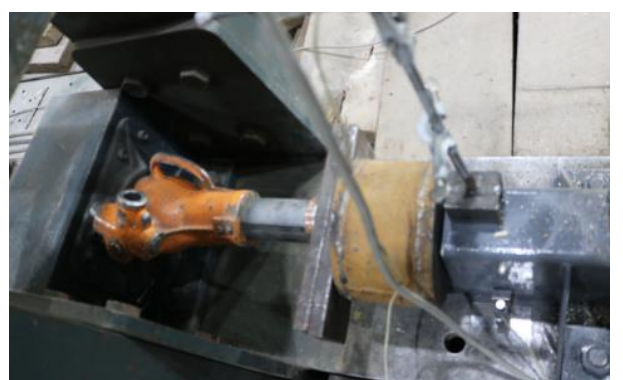

(a) connections. (b)

(c)

Fig. 9. Test configuration: (a) hydraulic jack to reduce displacement; (b) hydraulic actuator (500kN).

Following the test, standard cyclic tests (European Committee for Standardization 2013), the FPSW shear wall were set up on a total of 128 self-taping dowels $(\phi 7 \mathrm{~mm})$, and 6 bolted steel mechanical connections ( $\phi 38 \mathrm{~mm})$. The timber specimens were all made of CLT produced by gluing Chilean Pinus radiata boards of 20x150 mm in cross section and C24 grading class according to European Committee for Standardization (2016) at the fabrication plant of Forestal Tricahue Ltda., Coronel, Chile. The gluing was performed at both the edges and faces of the boards, casting a 3-ply laminate with a $60-\mathrm{mm}$ thickness. Finally, the use of steel cables (ATS) that hold the wall axially it is replaced in this case for 8 bolted connections at the top and bottom of the beams from the loading frame prevent an overturning deformation, checked on LVDT (Fig. $10)$.

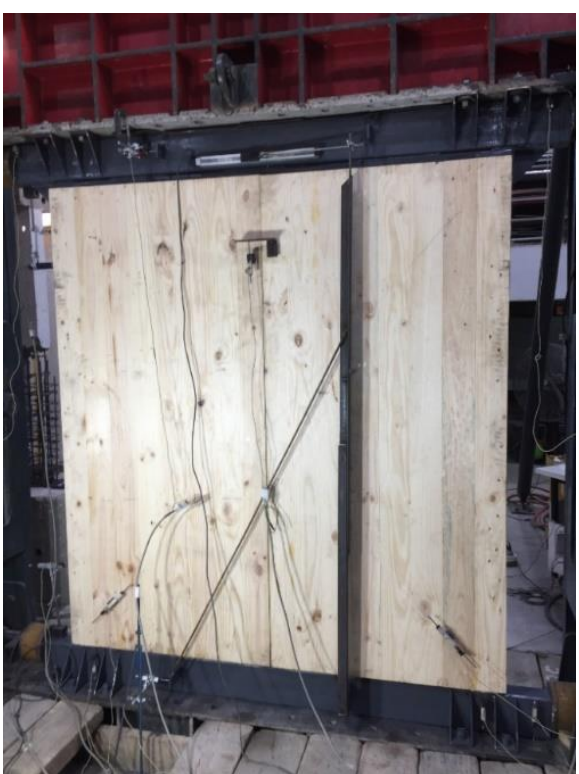

(a)

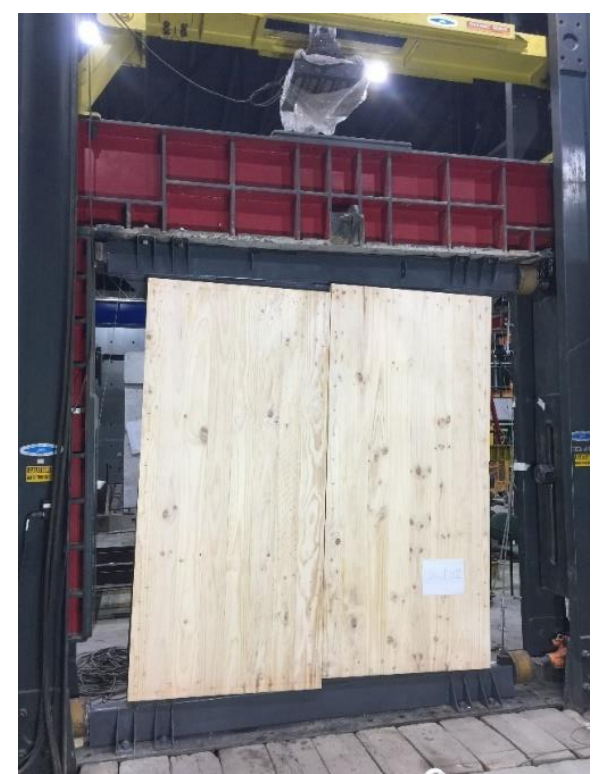

(b)

Fig. 10. Illustration of a FPSW wall: (a) instrumentation measures behind the wall; (b) the specimen in final loop from reversed cyclic test on loading frame.

\subsection{Load protocol}

The load protocol used for the wall consisted of the cyclic protocol used for testing (Fig. 11) according to the European Committee for Standardization, 2013. The EN 12512 method was used to perform the cyclic protocol at a speed of $0.2 \mathrm{~mm} / \mathrm{sec}$ in the case of connections and $0.1 \mathrm{~mm} / \mathrm{sec}$ on the walls. 


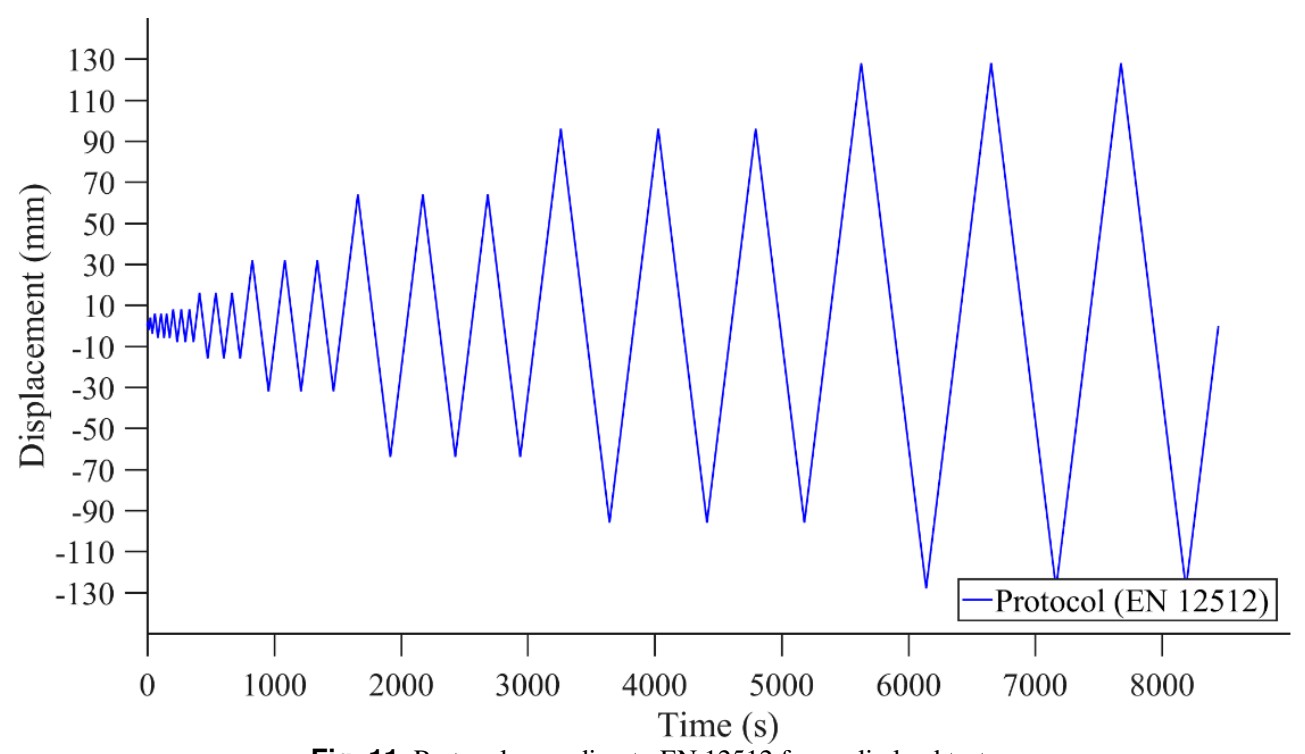

Fig. 11. Protocol according to EN 12512 for cyclic load test.

\subsection{Instrumentation}

Fifteen channels of the data acquisition system (CATMAN external hardware) were used to take readings on the walls. The channel number and its corresponding measurement are given in Fig. 12. An internal linear variable differential transducer, LVDT, and the $500 \mathrm{kN}$ load cell in the actuator took measurements at the top of the wall.

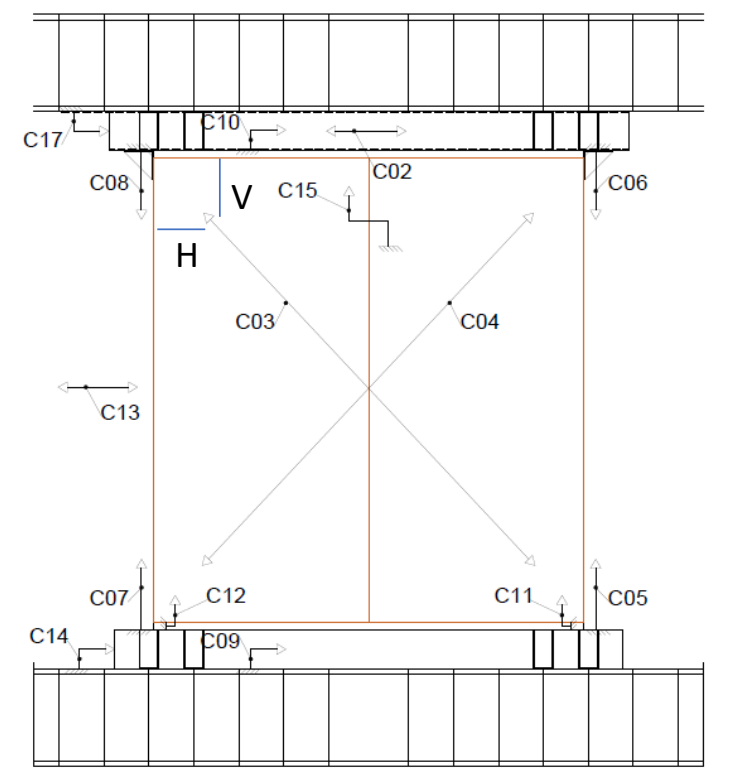

Instruments (measures):

$\mathrm{C}=$ HBM channel.

C15 = relative displacement measurement between CLT plates.

$\mathrm{C} 11 \& \mathrm{C} 12=$ relative deformation measurement between

CLT and lower steel sole.

$\mathrm{C} 02=$ global displacement of the actuator.

$\mathrm{C} 03$ \& $\mathrm{C} 04=$ measurement of diagonal deformation

$\mathrm{C} 07=$ left uplift bottom.

$\mathrm{C} 05=$ right uplift bottom .

C08 = left uplift top.

C06 $=$ right uplift top.

C14 = bottom displacement.

$\mathrm{C} 17=$ top displacement

$\mathrm{C} 13=$ records load (cell).

$\mathrm{C} 09=$ bottom relative displacement

$\mathrm{C} 10=$ top relative displacement

Fig. 12. Elevation-front view with LVDT locations.

An LVDT (channel C13) was used to measure the horizontal deflection at the top of the wall. The locations of diagonal transducers used to measure shear deformations are $\mathrm{H}$ and $\mathrm{V}=250 \mathrm{~mm}$. Instrumentation included vertical LVDTs located at the top and bottom of the wall to measure the overturning deformations (chanels C05 throuh C08). In Fig. 13 we can see the test adquisition system (CATMAN) for the CLT-steel wall. 

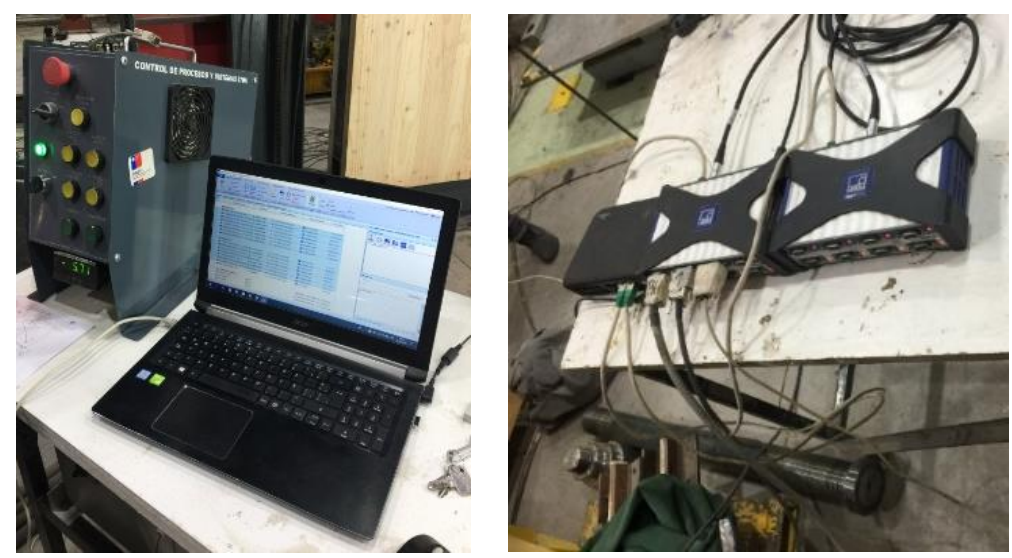

Fig. 13. Data acquisition equipment connected to LVDT and load cell.

\section{Test results}

The results of the FPSW (CLT-steel) wall test are presented in Table 6. The strain and maximum tensile and compressive strength per cycle of the wall test are presented, as well as the secant stiffness, hysteretic dissipation energy, and equivalent viscous damping per cycle. This wall was tested in the Structural Engineering Laboratory of the Faculty of Engineering of the Pontificia Universidad Católica de Chile. The envelope for the hysteretic curve from the FPSW shear wall is presented in Fig. 14.

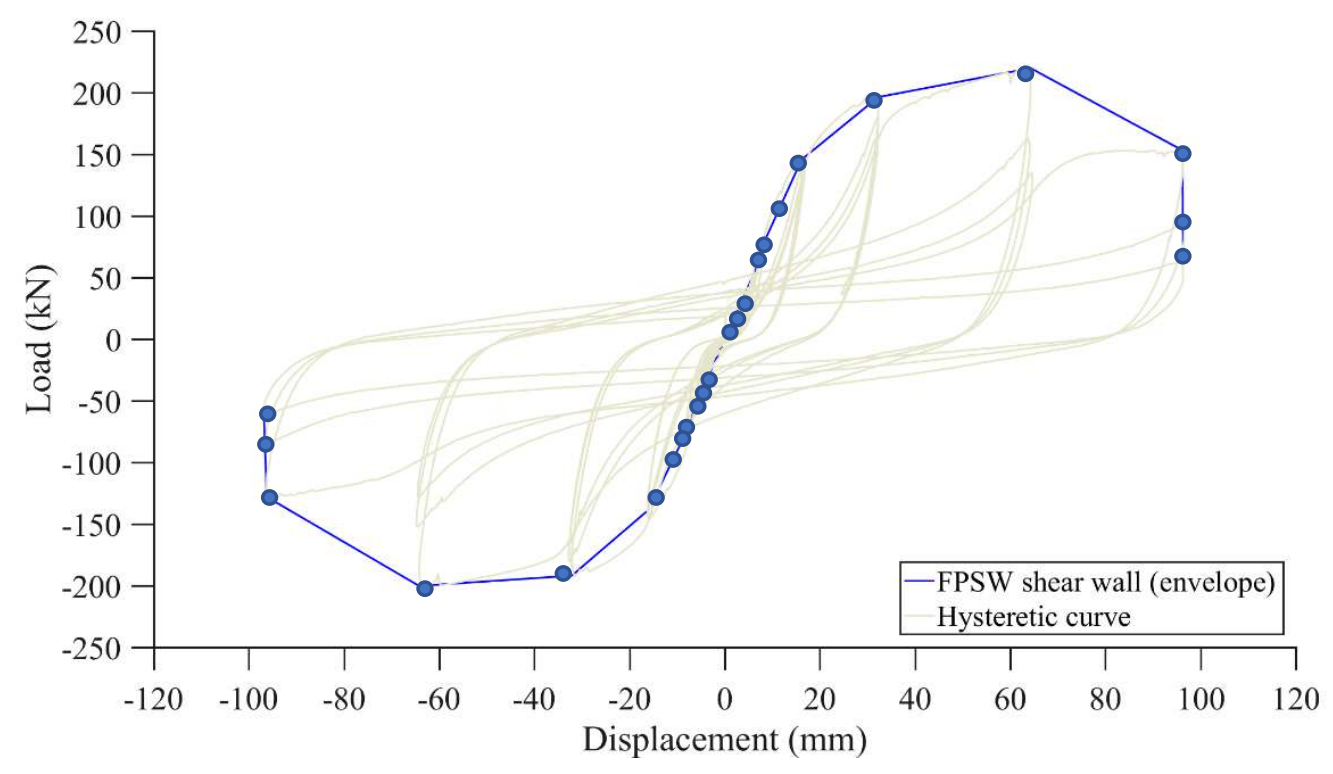

Fig. 14. FPSW envelope curve.

\subsection{Experimental results per cycle}

It can be noted that for load cycles up to 6 the stiffness degradation increases. On the other hand, the viscous damping increases from cycle 9 . These results ultimately mean that the shear wall by itself maintains a sufficient lateral load capacity, allowing it to have high deformations in the elastic range but then reaching its load capacity drastically reduces its resistance. For more detail the graphs of Fig. 24 of degradation of stiffness and resistance are presented. The equivalent viscous damping and dissipation energy graph are also presented.

Table 6. Wall results (FPSW)

\begin{tabular}{cccccccccc}
\hline Cycles & $\boldsymbol{\Delta}^{+}{ }_{\text {max }}$ & $\mathbf{F}_{\text {max }}^{+}$ & $\boldsymbol{\Delta}_{\text {max }}$ & $\mathbf{F}_{\text {max }}^{-}$ & $\begin{array}{c}\text { Average } \\
\boldsymbol{\Delta}_{\text {max }}\end{array}$ & $\begin{array}{c}\mathbf{K}_{\text {sec }} \\
\text { (tonf/cm) }\end{array}$ & $\begin{array}{c}\text { Dissipated } \\
\text { hysteretic } \\
\text { energy } \\
(\mathbf{E D})\end{array}$ & $\begin{array}{c}\text { Cumulative } \\
\mathbf{E D}\end{array}$ & $\xi_{\text {eq }}^{M}(\%)$ \\
& & & & & & & $(\mathrm{kJ})$ & $(\mathrm{kJ})$ & \\
\hline 1 & 2.4 & 1.38 & -2.03 & -1.1 & 2.22 & 5.6 & 0.01 & 0.01 & 8.57 \\
2 & 4.03 & 3.09 & -4.03 & -3.21 & 4.03 & 7.82 & 0.06 & 0.07 & 7.26
\end{tabular}




\begin{tabular}{cccccccccc}
3 & 6.02 & 5.35 & -6.25 & -5.74 & 6.14 & 9.03 & 0.12 & 0.19 & 5.63 \\
4 & 6.02 & 5.63 & -6.24 & -5.6 & 6.13 & 9.17 & 0.08 & 0.27 & 3.6 \\
5 & 6.07 & 5.64 & -6.01 & -5.1 & 6.04 & 8.89 & 0.06 & 0.33 & 3.24 \\
6 & 8.1 & 8.21 & -8.04 & -7.87 & 8.07 & 9.96 & 0.21 & 0.54 & 5.28 \\
7 & 8.12 & 8.21 & -8.06 & -7.69 & 8.09 & 9.83 & 0.15 & 0.69 & 3.69 \\
8 & 8.02 & 7.82 & -8.04 & -7.6 & 8.03 & 9.6 & 0.13 & 0.82 & 3.34 \\
9 & 16.15 & 14.87 & -16.26 & -14.9 & 16.21 & 9.19 & 1.61 & 2.43 & 10.83 \\
10 & 16.72 & 14.94 & -16.08 & -14.15 & 16.4 & 8.87 & 0.95 & 3.38 & 6.47 \\
11 & 16.12 & 13.18 & -16.05 & -13.69 & 16.09 & 8.35 & 0.77 & 4.15 & 5.76 \\
12 & 32.24 & 20.04 & -32.17 & -19.58 & 32.21 & 6.15 & 6.54 & 10.69 & 16.64 \\
13 & 32.2 & 18.29 & -32.76 & -18.43 & 32.48 & 5.65 & 4.15 & 14.84 & 11.28 \\
14 & 32.09 & 16.69 & -32.45 & -16.95 & 32.27 & 5.21 & 3.51 & 18.35 & 10.5 \\
15 & 64.27 & 22.44 & -64.24 & -20.43 & 64.26 & 3.34 & 18.61 & 36.96 & 21.94 \\
16 & 64.09 & 16.72 & -64.75 & -15.54 & 64.42 & 2.5 & 11.37 & 48.33 & 17.76 \\
17 & 64.63 & 13.8 & -64.47 & -13.09 & 64.55 & 2.08 & 9.32 & 57.65 & 17.42 \\
18 & 96.2 & 15.64 & -96.26 & -13.06 & 96.23 & 1.49 & 18.99 & 76.64 & 22.32 \\
19 & 96.53 & 9.51 & -96.35 & -8.49 & 96.44 & 0.93 & 11.48 & 88.12 & 21.46 \\
20 & 96.31 & 6.34 & -96.87 & -6.22 & 96.59 & 0.65 & 7.96 & 96.08 & 21.29 \\
\hline
\end{tabular}

\subsection{Failure mode}

The main results presented in this section are the observed failure modes of the tested wall. The FPSW wall in this study failed when the panel and frame connections either pulled out (Fig. 15c) of the framing or tore through the CLT panels (Fig. 15d). When this happened, the CLT panels were no longer effectively attached to the framing. Overall, the steel frames with the dowels (panels and frames connections) showed ductile behavior.

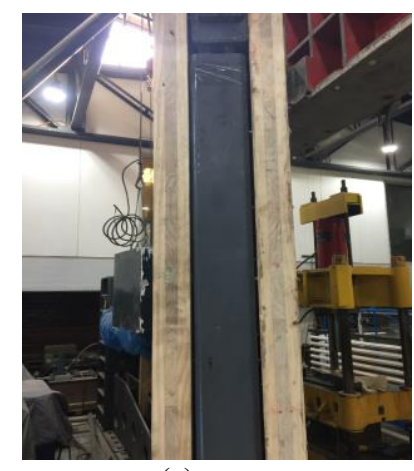

(a)

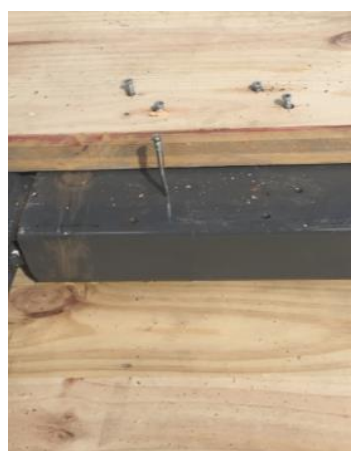

(b)

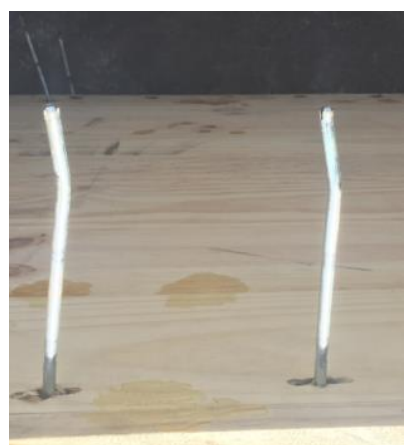

(c)

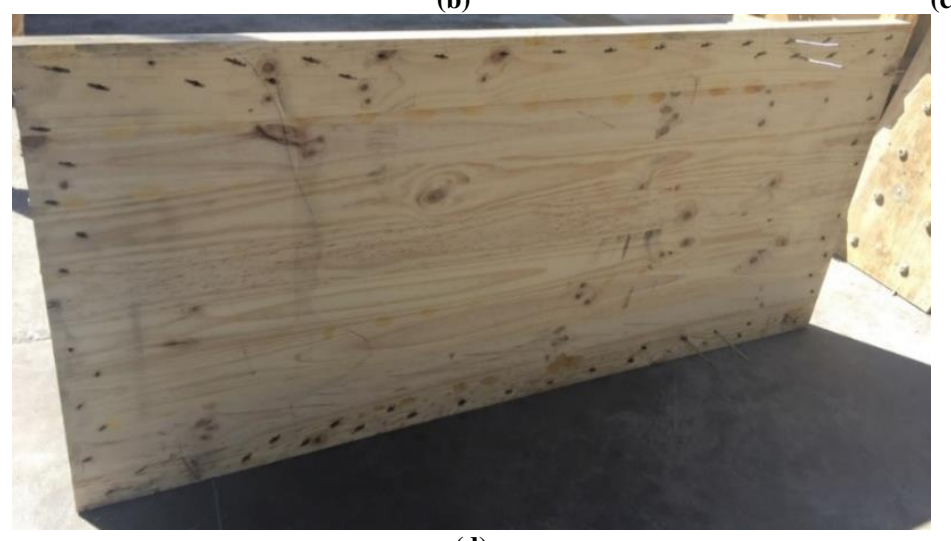

(d)

Fig. 15. Failure mode of the hybrid wall: (a) transverse view FPSW wall; (b) extraction of the dowels; (c) double plastic ball joint (failure mode f of Johansen, 1949); (d) wood with poor embedment resistance and ductile behavior.

At a displacement of $26.83 \mathrm{~mm}$, the C15 transducer (LVDT measured relative displacement between CLT plates) is corrected, due to the movement of the instrumentation (Fig. 16). 


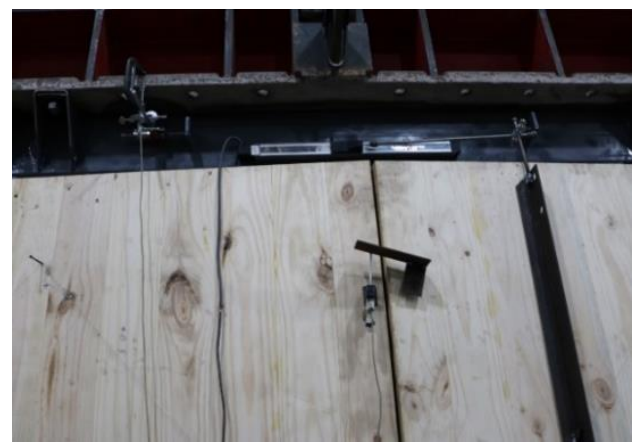

Fig. 16. Damage in middle panels of transducer $\mathrm{C} 15$

\subsection{Ductility evaluation}

The two methods used in this investigation to calculate ductility are EN 12512 and ASTM E2126. According to EN 12512. It is important to understand that the most representative parameters according to the European Committee for Standardization (2013) that are obtained within these curves are yielding load $\left(\mathrm{F}_{\mathrm{y}}\right)$, yielding displacement $\left(\delta_{\mathrm{y}}\right)$, maximum load $\left(\mathrm{F}_{\mathrm{max}}\right)$ and maximum displacement $\left(\delta_{\max }\right)$. The intersection between the red line (see detail in Carrero et al. 2020) and the green line defined by the slope of the stiffness characteristic of the behavior and the slope of $1 / 6$ of the red curve, respectively, defines the yielding point. See the graphic description in Fig. 17a. The most important result is the ductile behavior (ductility) which is nothing more than the ultimate displacement $\left(\delta_{\mathrm{u}}\right)$ between the yielding displacement $\left(\delta_{\mathrm{y}}\right)$.

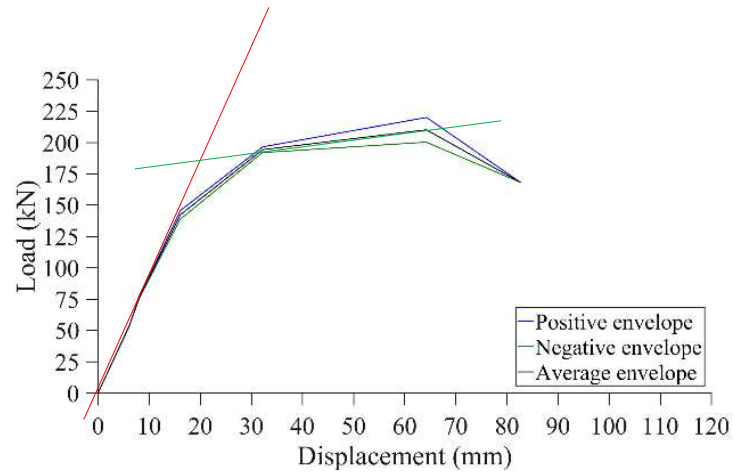

(a)

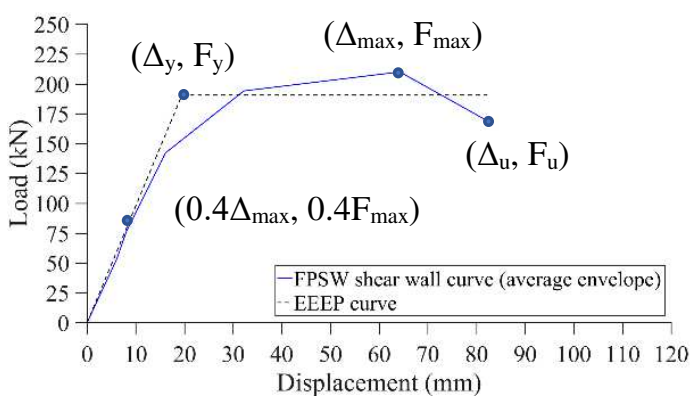

(b)

Fig. 17. (a) Average, positive and negative envelope of CLT-steel wall (FPSW) using EN 12512 methodology; (b) Method design of CLT-steel wall according to ASTM E2126.

In order to compare all the seismic parameters, it is proposed in this paper to obtain other cyclic analyses using the guidelines in ASTM International (2019). According to the ASTM E2126 procedure, it is important to make the best representation knowing the envelope of the hysteresis curve given in the tests and obtain the positive (compression) and negative (traction), understanding the most approximate behavior by making an average. This also applies for the EN 12512 method. The displacement $\Delta \mathrm{u}$ corresponding to the ASTM E2126 methodology is defined as $20 \%$ of the force denoted by the bilinear curve; the yield point is related to $(0.4 \Delta \max , 0.4 \mathrm{Fmax})$, see Fig. $17 \mathrm{~b}$. The approach used is the Equivalent Energy Elastic-Plastic (EEEP). For more details see Estrella et al. (2020) referring to the ASTM E2126 code. The parameters obtained are found in Table 7. 


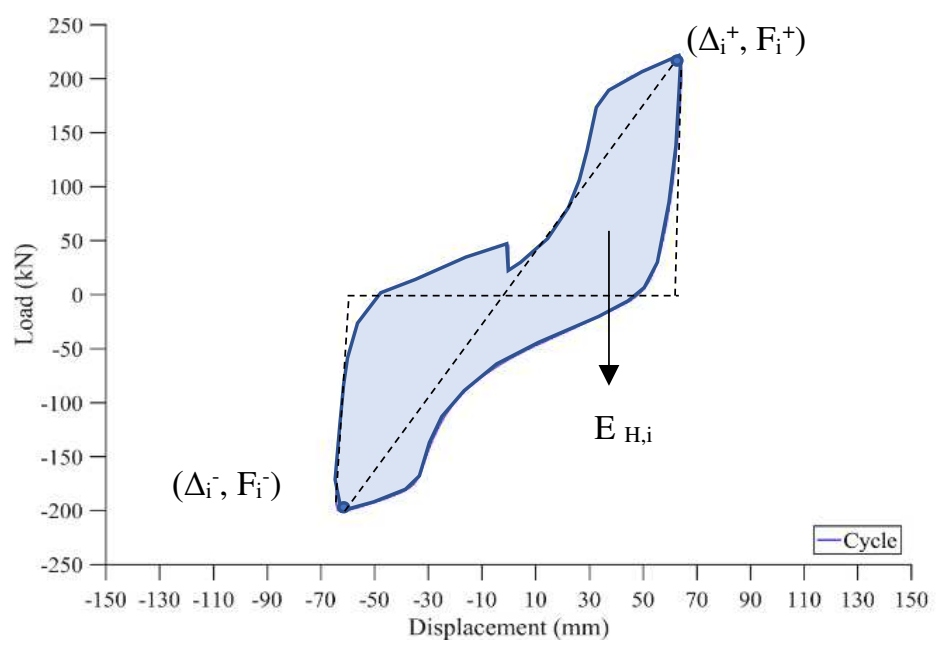

Fig. 18. Illustration of a loop for damping calculation.

On the other hand, the most common method for defining equivalent viscous damping is to compare the energy dissipated in one hysteretic loop of the actual structure to an equivalent viscous system (Fig. 18). All the details regarding the calculation of the equivalent viscous damping can be found in the work presented by Guiñez et al. (2019).

Table 7. Calculation of Ductility (FPSW)

\begin{tabular}{|c|c|c|c|c|c|c|c|c|c|}
\hline Wall & $\begin{array}{l}\mathbf{F}_{\text {max. }} \\
(\mathbf{k N})\end{array}$ & $\begin{array}{l}\begin{array}{l}\Delta_{\max } \\
(\mathbf{m m})\end{array} \\
\end{array}$ & $\begin{array}{l}\begin{array}{l}\Delta_{\mathbf{u}} \\
(\mathbf{m m})\end{array} \\
\end{array}$ & $\begin{array}{l}\begin{array}{l}\Delta_{\mathbf{y}} \\
(\mathbf{m m})\end{array} \\
\end{array}$ & $F_{y}(\mathbf{k N})$ & $\mathrm{K}_{\mathbf{0}}(\mathrm{kN} / \mathrm{mm})$ & $\begin{array}{c}\text { Dissipation } \\
\text { energy }\end{array}$ & Ductility & $\begin{array}{l}\xi_{e q}^{M} \\
(\%)\end{array}$ \\
\hline \multirow{4}{*}{$\begin{array}{l}\text { FPSW } \\
\text { (CLT- } \\
\text { steel) }\end{array}$} & \multicolumn{9}{|c|}{ According to EN 12512} \\
\hline & 219.90 & 63.00 & 96.53 & 20.00 & 181.00 & 9.05 & Per cycles & 4.83 & 12.5 \\
\hline & \multicolumn{9}{|c|}{ According to ASTM E2126 } \\
\hline & 219.90 & 63.00 & 82.70 & 20.17 & 190.57 & 9.45 & Per cycles & 4.10 & 12.5 \\
\hline
\end{tabular}

\section{FPSW wall modeling}

This section defines the important shear wall parameters that define the behavior of the specimens. As mentioned before, the key parameters for the evaluation of shear walls are the stiffness, ductility, strength, deformation characteristics, energy dissipation, damping, yield load and yield displacement. The non-linear model of the FPSW wall is developed in the MCASHEW software designed by Folz et al. (2020). This program is developed for conventional frame-platform walls, see Fig. 19.

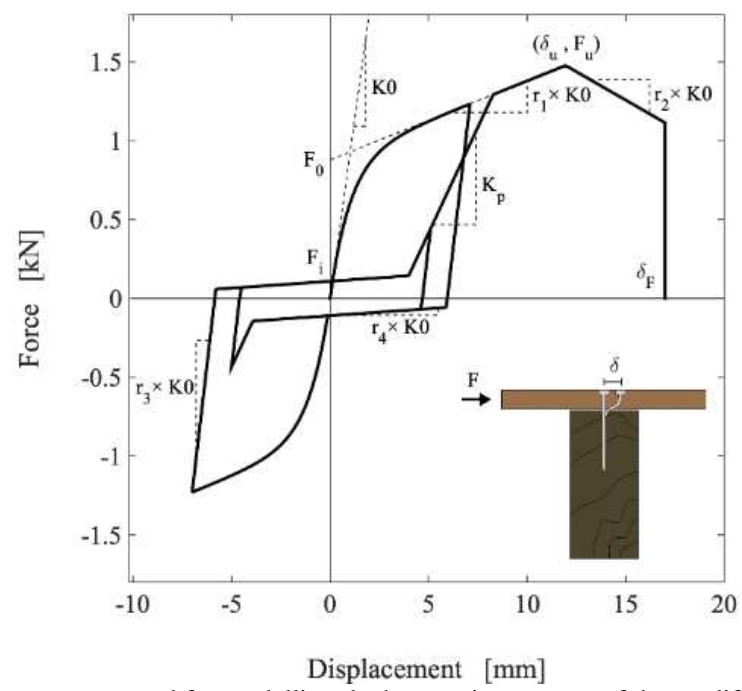

Fig. 19. Illustration of the parameters used for modelling the hysteretic response of the modified Stewart hysteretic model (MSTEW) proposed by Folz et al. (2002), based on Estrella et al. (2020). 
For more information on the model used in this paper see Folz et al. (2002) according to Carrero et al. (2020). In principle there are 10 parameters showed in Fig. 19. It is important to know that these parameters are found after obtaining the experimental curves. After that and the MSTEW model (Fig. 19), the parameters are calibrated minimizing the cumulative energy error (CEE), for the best representation of the behavior. The results are presented in Table 8. Equation of the CEE calculation can be found in Carrero et al. (2020).

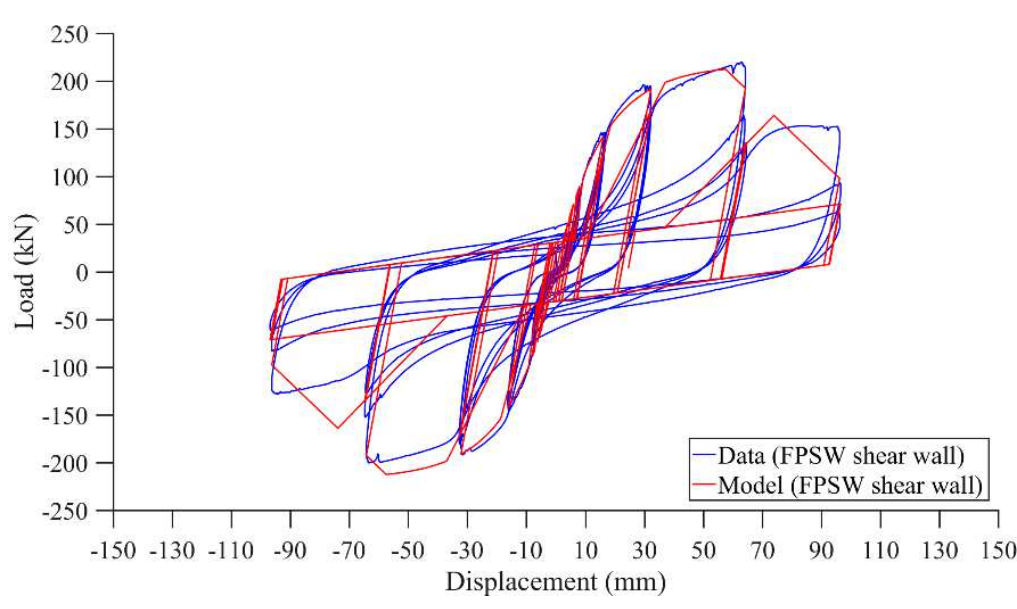

Table 8. MSTEW hysteretic modelling parameters.

\begin{tabular}{cc}
\hline Parameter & $\begin{array}{l}\text { CLT-steel } \\
\text { hybrid shear } \\
\text { wall (FPSW) }\end{array}$ \\
\hline $\boldsymbol{K}_{\boldsymbol{0}}$ (kN/mm) & 14.3402 \\
$\boldsymbol{r}_{\boldsymbol{I}}$ (unitsless) & $6.86 \mathrm{E}-10$ \\
$\boldsymbol{r}_{\boldsymbol{2}}$ (unitsless) & -0.20637 \\
$\boldsymbol{r}_{\boldsymbol{3}}$ (unitsless) & 1.1793 \\
$\boldsymbol{r}_{\boldsymbol{4}}$ (unitsless) & 0.02896 \\
$\boldsymbol{F}_{\boldsymbol{0}}$ (kN) & 217.3023 \\
$\boldsymbol{F}_{\boldsymbol{i}}$ (kN) & 30.8793 \\
$\boldsymbol{A}_{\boldsymbol{u}}$ (mm) & 57.5113 \\
$\boldsymbol{\alpha}$ (unitsless) & 1 \\
$\boldsymbol{\beta}$ (unitsless) & 1.1607 \\
CEE (error fit, \%) & 4.491 \\
\hline
\end{tabular}

Fig. 20. Full detail of the cyclic hysteretic curve and corresponding numerical MSTEW fit of the FPSW wall (CLT-steel).

The numerical results with the MCASHEW non-linear model indicate a maximum capacity of the first wall configuration to be tested (CLT-profile steel panels) of around $220 \mathrm{kN}$. A hysteretic load-displacement curve is plotted using the recorded data for force $\mathrm{F}$ and displacement $\Delta$. The load-displacement curve is shown in Fig. 20 with full details of the cyclic hysteretic curve, and the corresponding numerical fit (nonlinear model) of the FPSW wall in the cyclic test was fully reversed (see seismic parameters in Table 8) dropped by MCASHEW.

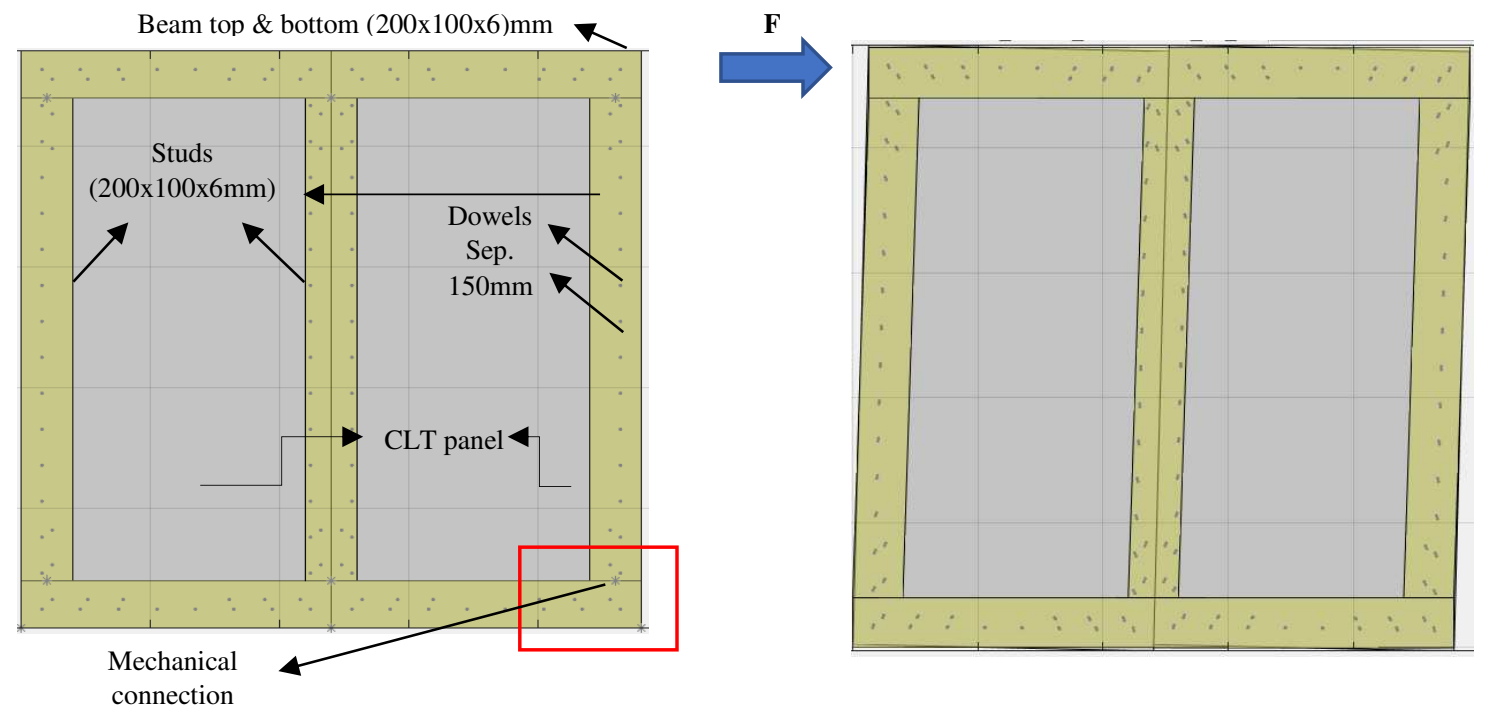

Fig. 21. MCASHEW non-linear model prediction for the FPSW test. 
Numerical models of the specimen were developed before testing in order to better understand the behavior of these elements when subjected to large deformations within the non-linear range. A simplified approach was adopted to develop the non-linear model presented in this paper. Hence, some assumptions were considered in order to simplify the modeling process and minimize the data input required. In this sense, a model for platform frame walls was developed, consisting of: (1) Euler-Bernoulli frame elements with three degrees of freedom per node to represent the studs and beams (hollow steel 200x100x6mm), (2) elastic plate elements with five degrees of freedom to model the CLT panels, and (3) two-node-link elements to represent the nailed CLT-steel connections and mechanical articulated joints.

The accuracy of the proposed model when predicting the load-slip response of strong wood-frame walls of different spacing ratios is verified in this section. One model was developed for each specimen for previous work in the experimental program (Carrero et al. 2020), replicating as much as possible the geometry and characteristics of each wall. The MCASHEW program develops a pushover for the representation of monotonic tests (control by displacement at $0.5 \mathrm{~mm}$ ), for more detail in the calculation analysis see Estrella et al. (2020). Ultimately, the important thing is that the algorithm finds $40 \%$ of the maximum capacity.

Cyclic analyses (Fig. 21) were also conducted to prove the accuracy of the model under a reversed load path. Hysteretic curves were constructed using the total lateral displacement from the EN 12512 protocol (European Committee for Standardization 2013). The model test name implemented in this paper is FPSW240-A-B, where A refers to the dowel spacing, and B to the CLT panel thickness. FPSW is the wall name and 240 is the wall length. The seismic parameters found within the modeling and testing process were ductility $(\mu)$, stiffness $\left(K_{0}\right)$, and the ultimate and yielding displacements $\left(\Delta_{\mathrm{y}}\right.$ and $\left.\Delta_{\mathrm{u}}\right)$, summarized in Table 9.

Table 9 shows that ductility, stiffness and lateral load capacity increase as the spacing of the dowels decreases. It is important to highlight that the results between the model and the experimental test for the FPSW wall capture a similarity with a very small percentage of error. Also, the characteristic properties of non-linear behavior, such as force, stiffness degradation and pinching. Previous research on the concepts carried out by the authors of this paper has also demonstrated that current non-linear numerical models are capable of capturing the hysteretic behavior of such ultra-strong connections.

Table 9. Cyclic results model test from MCASHEW of CLT-steel shear wall (FPSW)

\begin{tabular}{|c|c|c|c|c|c|}
\hline \multirow[b]{2}{*}{ Parameters } & \multicolumn{5}{|c|}{ Cyclic results model test MCASHEW) } \\
\hline & $\begin{array}{c}\text { FPSW240-200- } \\
60 \\
\end{array}$ & $\begin{array}{c}\text { FPSW240-150- } \\
60 \\
\end{array}$ & $\begin{array}{c}\text { FPSW240- } \\
100-60 \\
\end{array}$ & $\begin{array}{c}\text { FPSW240-80- } \\
60 \\
\end{array}$ & $\begin{array}{c}\text { FPSW240-50- } \\
60 \\
\end{array}$ \\
\hline \multicolumn{6}{|c|}{ Ductility according to DIN EN-12512 } \\
\hline$\alpha=$ & 46 & 33 & 30 & 35 & 27 \\
\hline$\beta=$ & 0.17 & 0.11 & 0.1 & 0.12 & 0.08 \\
\hline$F_{\max }=$ & 273.02 & 278.81 & 411.9 & 628.57 & 792.06 \\
\hline $0.40 \mathrm{~F}_{\max }=$ & 109.21 & 111.52 & 164.76 & 251.43 & 316.82 \\
\hline $0.10 \mathrm{~F}_{\max }=$ & 27.3 & 27.88 & 41.19 & 62.86 & 79.21 \\
\hline$\Delta_{\mathrm{u}}=$ & 97.5 & 125 & 132.5 & 115 & 142 \\
\hline$\Delta_{\mathrm{y}}=$ & 27.86 & 68.21 & 78.46 & 53.87 & 98.91 \\
\hline $\mathrm{F}_{\mathrm{y}}=$ & 235.71 & 252.38 & 385.96 & 611.11 & 758.33 \\
\hline Ductility $($ DIN $)=$ & 3.5 & 1.83 & 1.69 & 2.13 & 1.44 \\
\hline \multicolumn{6}{|c|}{ Ductility according to ASTM-2126 } \\
\hline $0.40 \Delta_{\max }=$ & 13.57 & 29.74 & 32.82 & 21.74 & 41.76 \\
\hline $\mathrm{F}_{\mathrm{u}}\left(0.80 \mathrm{~F}_{\max }\right)=$ & 218.42 & 223.05 & 329.52 & 502.86 & 633.65 \\
\hline$\Delta_{\mathrm{u}}\left(0.80 \mathrm{~F}_{\max }\right)=$ & 96.38 & 124.49 & 132.2 & 114 & 140.69 \\
\hline Area $=$ & 20282 & 22418 & 34855 & 52033 & 67860 \\
\hline $\mathrm{K}_{0}=$ & 8.05 & 3.75 & 5.02 & 11.57 & 7.59 \\
\hline $\mathrm{F}_{\mathrm{y}}(\mathrm{EEEP})=$ & 251.07 & 243.67 & 362.84 & 587.19 & 736.28 \\
\hline$\Delta_{\mathrm{y}}=$ & 31.2 & 64.98 & 72.28 & 50.77 & 97.05 \\
\hline Ductility $($ ASTM $)=$ & 3.09 & 1.92 & 1.83 & 2.25 & 1.45 \\
\hline
\end{tabular}

Envelope curves obtained from the cyclic tests are compared to observe the effect of dowel spacing (50, $80,100,150$ and $200 \mathrm{~mm})$ and quantity $(104,128,184,244,348$ units) on the performance of the walls. Finally, the experimental results are compared with the estimations of strength and stiffness from ASTM International (2019).

\subsection{Comparison of cyclic test curves, envelope response and stiffness with CLT and LFT Walls}

In Fig. 22, the hysteresis curve of the ultra-strong developed shear wall (FPSW), compared to a conventional timber LFTB and CLT wall, is presented. The main findings in this comparison of cyclic load 
and deformation curves is the high contribution generated by the hybrid composition of the FPSW wall, which generates better behavior under lateral loads, such as improving the stiffness in relation to the LFTB and conventional CLT wall, as can be seen clearly in the graph. The high lateral load capacity in the FPSW wall is remarkable, unlike the two walls it is compared to (LFTB and CLT), amounting to at least twice as much.

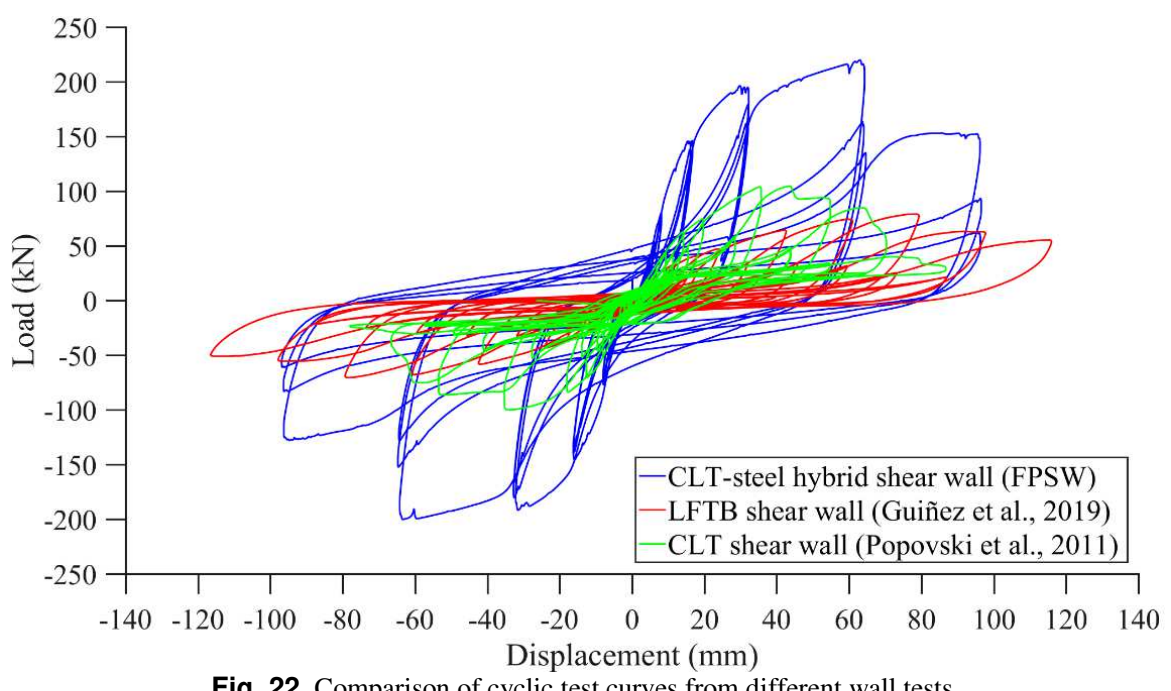

In order to be able to compare the graphs, both the load and displacement data are normalized to obtain a better version based on ductility and pinching effect. It can be seen in Fig. 23 that in the red curve (Guiñez et al. 2019) and the blue curve (FPSW) a similar ductility is appreciated and the pinching effect is shortened in relation to the wall of the green line (Popovski et al. 2011) showing its high pinching effect.

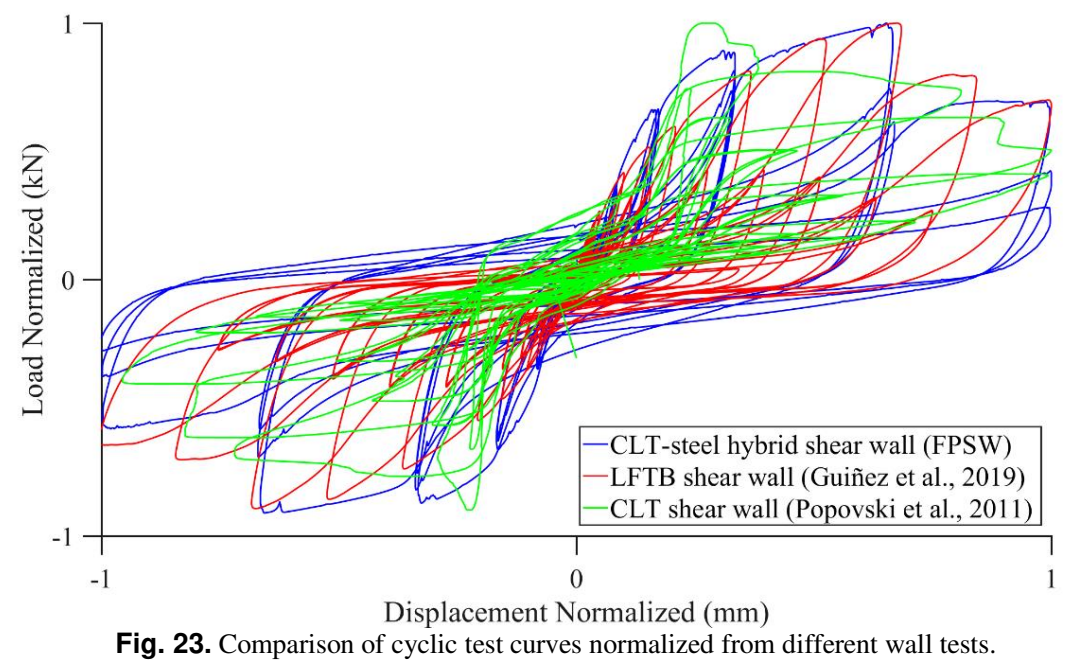

Once the wall was analyzed, comparative graphs were made, in order to evaluate the differences between the different wooden structures' configuration in contrast with the FPSW test. For example, compare walls that had the LFTB system (Guíñez et al. 2019) with nails $(\phi 3 \times 70 \mathrm{~mm})$ every $100 \mathrm{~mm}$ versus the CLT wall (Popovski et al. 2011) with 10d annular ring nails per angle bracket. in contrast FPSW configuration, (see hysteretic envelope from Fig. 24a). It was also evaluated what happens with dissipated energy, stiffness and strength degradation per cycle. 

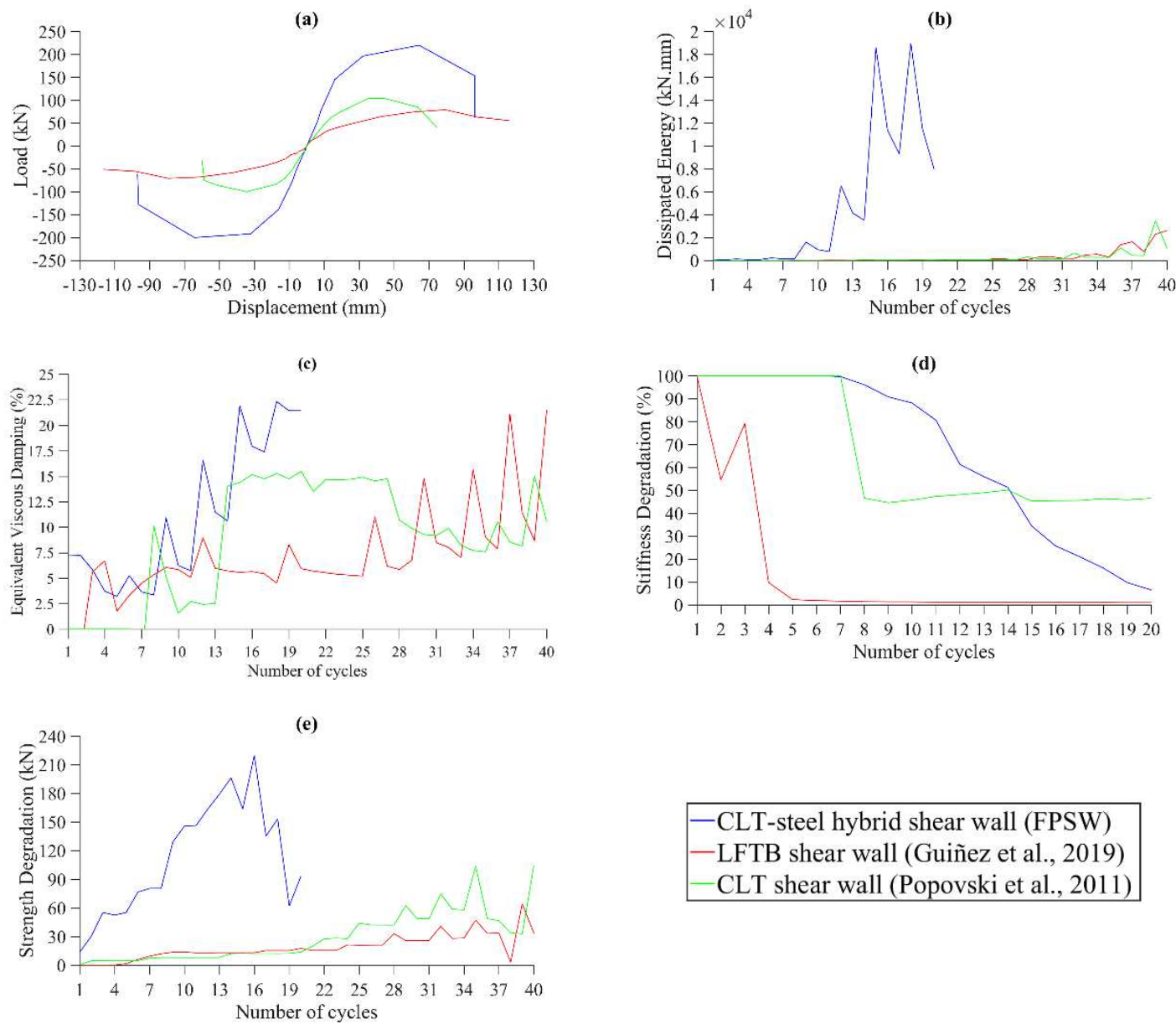

Fig. 24. Comparison of the cyclic performance of the shear walls compared including the innovation CLT-steel wall. (a) hysteresis envelopes; (b) energy dissipation per cycle; (c) equivalent viscous damping per cycle; (d) stiffness degradation per cycle; (e) strength degradation per cycle.

\subsubsection{Comparison of energy dissipation}

It is important to know the relationship (CEE) between the experimental models and the calibration of the MSTEW program in order to find the error percentages in which the CLT (Popovski et al. 2011), LFTB (Guíñez et al. 2019) and FPSW models in shear wall configurations are found. This represents a comparison parameter for energy dissipation, as illustrated in Fig. 24. In the case of shear wall testing, the main source of energy dissipation comes from friction of the fastener with the sheathing and framing (CLT panels and hollow steel profile). 


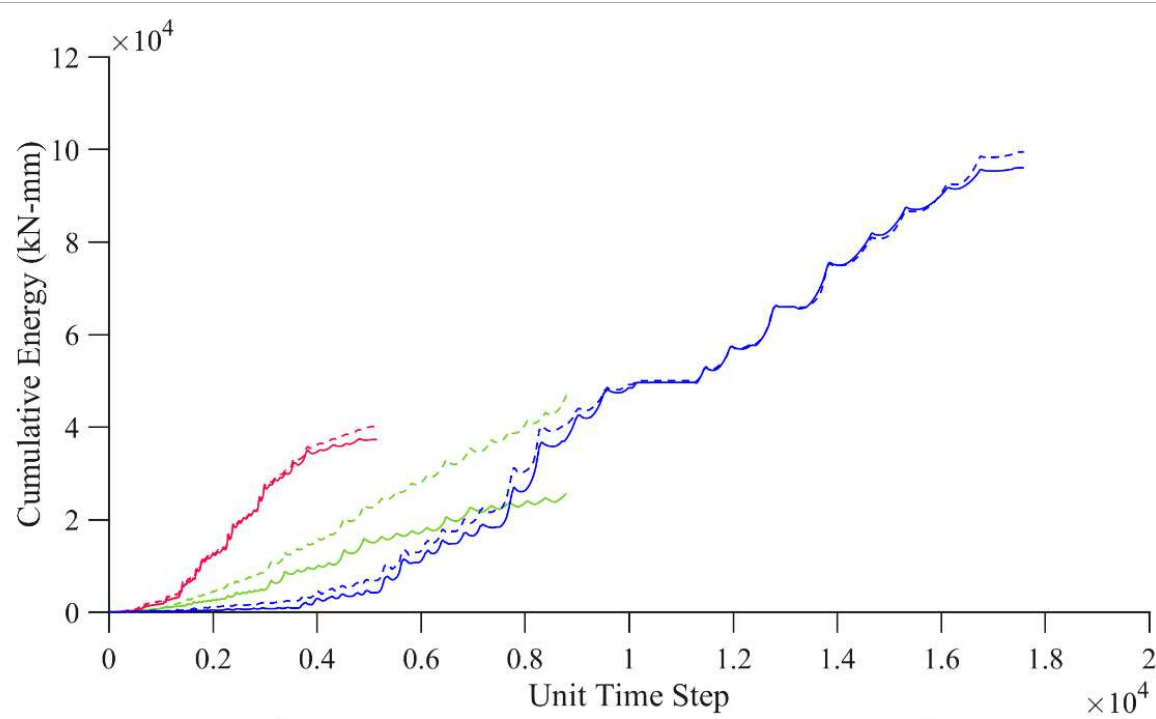

- Data CLT shear wall (Popovski et al., 2011)

- Model CLT shear wall (Popovski et al., 2011)

-Data LFTB shear wall (Guiñez et al., 2019)

- - Model LFTB shear wall (Guiñez et al., 2019)

-Data FPSW shear wall

- - Model FPSW shear wall

Fig. 24. Comparison of the cyclic performance of the shear walls' cumulative energy dissipation.

The result indicates the high similarity between the experimental and numerical model for the cases presented, especially in the FPSW wall, the type of hybrid CLT-steel shear wall, as the error (CEE) is approximately $4.5 \%$.

\section{Building modeling}

\subsection{Design procedure of buildings with six and ten stories}

Here are some important concepts to understand the results, which will be discussed later. The maximum allowable resistance of platform frame walls is $1.741 \mathrm{tonf} / \mathrm{m}$. The admissible resistance of FPSW walls is $4.67 \mathrm{tonf} / \mathrm{m}$. For construction purposes, a maximum of one $10 \times 20 \mathrm{~cm}$ steel profile can fit two $13 / 4 "$ bars.

This configuration has an effective area equal to that of a bar with a diameter of $21 / 2 "$, despite the fact that constructively we would have to put two $13 / 4$ "bars. The shear stiffness of the tested walls (FPSW) is 10 $\mathrm{kN} / \mathrm{mm}$, corresponding to the wall with self-taping dowels every $15 \mathrm{~cm}$. This will allow to evaluate whether it is feasible to obtain six-story buildings with a lesser amount of wall and whether it will be possible to reach ten floors.

This system is cheaper than a conventional wall. In general, CLT walls are dimensioned according to the seismic load than they must support. In this way, the following example can be shown based on the Chilean Seismic Design Standard (Instituto Nacional de Normalización 2009) and the CIM methodology implemented by the Centro de Innovacción en Madera (CIM) and Pontificia Universidad Católica de Chile (PUC).

The six- and ten-story building methodology consists of a spectral modal matrix analysis according to what is specified in (Instituto Nacional de Normalización 2009). Until now, the only reference to develop a matrix analysis for platform frame buildings is presented by Rossi, who proposes the formulation to obtain the flexibility matrix. For the developed methodology, it generated a modification of the Rossi Flexibility Matrix formulation. In the first place, the accumulated rotation was eliminated, due to the fact that this was thought to provide excessive and unrealistic displacements, because in practice the walls cannot overturn independently on the same axis. The expression that allows to obtain the stiffness matrix of a wall in height is shown in Eq. 1. 


$$
\widetilde{U}_{j, \xi}=\sum_{r=1}^{\min (j, \xi)} \frac{1}{K_{F, r}}+\frac{1}{K_{C, r}}+\frac{\left(z_{\xi}-z_{r-1}\right)\left(z_{r}-z_{r-1}\right)}{b^{2} * K_{\text {Anclaje }, r}}
$$

The above flexibility matrix is used to obtain the displacements of the building, once the modal forces have been applied and obtained. Unlike Rossi, for our calculations we assume that the anchors are always active, and it does not carry out a reduction in displacements due to gravitational loads. This is done with the aim of compensating for the effect of removing the accumulated turn, since if we do not consider this, much smaller displacements would be obtained. To obtain the fundamental period, since the Rossi methodology provided very long periods, the use of a stiffness matrix that considers the anchors not to be active was considered adequate. This is because when the building is at rest, it does not want to overturn and therefore the anchors are not in tension and there is no contribution to flexibility. In practical terms, this implies that the stiffness matrix considered to obtain the periods and modes of vibrating is given in Eq. 2 .

$$
\widetilde{U}_{j, \xi}=\sum_{r=1}^{\min (j, \xi)} \frac{1}{K_{F, r}}+\frac{1}{K_{C, r}}
$$

This matrix gives us the shortest fundamental periods, which are also consistent with the fundamental periods that have been measured in buildings and are found in the literature.

In order to incorporate the wall tested (FPSW), it is necessary to obtain its rigidity, which must be obtained at a load of $40 \%$ of the ultimate load. The stiffness obtained was $10 \mathrm{kN} / \mathrm{mm}$, and according to what was discussed, this includes the flexural stiffness of the frame, the shear of the CTL boards and the self-taping dowels. This implies that, for its incorporation to generate stiffness matrices, the expression to be used would be the following equations:

$$
\begin{aligned}
\widetilde{U}_{j, \xi} & =\sum_{r=1}^{\min (j, \xi)} \frac{1}{K_{\text {experimental }, r}}+\frac{\left(z_{\xi}-z_{r-1}\right)\left(z_{r}-z_{r-1}\right)}{b^{2} * K_{\text {Anclaje }, r}} \\
\widetilde{U}_{j, \xi} & =\sum_{r=1}^{\min (j, \xi)} \frac{1}{K_{\text {experimental }, r}}
\end{aligned}
$$

An important issue regarding stiffness is that the shear stiffness obtained by the FPSW test (10kN) is almost twice as high as the experimental stiffness of Guíñez et al. (2019) walls (5.4kN). It should be considered that LFTB experimental walls have a 10-cm nail spacing, while FPSW walls have self-taping dowels spaced $15 \mathrm{~cm}$. The stiffness and deformations implemented in the calculus design showed in the following equation from Special Design Provisions for Wind and Seismic standard (SDPWS) with Commentary (2015):

$$
\delta=\left(\frac{8 v h^{3}}{E A b}\right)_{\text {Bending }}+\left(\frac{v h}{1000 n G_{a}}\right)_{\text {Shear }}+\left(\frac{h \Delta_{a}}{b}\right)_{\text {Overtuning }}
$$

where $h$ is the wall height in $\mathrm{mm} ; b$ is the length of the wall in $\mathrm{mm} ; E$ is the modulus of elasticity of the stud's edge in $\mathrm{MPa} ; A$ is the cross-sectional area of the stud's edge at one end of the wall in $\mathrm{mm}^{2} ; v$ is the shear per unit length of the wall in $\mathrm{kN} / \mathrm{mm} ; G_{\mathrm{a}}$ is the apparent modulus of shear wall in $\mathrm{kN} / \mathrm{mm}$ (see Eq. 6); $\Delta_{\mathrm{a}}$ is the total vertical deformation of the anchor in $\mathrm{mm}$; traction and compression are the forces $\mathrm{P}$ in $\mathrm{kN}$. Finally, $n$ is the number of sheathed wall faces $=2$.

$$
G_{a}=\frac{F}{\delta_{\text {shear }}} \frac{h}{n L} \rightarrow G_{a}=K_{\text {shear }} \frac{h}{n L}
$$

The overturning deformation is the lateral displacement of the wall due to the lifting of the wall as a result of the tensile deformation of the anchoring system. Therefore, $\Delta_{\mathrm{a}}$ is the deformation of the anchoring system under the tensile load generated by the overturning moment (see Eq. 7), and it is necessary to know the rigidity of the anchoring system to be able to estimate the deformation. 


$$
\Delta_{a}=\frac{T_{A T S}}{K_{A T S}}=\frac{F h}{K_{A T S} b}
$$

The rigidity of the ATS system (post-tensioned bars) is simply the axial stiffness of the bar, which is obtained as follows, where the effective area $\left(\mathrm{A}_{\mathrm{e}}\right)$ is from ATS bars.

$$
K_{A T S}=\frac{E A_{e}}{L}=\frac{E A_{e}}{\left(h_{\text {wall }}+h_{\text {inter-story }}\right)}
$$

It is recommended to consider the effective area in tension obtained from the expression in American Institute of Steel Construction (2016):

$$
A_{e}=0.7854 *\left(d-\frac{0.9743}{n}\right)^{2}\left[i n^{2}\right]
$$

where $d$ is the nominal diameter of the bar and $n$ is the number of threading per inch that can be found in the AISC Steel Construction Manual 2011. Then, it is possible to calculate the equivalent wall stiffness from Special Design Provisions for Wind and Seismic standard (SDPWS) with Commentary (2015) as:

$$
K_{e q}=\left(\frac{8 h^{3}}{E A b^{2}}+\frac{h}{1000 G_{a} b}+\frac{h^{2}}{b^{2}} \frac{1}{K_{A T S}}\right)^{-1}
$$

\subsection{Design considerations and results}

The objective of using this wall system (FPSW) would be to reduce the number of structural walls in the plane and complement it with the post beam system, with the idea of generating open-plan buildings that allow to open the market for wooden buildings in the private environment, mainly with office buildings in mind.

The same plane building for LFTB (Fig. 25a) but with the CLT-steel frame wall (FPSW) system (Fig. 25b) with a different density walls by plane.

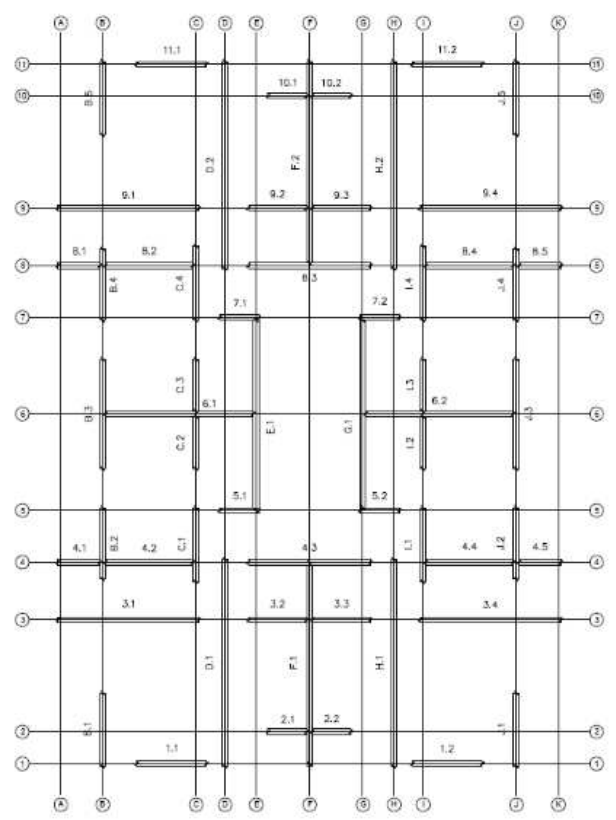

(a)

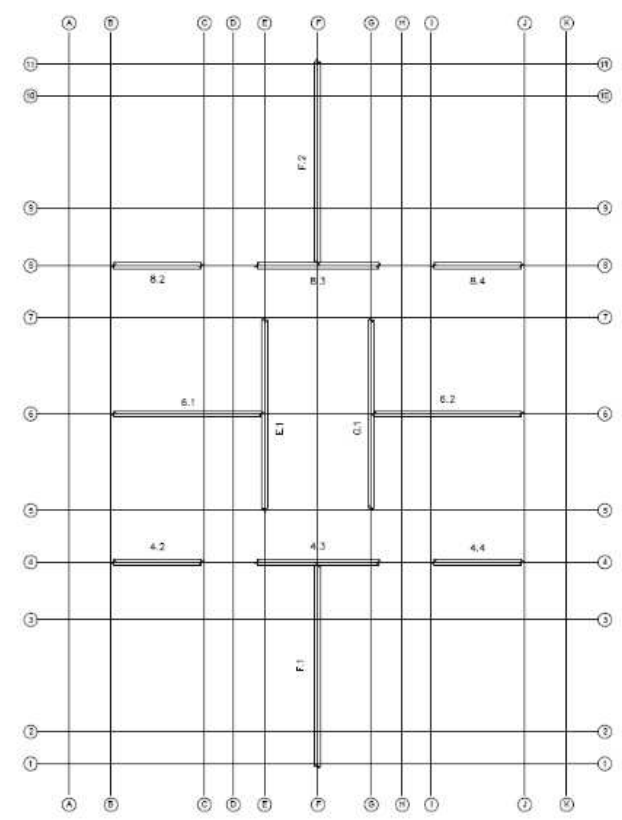

(b)

Fig. 25. Floor plan and wall distribution of building: (a) normal frame-platform shear wall (LFTB) density distribution with total walls; (b) FPSW shear wall density distribution with some walls.

In the preliminary design of the buildings with FPSW walls corresponding to the six-story P1 building (on floor C and zone 2) and the ten-story P2 building (on floor D and zone 3) using the Chilean code (Instituto Nacional de Normalización 2009), the design results accomplish drift and shear limit requirements for modal analysis. An important observation regarding models is that they are designed for minimal basal 
shear, because they have a period of approximately $0.75 \mathrm{~s}$. The advantage of this design is that it allows much fewer walls (FPSW) to be used than it would for a platform frame (LFTB) building. It is important to mention that with this design the drift limit requirement $(0.002)$ is achieved, which is defined as the relationship between the maximum displacement obtained from each floor and the mezzanine height when applying the seismic load (see Fig. 26).

\subsubsection{Six-story buildings}

a) Six-story LFTB building (total walls): all platform frame walls were designed for soil type C, and zone 2 by seismic design from (Instituto Nacional de Normalización 2009), designed with maximum seismic coefficient. This is the most demanded six-story building available with traditional platform frame walls. The maximum anchorage (post-tensioned bars) diameter is $3.49 \mathrm{~cm}$ in $\mathrm{X}$ and $2.86 \mathrm{~cm}$ in $\mathrm{Y}$. The maximum demand for shear of any of its walls is $1.69 \mathrm{tonf} / \mathrm{m}$.

b) Six-story FPSW building (total walls): all FPSW walls were designed for soil C, and zone 2 , designed with maximum seismic coefficient. The post-tensioned bar diameters were adapted to achieve drift (0.002), given the experimental rigidity of the walls. The maximum anchorage diameter is $3.81 \mathrm{~cm}$ in $\mathrm{X}$ and $2.86 \mathrm{~cm}$ in $\mathrm{Y}$. The maximum demand for shear of any of its walls is 1.797 tonf $/ \mathrm{m}$.

c) Six-story FPSW building (some walls): some FPSW walls were designed for soil C, and zone 2. By reducing the number of linear meters of walls ( $63 \%$ and $73 \%$ reduction), the building became more flexible, reducing the designed seismic coefficient. The maximum anchorage diameter is $5.40 \mathrm{~cm}$ in $\mathrm{X}$ and $5.08 \mathrm{~cm}$ in $\mathrm{Y}$, which is necessary to achieve compliance with the designed drift. The maximum demand for the shear of any of the walls is $1.818 \mathrm{tonf} / \mathrm{m}$. This design indicates that it is possible to reduce the number of walls by $63 \%$ and $73 \%$, but with the need to increase the diameter of the anchors.

In conclusion, for six-story designs it can be considered possible to reduce the number of walls by $63 \%$ in $\mathrm{X}$ and $73 \%$ in $\mathrm{Y}$ compared to the conventional LFTB building plan. On the other hand, depending on the type of soil and seismic zone, to obtain the derivative design, it may be necessary to anchor more than the constructive limit of two post-tensioned bars with a diameter of $13 / 4 "$. A flexibility effect is generated that benefits the design.

This would not have been feasible for platform frame walls (LFTB) with a maximum resistance of 1.741 tonf $/ \mathrm{m}$. A flexibility effect is generated that benefits the design (FPSW). Another design of total CLT walls indicates that it would not be possible to design a platform frame (LFTB) for a maximum unit shear obtained of 2,748 tonf/m exceeding 1,741 tonf/m, this for a design according to the Chilean code NCh 433 for soil $\mathrm{D}$ and zone 3 .

It is observed that fewer walls could be used with this system, but for buildings with six floors or less, or at least for the density of walls considered in this case.

\subsubsection{Ten-story buildings}

a) Ten-story FPSW building (total walls): all FPSW walls were designed for soil C, and zone 3, with the design controlled by the maximum seismic coefficient. In order to comply with the drift, diameters of $6.99 \mathrm{~cm}$ in $\mathrm{X}$ and $5.72 \mathrm{~cm}$ in $\mathrm{Y}$ are necessary. The maximum demand for the shear of any of the walls is 2.010 tonf $/ \mathrm{m}$. The question that remains with these buildings is that flexibility is what allows them to be built, due to the lengthening of the period $(0.867 \mathrm{~s})$.

\subsection{Drift discussion}

To design a ten-story building, it can be mentioned that, even complying with the requirements given in the Chilean code, it is necessary to increase the profile section of the right feet of the FPSW walls by at least $80 \%$, to use diameters of threaded bars that can be placed inside the hollow steel profile. This taking into account that all the walls will be structural. On the other hand, we have to increase the area of the steel frame. In terms of shear strength, we do not require stronger walls at least for all-wall cases. In the case of removing walls, stronger walls may be required; however, we will most likely consider walls with an increase in stiffness greater than $80 \%$, which are likely to have greater strength. The drifts of the six-ten 
story buildings met the requirements of the Chilean code (Instituto Nacional de Normalización 2009), see Fig. 26.
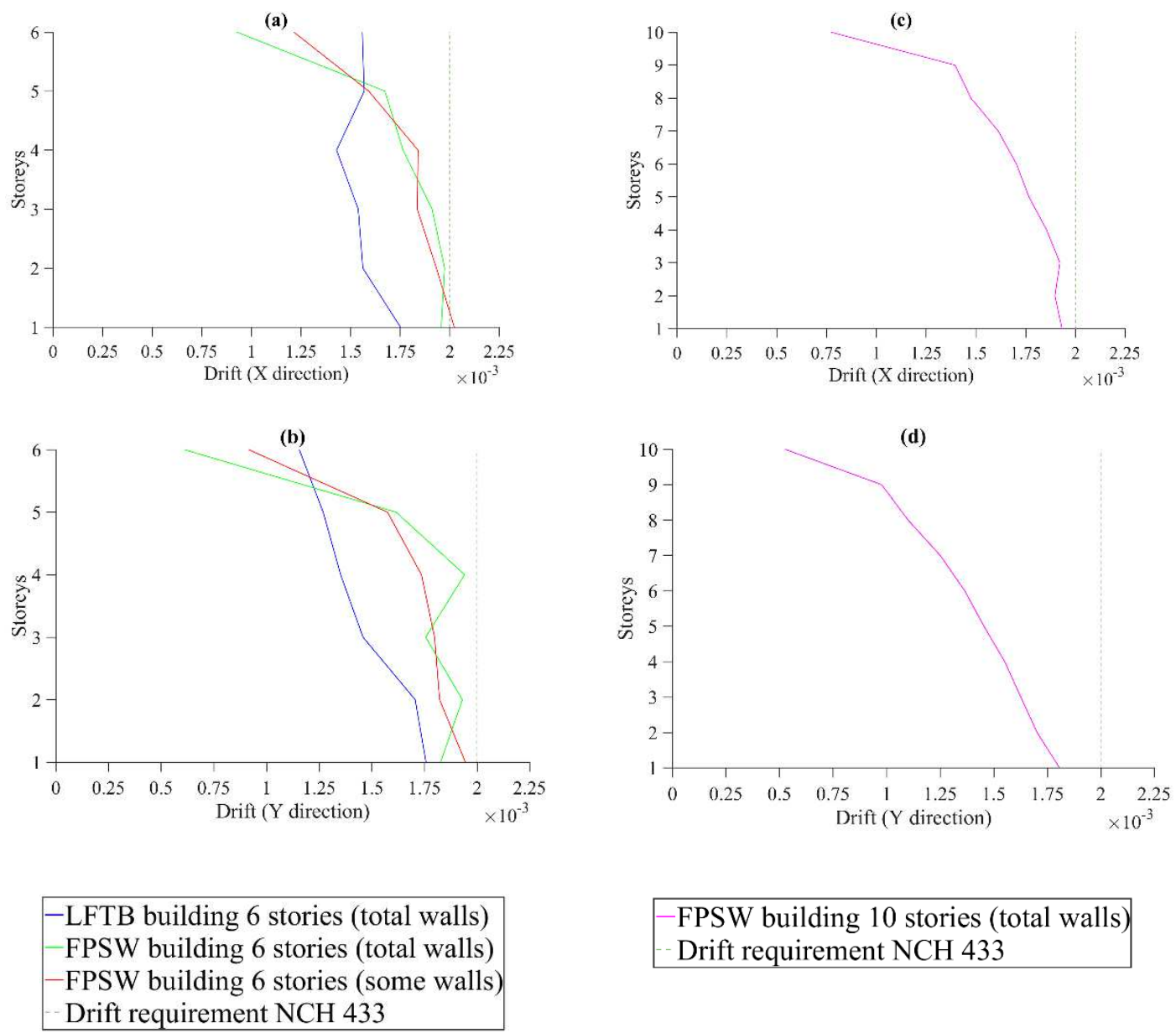

FPSW building 10 stories (total walls) Drift requirement $\mathrm{NCH} 433$

Fig. 26. Drifts limit requirements by (Instituto Nacional de Normalización 2009).

\section{Conclusions}

The research team of this work has achieved a much stronger lateral capacity, stiffness and ductility using a new lateral system based on a robust frame and side CLT panels along with steel tendons. The initial proof of concept, already validated in the lab, must be refined to further develop the theoretical concept achieving much more cost-effective solutions.

In general terms, a good agreement between the test and model results is observed, and the characteristic properties of non-linear behavior, such as force and stiffness degradation and pinching, are fully captured. Previous research on the concepts carried out by the authors of this paper has also demonstrated that current non-linear numerical models are capable of capturing the hysteretic behavior of such ultra-strong connections.

In this investigation into ultra-strong shear walls, following and applying very innovative concepts, unprecedented stiffness, strength and ductile shear walls are achieved in timber construction. The comparison of cyclic load-deformation curves is the high contribution generated by the hybrid composition of the FPSW wall, which generates better behavior under lateral loads, such as improving the stiffness, which can clearly be seen in the graph in relation to the LFTB and conventional CLT. The high lateral load capacity in the FPSW wall is remarkable, unlike the two walls it is compared to (LFTB and CLT) and is at least twice as high.

It is important to consider the valuable reduction in wall density by introducing the FPSW wall system in a private building plant for 6 and 10 story structures. Requirements according to seismic codes (National Institute of Normalization 2009). The reduction varies on average 65\% for 6-story buildings. 


\section{Acknowledgements}

This research has been funded by CONICYT Chile, FONDECYT PROJECT 11170863, and the APC was also funded by FONDECYT PROJECT 11170863. The authors thank Conicyt for the financial support, as well as the structural lab team of the Laboratory of Structural Engineering of the UC and the team of the Timber Innovation Center CIM-UC.

It is important to mention that an abstract was presented at the Proceedings of the 2020 Society of Wood Science and Technology International Convention on July 12-15, 2020, Slovenia.

\section{References}

Amini, M. O., van de Lindt, J. W., Rammer, D., Pei, S., Line, P., \& Popovski, M (2018). Systematic Experimental Investigation To Support The Development Of Seismic Performance Factors For Cross Laminated Timber Shear Wall Systems. Engineering Structures; 172, 392-404. https://doi.org/10.1016/j.engstruct.2018.06.021

ASTM International (2019). ASTM E2126-19: Standard test methods for cyclic (reversed) load test for shear resistance of vertical elements of the lateral force resisting systems for buildings. West Conshohocken, PA, USA.

American Institute of Steel Construction (2016). ANSI/AISC 360-16 Specification for structural steel buildings. AISC.

Brandner, R., Tomasi, R., Moosbrugger, T., Serrano, E., \& Dietsch, P (2018). Properties, Testing and Design of Cross Laminated Timber.

Carrero, T., Montaño, J., Santa-María, H., \& Guindos, P (2020). Static and dynamic performance of direct hybrid connections of cross-laminated timber with steel, concrete and laminated strand lumber composites. Latin American Journal of Solids and Structures.

Casagrande, D., Rossi, S., Sartori, T., \& Tomasi, R (2016). Proposal of an analytical procedure and a simplified numerical model for elastic response of single-storey timber shear-walls. Construction and Building Materials; 102, 1101-1112. https://doi.org/10.1016/j.conbuildmat.2014.12.114

Ceccotti, A., Lauriola, M. P., Pinna, M., \& Sandhaas, C (2006). SOFIE Project - Cyclic Tests on Cross-Laminated Wooden Panels. In "9th World Conference Timber Engineering (WCTE)" (pp. 805-812). https://doi.org/10.1016/0263-8223(93)90191-R

Clark Isaac Miller (2017). US9765510-Structural Wall Panels for use in Light-frame construction and methods of Construction employing structural wall panels.

Dechent, P., Giuliano, G. C., Dolan, J. D., Silva, R., Crempien, J., Matamala, J., \& Acuña, G (2016). Development of a Simplified Design Seismic-Resistant Method for Timber Multi Story Buildings; 2016. Proceedings of the WCTE 2016 World Conference on Timber Engineering, Vienna, Austria, August 22-25

Di Cesare A, Ponzo FC, Nigro D, Pampanin S, Smith T (2017). Shaking table testing of post-tensioned timber frame building with passive energy dissipation systems. Bull Earthq Eng 15(10):4475-4498

Dujic, B., Aicher, S., \& Zarnic, R (2006). Testing of Wooden Wall Panels Applying Realistic Boundary Conditions. WCTE. https://doi.org/10.1002/cphc.200500588

Dujic, B., Klobcar, S., \& Zarnić, R (2015). Shear Capacity of Cross-Laminated Wooden Walls. ResearchGate.

Durham, J., Lam, F., \& Prion, H. G. L (2001). Seismic Resistance of Wood Shear Walls with Large OSB Panels. Journal of Structural Engineering; 127; 12, 1460-1466.

https://doi.org/10.1061/(ASCE)0733-9445(2001)127:12(1460)

Estrella, X., Guindos, P., \& Almazán, J. L (2019). Ground motions for FEMA P-695 application in subduction zones. Latin American Journal of Solids and Structures; 16; 9, 237. https://doi.org/10.1590/1679-78255848

Estrella, X., Guindos, P., Almazán, J. L., \& Malek, S (2020). Efficient nonlinear modeling of strong wood frame shear walls for midrise buildings. Engineering Structures; 215. https://doi.org/10.1016/j.engstruct.2020.110670

European Committee for Standardization (2013). (CEN) EN 12512:2001/A1:2005. Timber structures-Test Methods - Cyclic testing of joints made with mechanical fasteners. European Committee for Standardization CEN. 123 p.

European Committee for Standardization (2016). EN 1995-1-1: Eurocode 5: Design of timber structures - Part 1-1: General - Common rules and rules for buildings. Brussels.

Folz, B., \& Filiatrault, A (2002). Computer Program for Cyclic Analysis of Shearwalls in Woodframe Structures.

Gavric, I., Fragiacomo, M., Popovski, M., \& Ceccotti, A (2013). Behaviour of Cross-Laminated Timber Panels under Cyclic Loads. RILEM Bookseries, 9, 689-702.

https://doi.org/10.1007/978-94-007-7811-5 62

Gavric, I., Fragiacomo, M., \& Ceccotti, A (2015). Cyclic Behavior of CLT Wall Systems: Experimental Tests and Analytical Prediction Models. Journal of Structural Engineering; 141; 11; 04015034.

https://doi.org/10.1061/(asce)st.1943-541x.0001246

Guindos P, Carrero T, Montaño J, Santa María H (2019). PCT/CL2019/050111. Hybrid shear wall system for construction of massive timber buildings in seismic zones. "Patent Pending".

Guindos, P (2020). Conceptos Avanzados del Diseño Estructural con Madera. Parte II: CLT, Modelación Numérica, Diseño Antiincendios y Ayudas al Cálculo. Santiago, Chile. Ediciones UC.

Guínez, F., Santa María, H., \& Almazán, J. L (2019). Monotonic and cyclic behaviour of wood frame shear walls for mid-height timber buildings. Engineering Structures, 189, 100-110. https://doi.org/10.1016/j.engstruct.2019.03.043

Hummel, J (2016). Displacement-based seismic design for multi-storey cross laminated timber buildings. Kassel University. https://doi.org/10.19211/KUP9783737602891

Instituto Nacional de Normalización (2009). NCh 433. Of96: Diseño Sísmico de Edificios. Norma Chilena Oficial.

Iqbal, A., Pampanin, S., Palermo, A., \& Buchanan, A. H (2015). Performance and Design of LVL Walls Coupled With UFP Dissipaters. Journal of Earthquake Engineering; 19; 3, 383-409.

https://doi.org/10.1080/13632469.2014.987406

Johansen, K.W (1949). Theory of timber connections. International Association for Bridge and Structural Engineering; 9; 249-262.

Montaño, J., Maury, R., Luis Almazán, J., Estrella, X., \& Guindos, P (2020). Development of an amplified added stiffening and damping system for wood-frame shear walls. Latin American Journal of Solids and Structures; 5; 283. https://doi.org/10.1590/1679-78256109

Murray-Parkes, J (2016). AU2015367279A1 - Connection system - Google Patents. 
Newcombe MP, Pampanin S, Buchanan AH (2010). Global response of a two-storey Pres-Lam building. In: Proceedings of New Zealand society for earthquake engineering conference, Wellington, New Zealand: New Zealand Society for Earthquake Engineering.

Norma Chilena Oficial "NCh 1198" (2014). Madera - Construcciones en madera - Cálculo.

Pang, W., Rosowsky, D., Pei, S., \& Van De Lindt, J. W (2007). Evolutionary Parameter Hysteretic Model for Wood Shear Walls. https://doi.org/10.1061/ASCE0733-94452007133:81118

Pei S, van de Lindt JW, Barbosa AR, Berman JW, McDonnell E, Dolan JD, Blomgren HE, Zimmerman RB, Huang D, Wichman S (2019). Experimental seismic response of a resilient 2-story mass-timber building with post-tensioned rocking walls. J Struct Eng 145(11):04019120

Popovski, M.m Karacabeyli, E., Ceccotti, A (2011). CLT Handbook - Cross laminated timber. Chapter: Seismic performance of crosslaminated timber buildings. FPInnovations

Priestley, M. J. N., Sritharan, S., Conley, J. R., \& Stefano Pampanin, S (1999). Preliminary Results and Conclusions From the PRESSS Five-Story Precast Concrete Test Building. PCI Journal, 44(6), 42-67. https://doi.org/10.15554/pcij.11011999.42.67

Shahnewaz, M., Tannert, T., Popovski, M., \& Alam, S (2018). Strength and Stiffness of CLT Shear Walls in Platform Construction. In " $18^{\text {th }}$ World Conference Timber Engineering (WCTE)". Seoul, Republic of Korea.

Special Design Provisions for Wind and Seismic standard (SDPWS) with Commentary (2015). Washington, DC.

https://doi.org/ISBN 0-9786245-9-9 
Figures

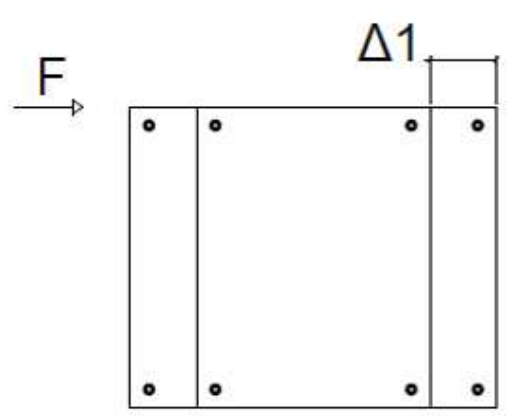

(a) $\Delta_{\text {Rigid body }}=\Delta 1$

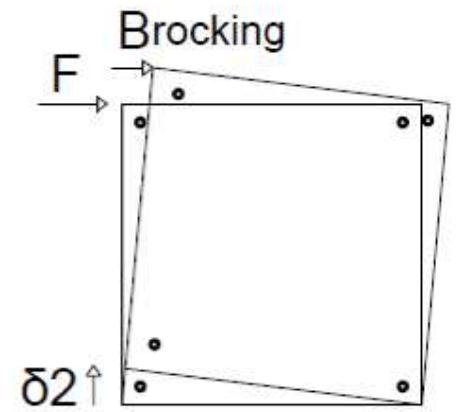

(b) $\Delta_{\text {bending }}=\Delta_{2}=L * \theta=L \frac{\delta_{2}}{B_{\text {rocking }}}$

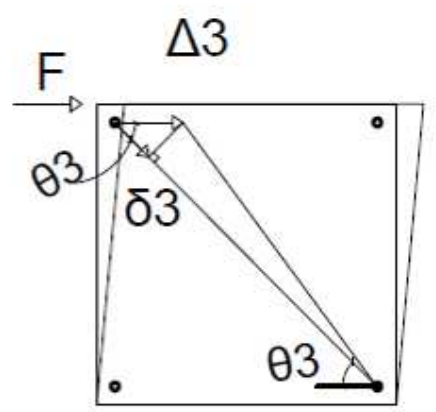

(c) $\Delta_{\text {shear }}=\Delta_{3}=\frac{\delta_{3}}{\cos \left(\theta_{3}\right)}$

\section{Figure 1}

(a) Lateral displacement due to rigid body; (b) Lateral displacement due to bending and overturning deformations; (c) Lateral displacement due to shear deformations.

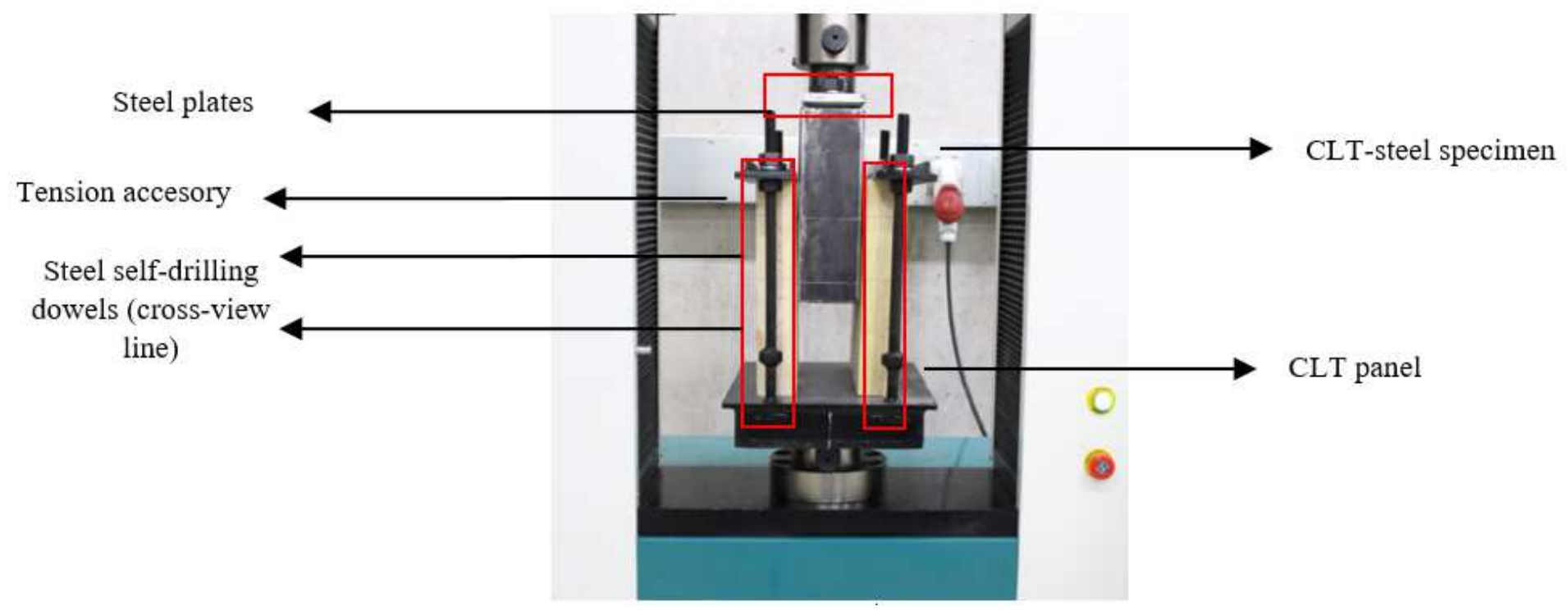

Figure 2

Mechanical testing of the connection according to EN 12512, including the layout for the CLT-steel connection during cyclic testing (Carrero et al. 2020). 

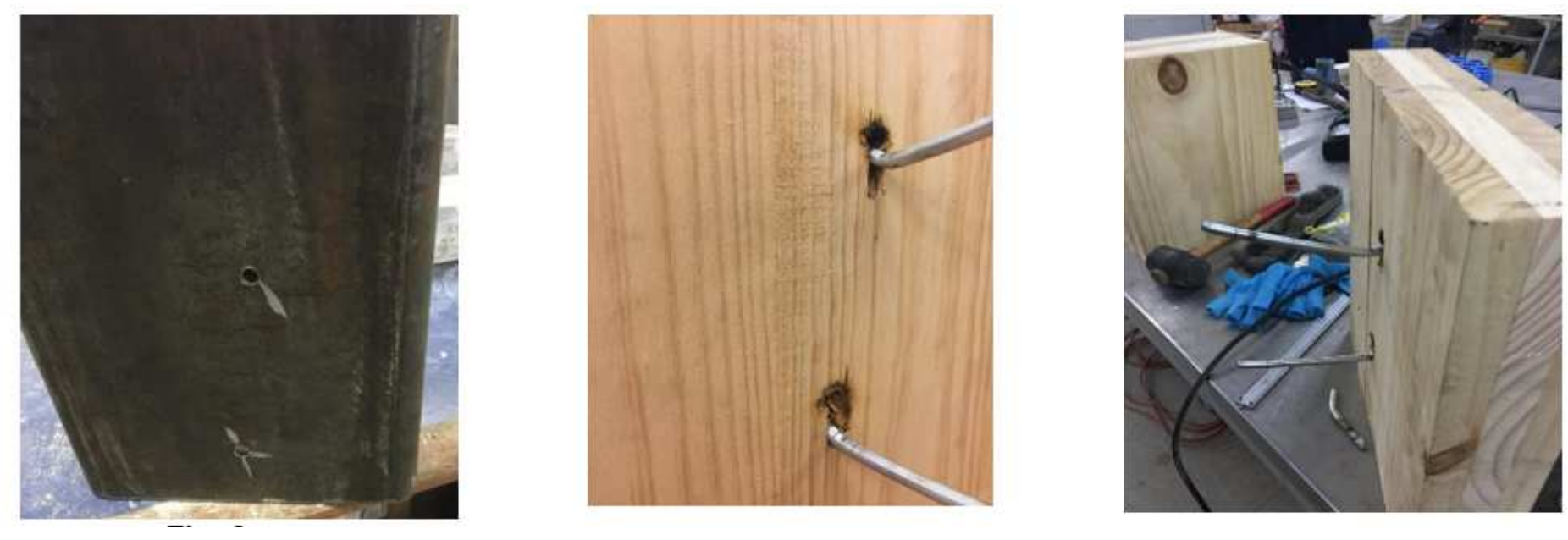

Figure 3

Ductile failure after fatigue of the dowels in the CLT-steel connection (Carrero et al. 2020).
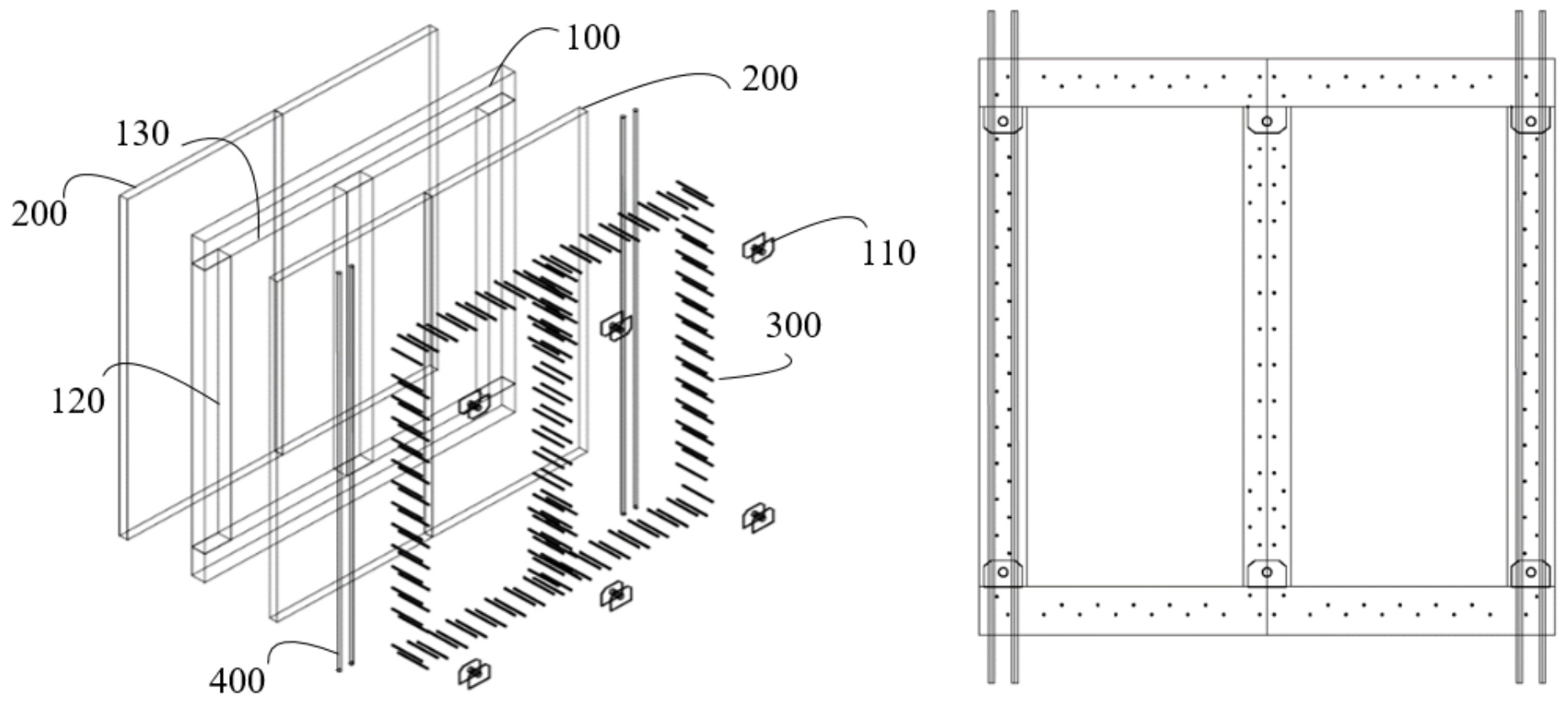

Figure 4

Schematic isometry of Robust framing CLT, Frame-Panel Shear Wall (FPSW) by Guindos et al. (2019). 


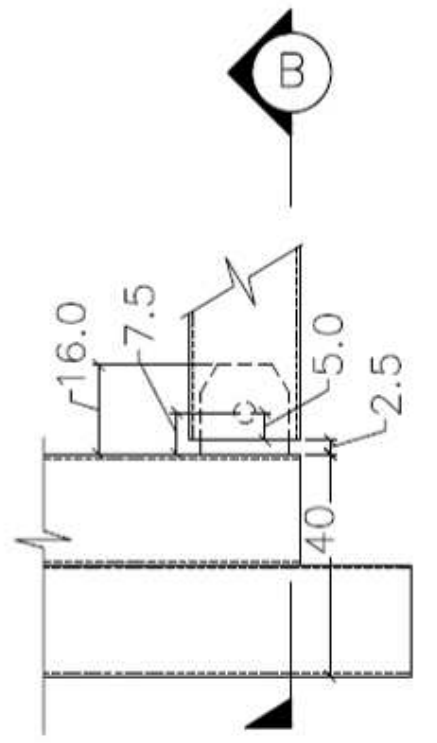

DETAILS OF ARTICULATED MECHANICAL CONNECTION

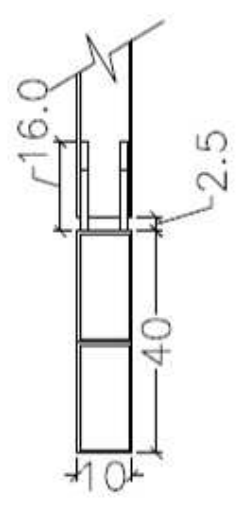

$B-B^{\prime}$

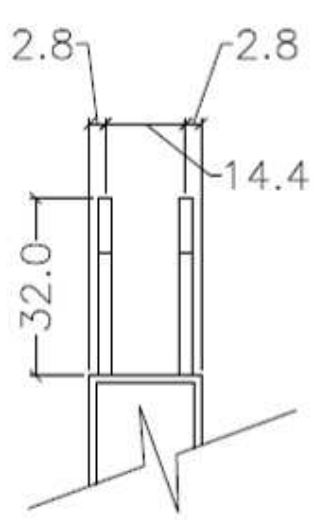

METAL PLATES

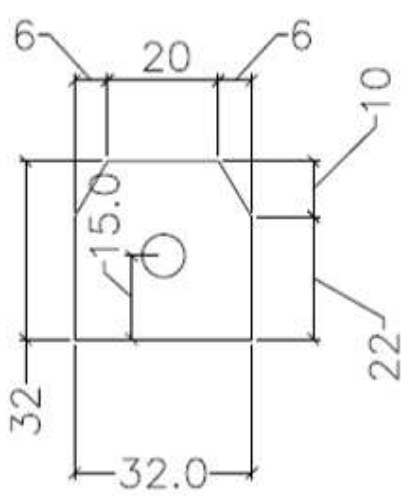

METAL PLATES $-16 \times 16 \times 1.0 \mathrm{~cm}$ AMOUNT OF $=12$ UNITS. PERFORATION $\varnothing=3.8 \mathrm{~cm}$

\section{Figure 5}

Test details from mechanical articulated connection (lengths in millimeters).

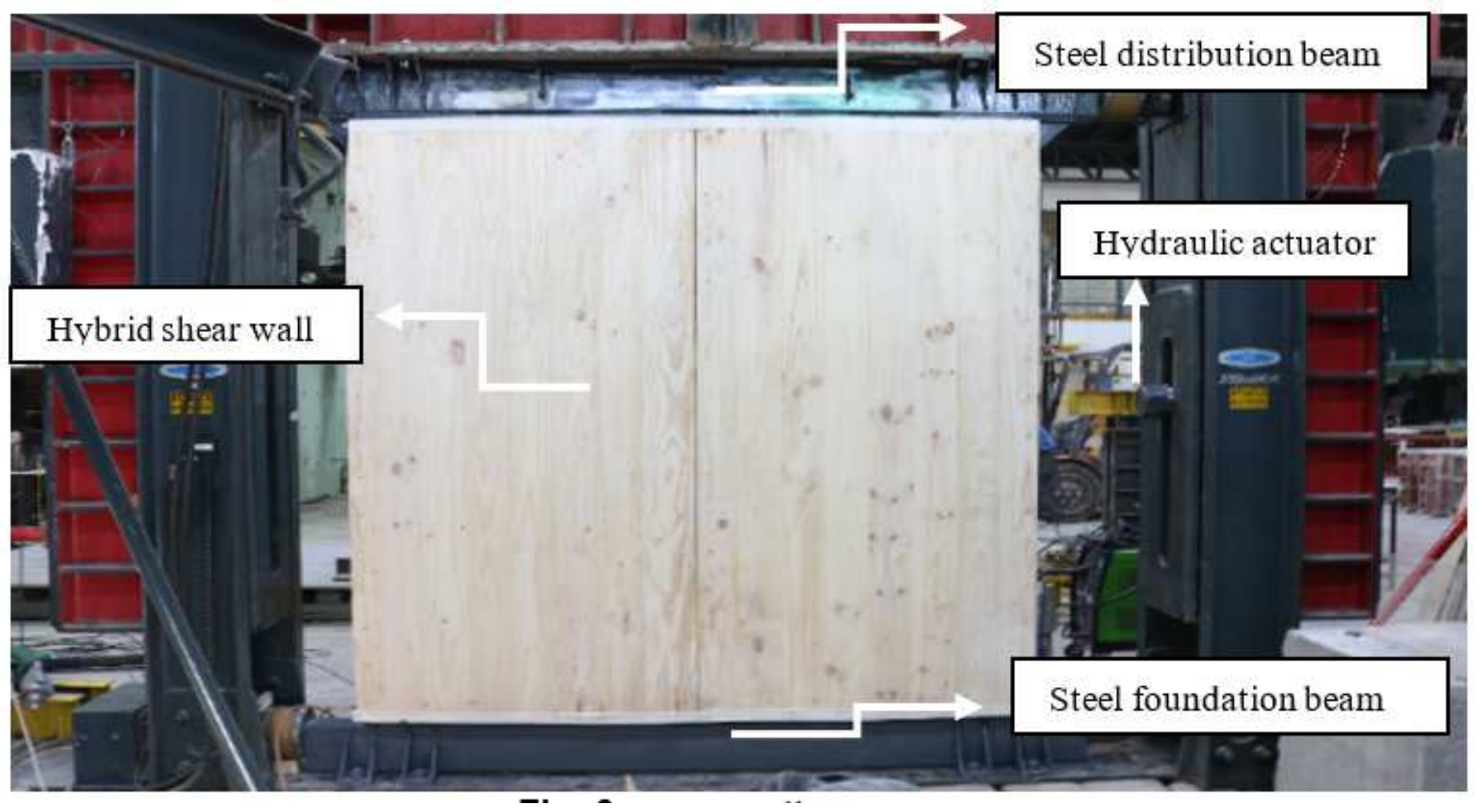

Figure 6

FPSW wall test setup. 


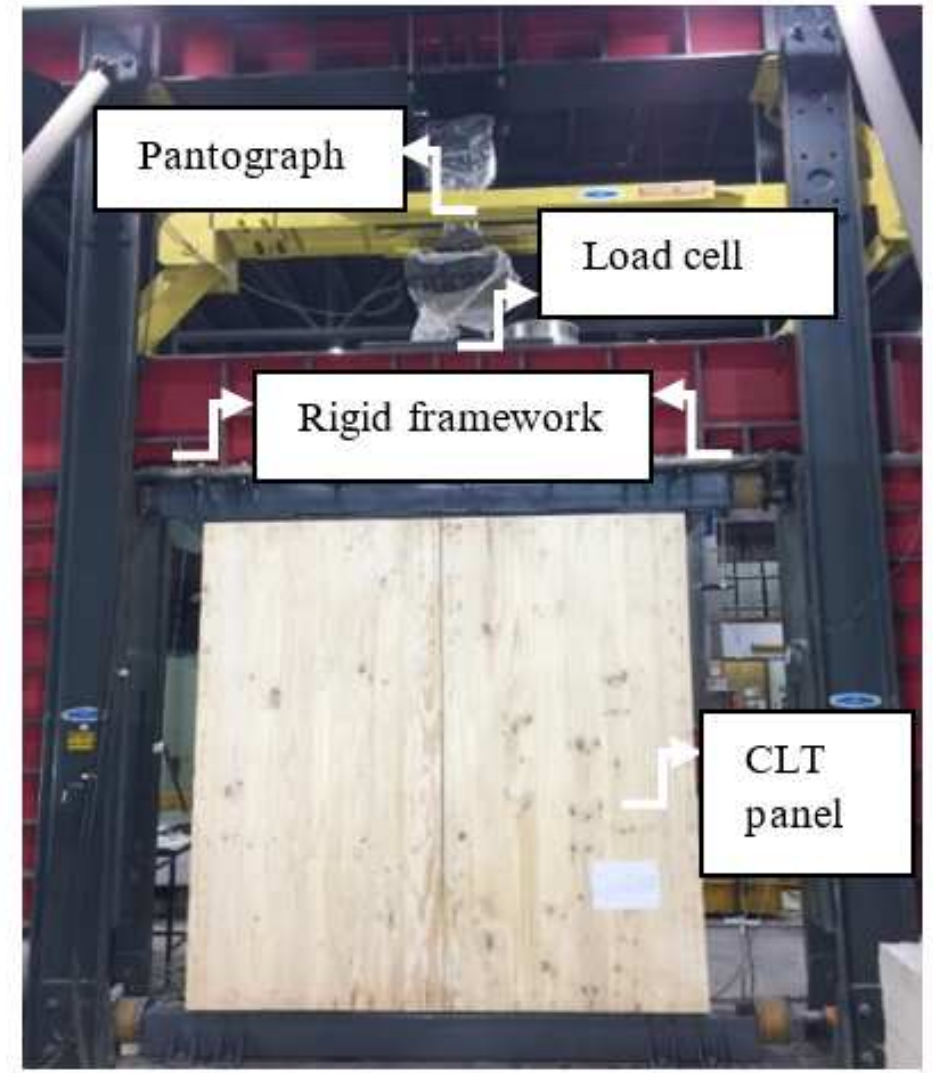

(a)

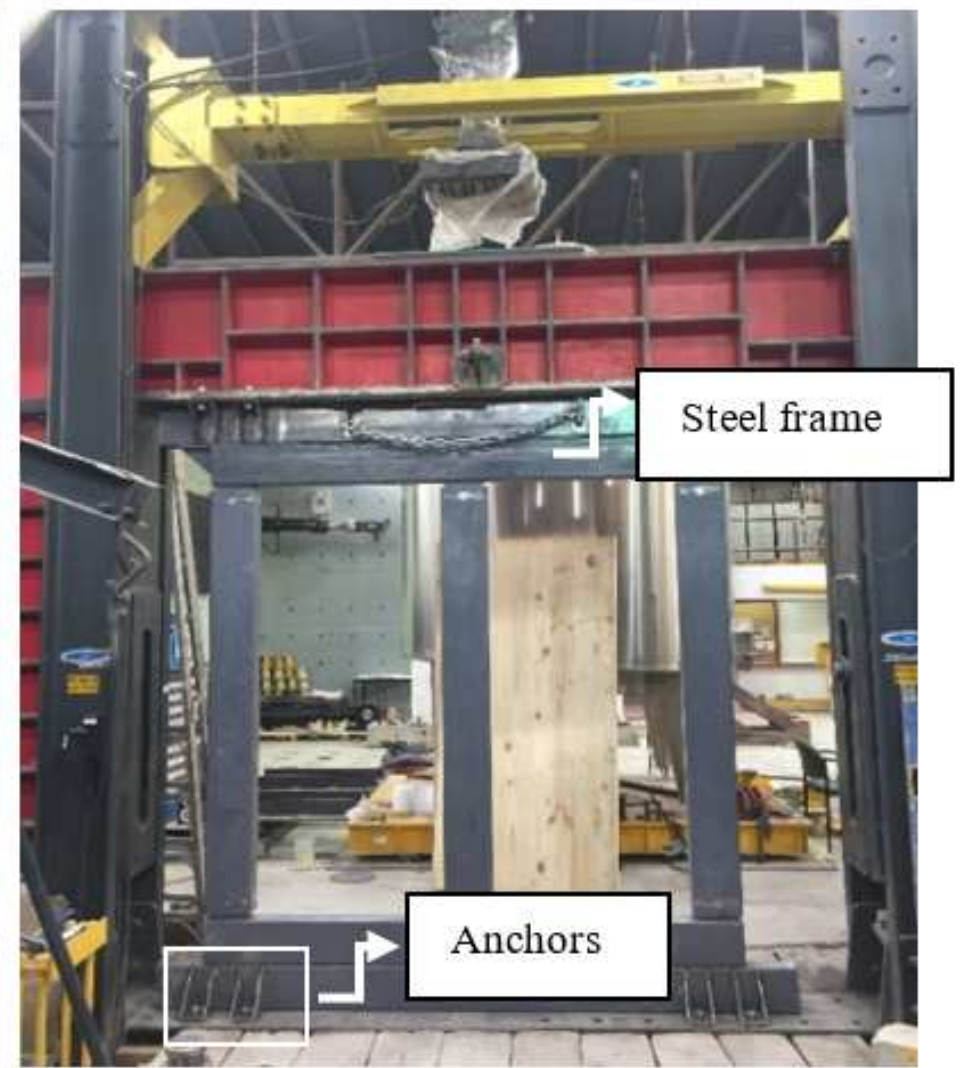

(b)

\section{Figure 7}

Details from FPSW configuration: (a) CLT panel assembly; (b) hollow steel frame assembly.

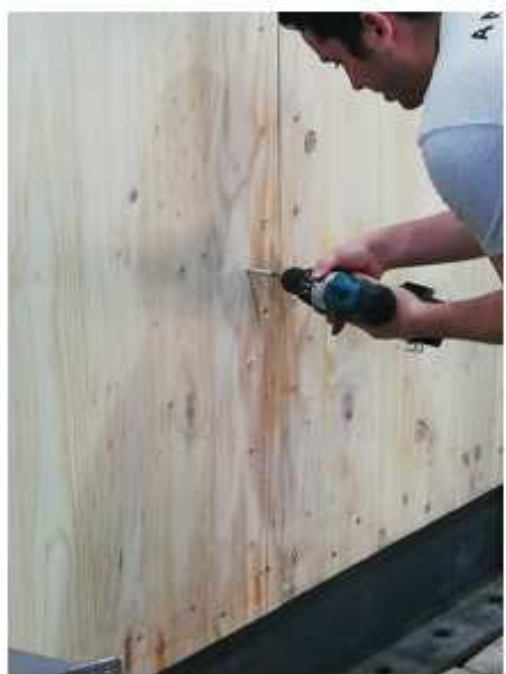

(a)

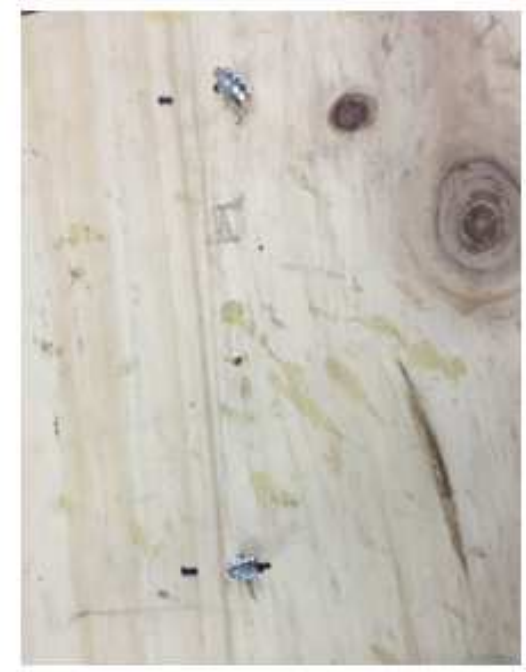

(b)

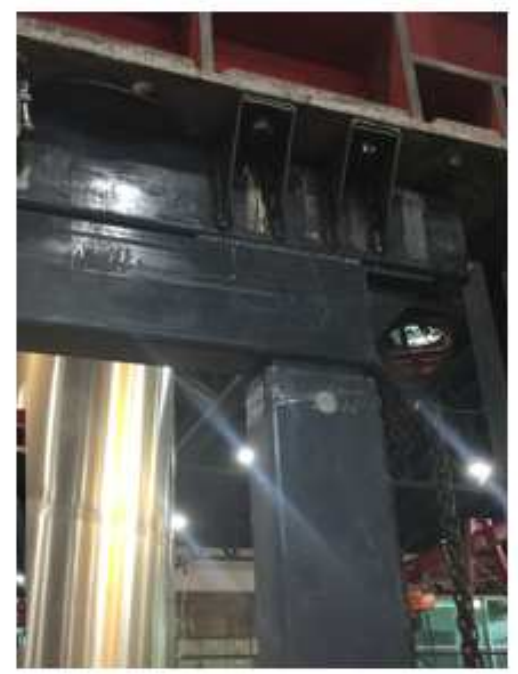

(c)

\section{Figure 8}

Test setup procedure: (a) drilling the CLT panels; (b) pins output in drilling process; (c) mechanical articulated connections. 


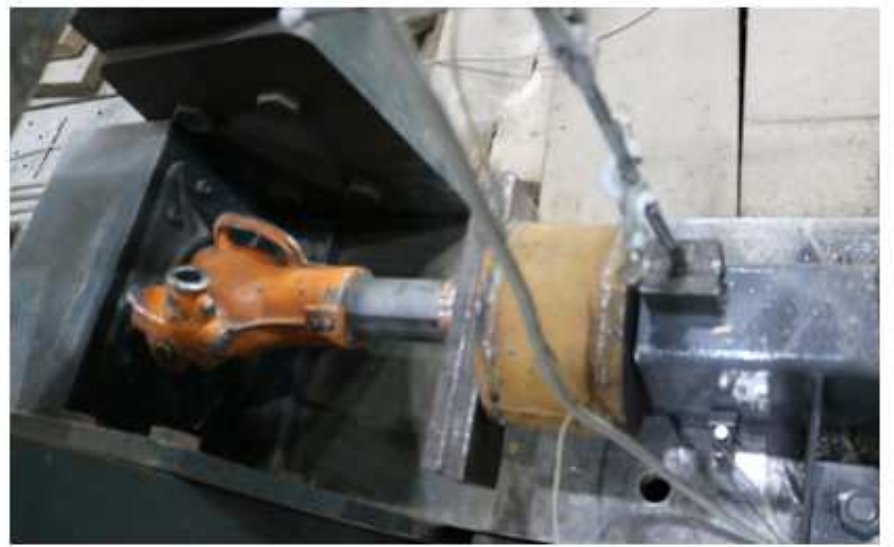

(a)

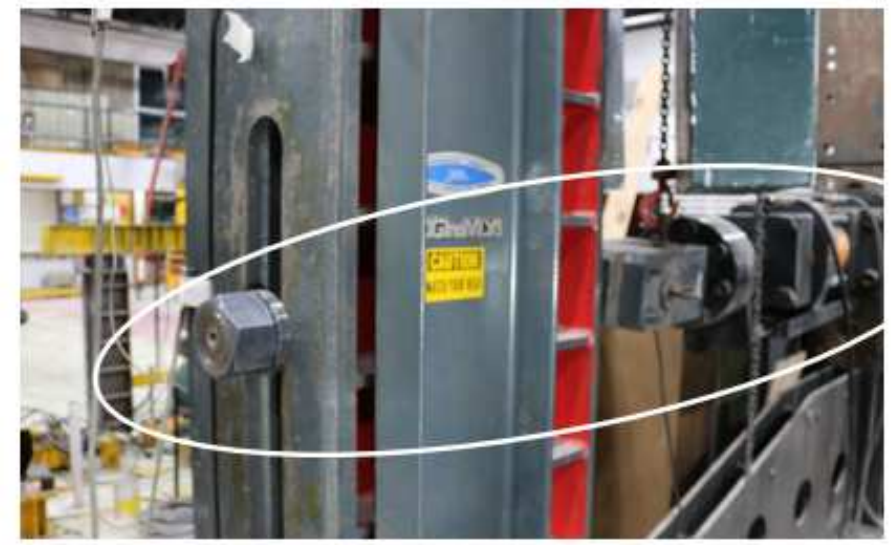

(b)

\section{Figure 9}

Test configuration: (a) hydraulic jack to reduce displacement; (b) hydraulic actuator (500kN).

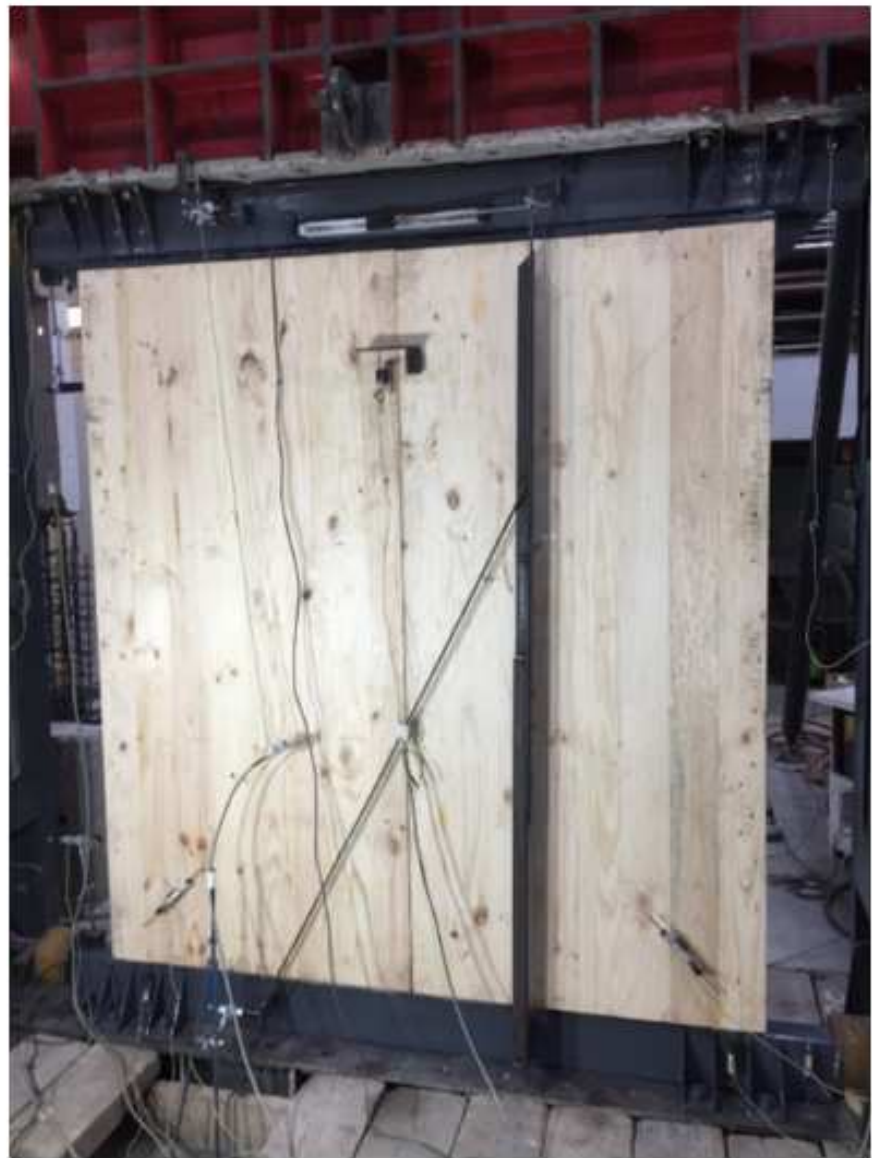

(a)

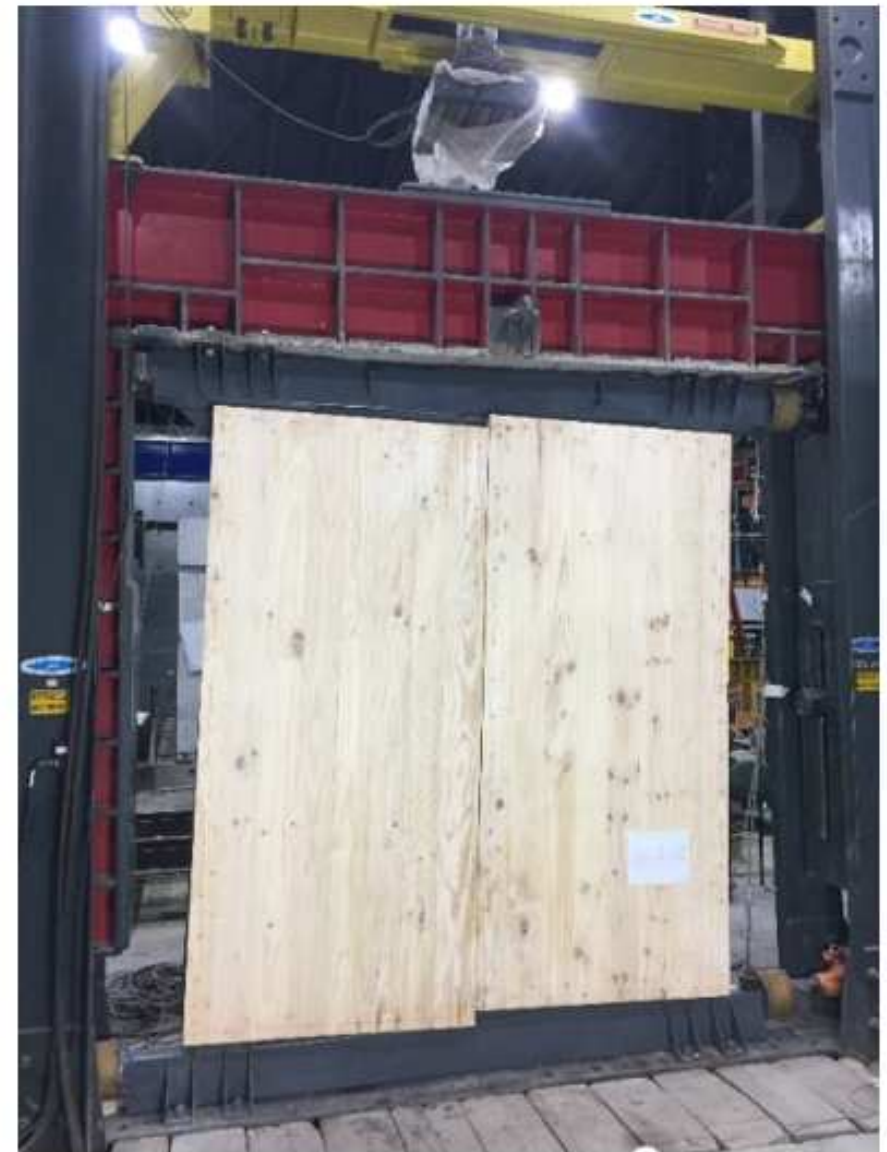

(b)

\section{Figure 10}

Illustration of a FPSW wall: (a) instrumentation measures behind the wall; (b) the specimen in final loop from reversed cyclic test on loading frame. 


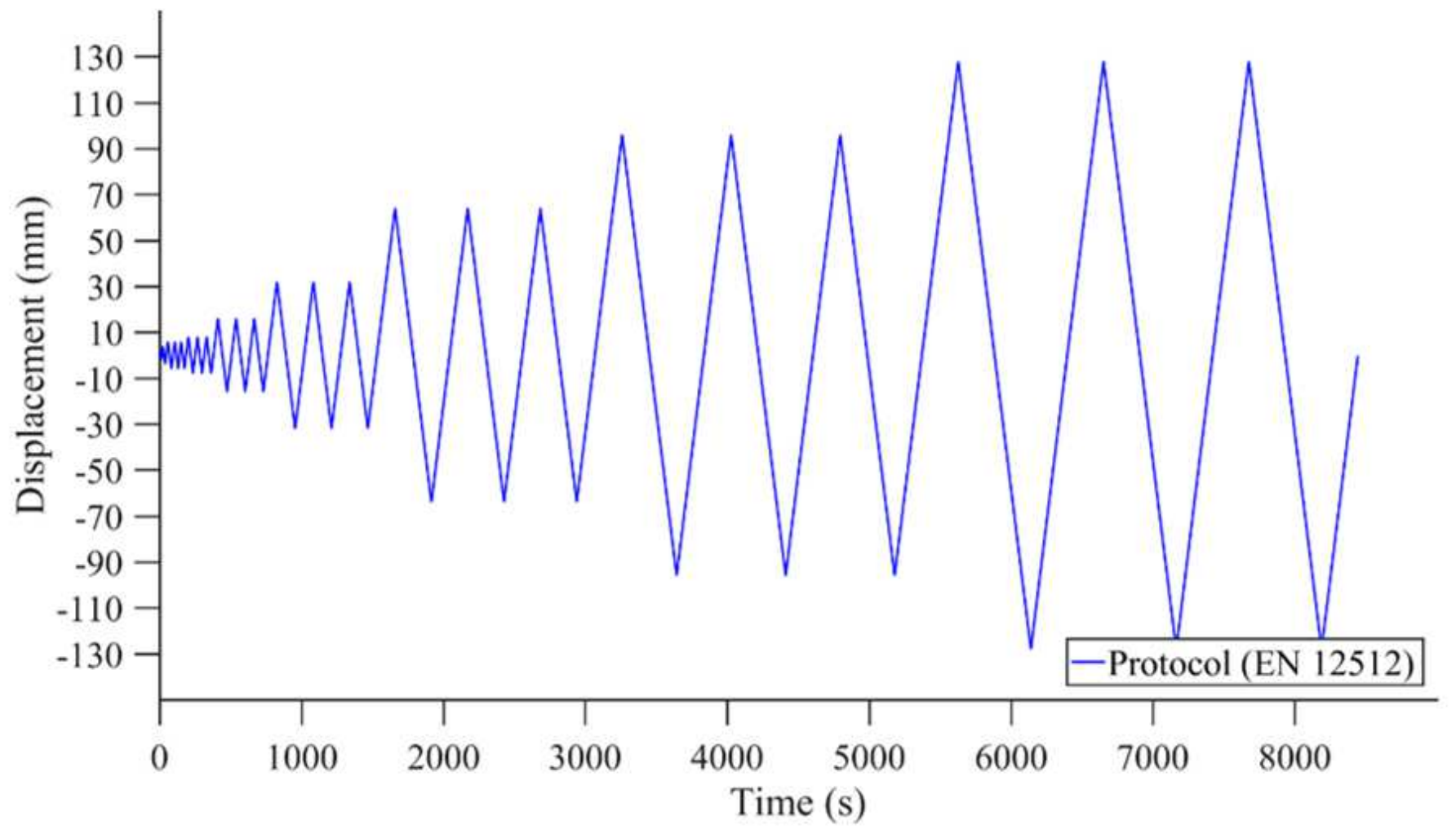

Figure 11

Protocol according to EN 12512 for cyclic load test.

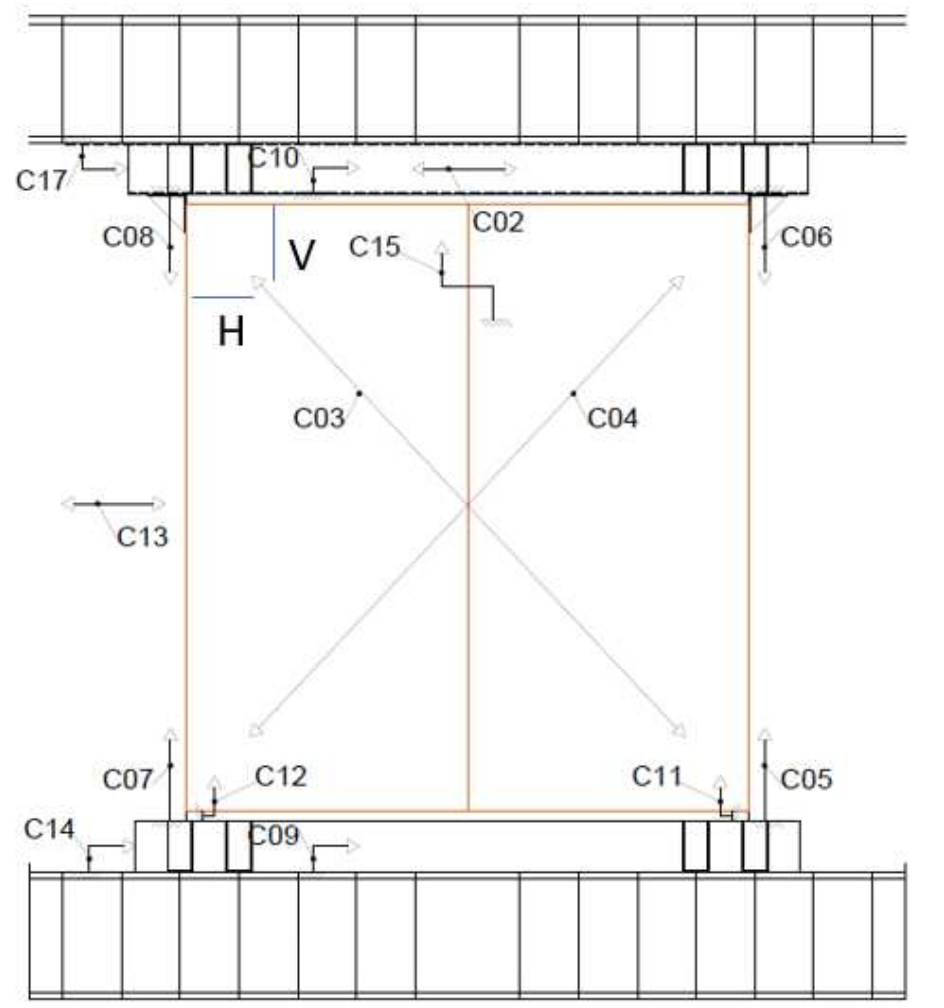

\section{Instruments (measures):} C $=$ HBM channel.

$\mathrm{C} 15=$ relative displacement measurement between CLT plates.

C11 \& C12 = relative deformation measurement between CLT and lower steel sole.

$\mathrm{C} 02$ = global displacement of the actuator.

C03 \& C04 = measurement of diagonal deformation.

$\mathrm{C} 07=$ left uplift bottom.

$\mathrm{CO5}=$ right uplift bottom.

$\mathrm{C} 08=$ left uplift top.

C06 = right uplift top.

$\mathrm{C} 14=$ bottom displacement.

$\mathrm{C} 17=$ top displacement.

$\mathrm{C} 13=$ records load (cell).

$\mathrm{C} 09=$ bottom relative displacement

$\mathrm{C} 10=$ top relative displacement

Figure 12 
Elevation-front view with LVDT locations.
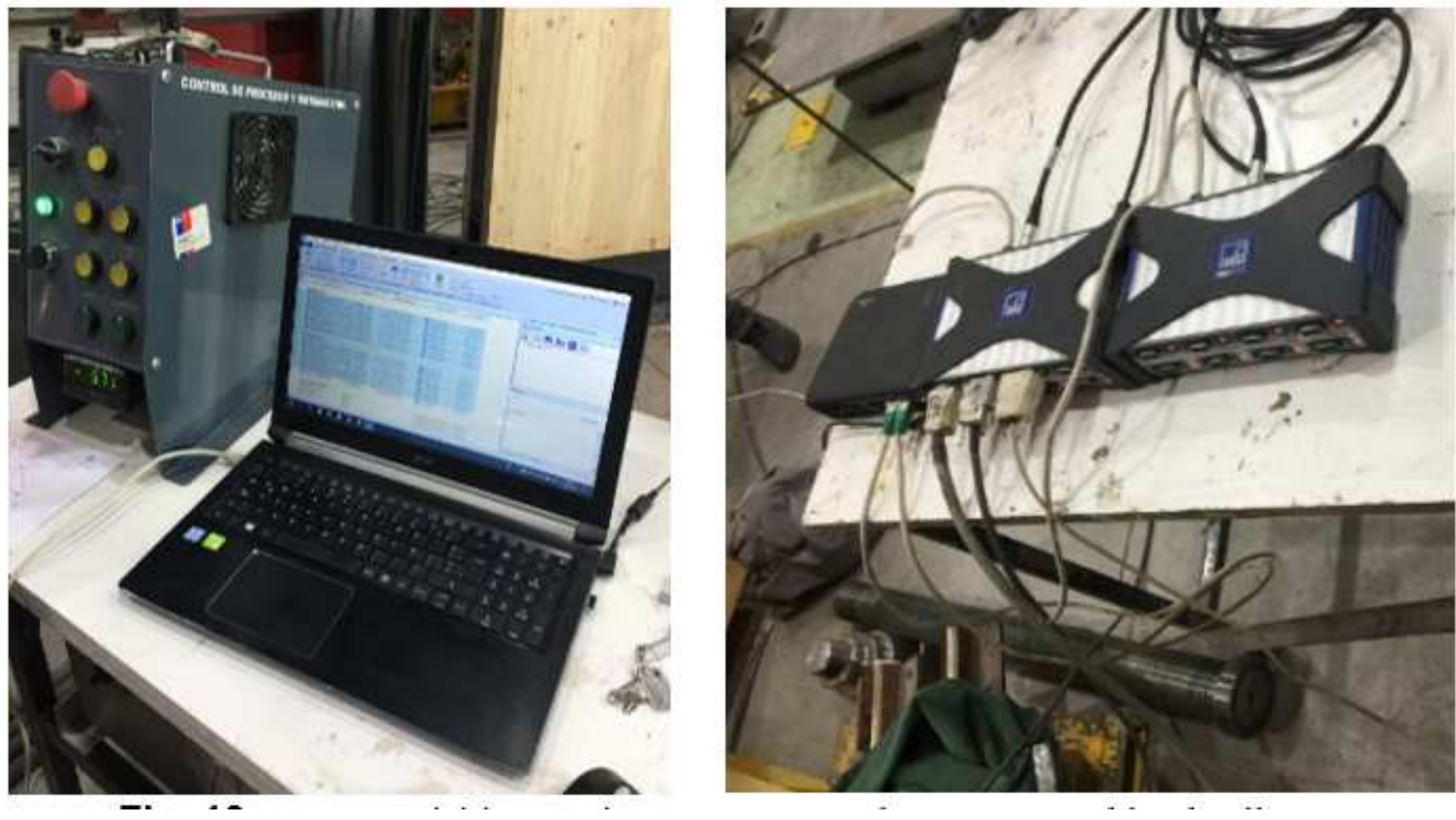

\section{Figure 13}

Data acquisition equipment connected to LVDT and load cell.

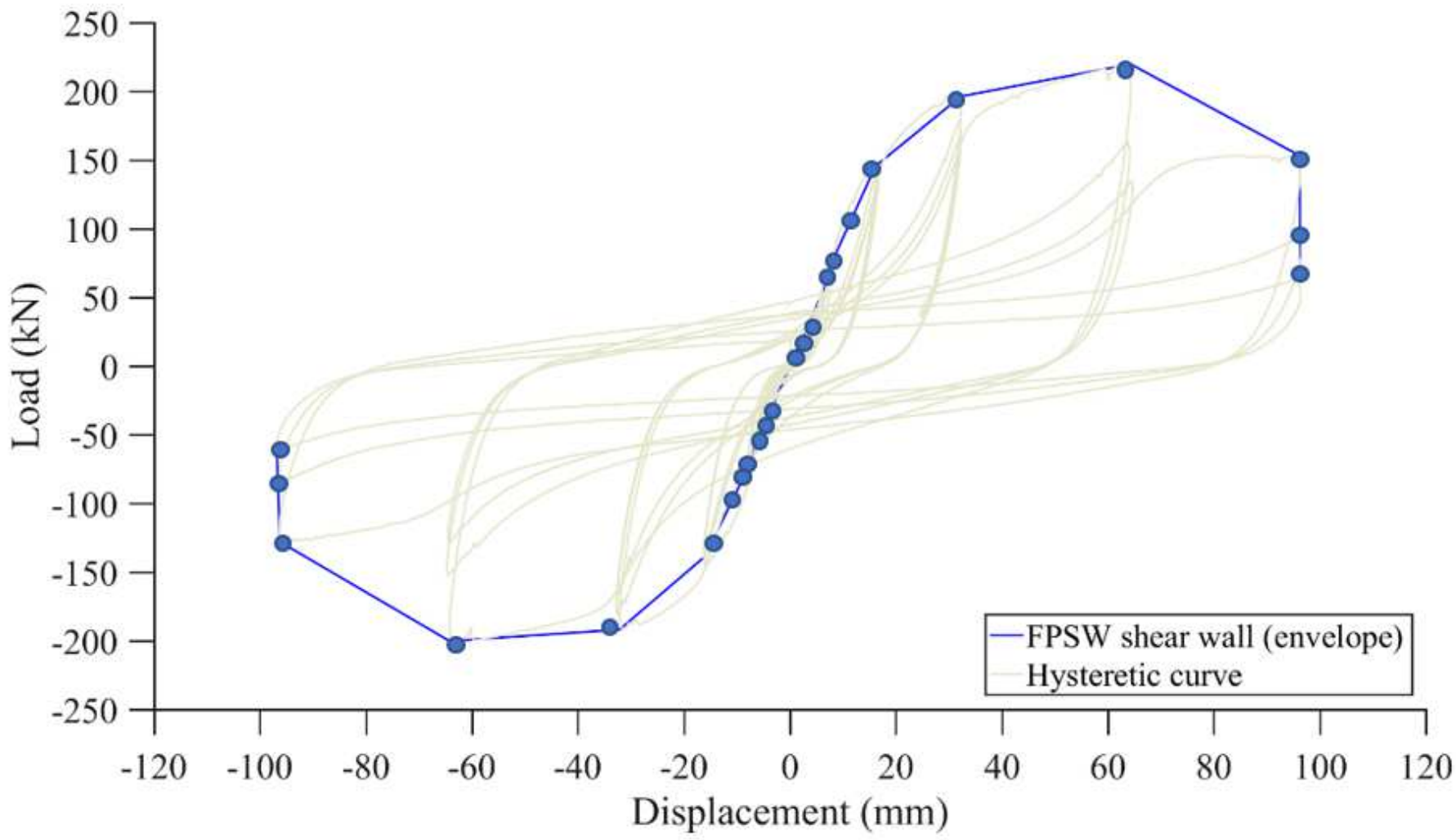

Figure 14 
FPSW envelope curve.
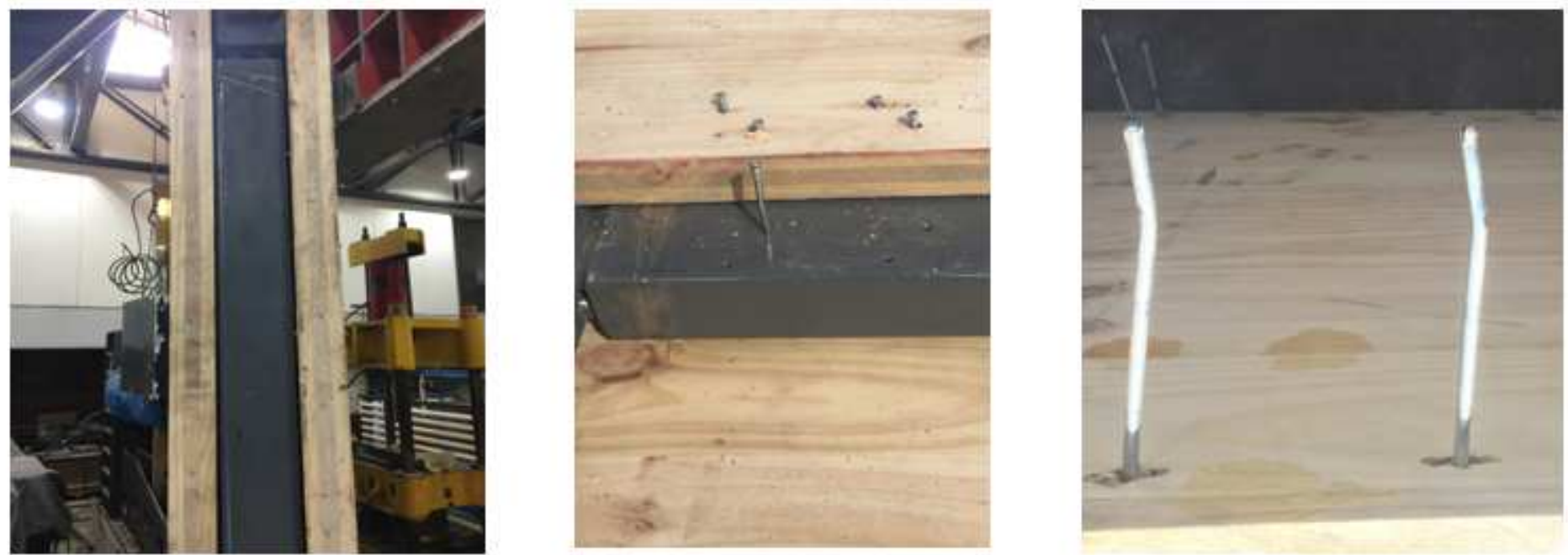

(a)

(b)

(c)

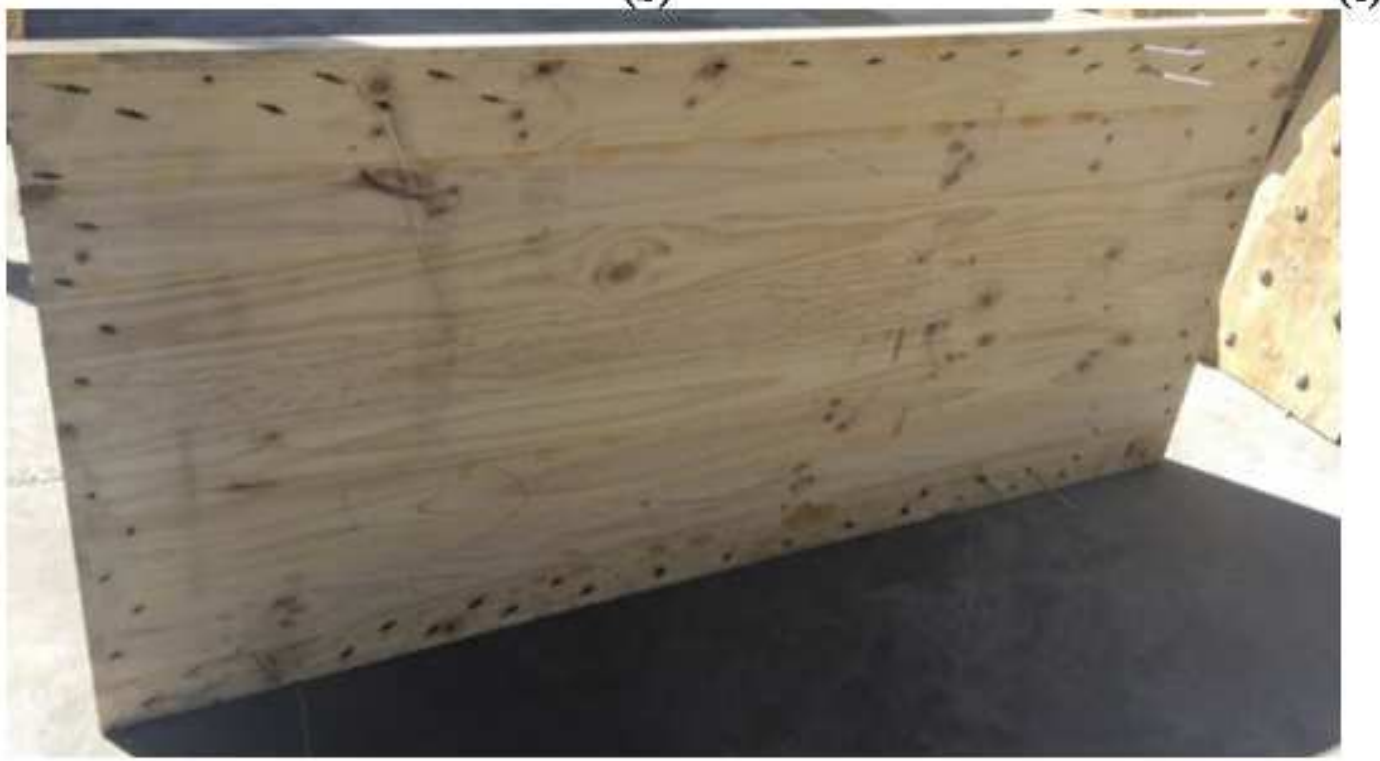

(d)

\section{Figure 15}

Failure mode of the hybrid wall: (a) transverse view FPSW wall; (b) extraction of the dowels; (c) double plastic ball joint (failure mode f of Johansen, 1949); (d) wood with poor embedment resistance and ductile behavior. 


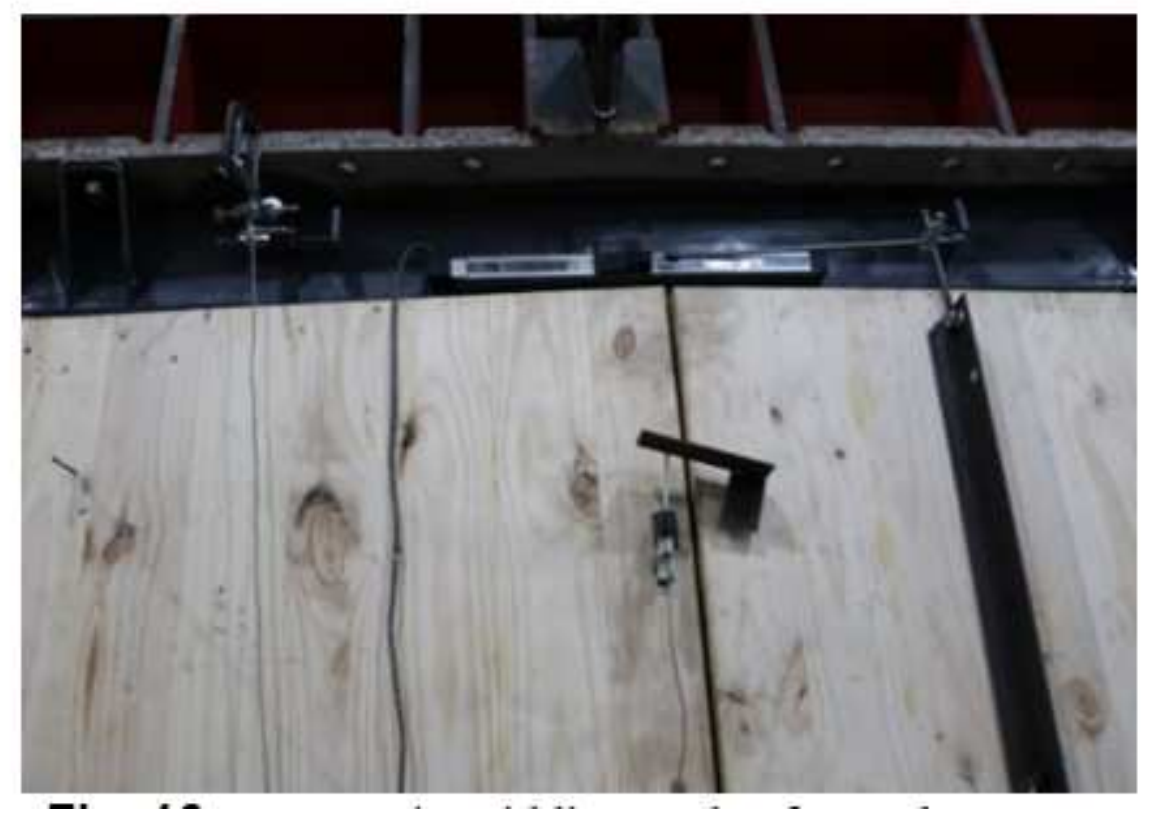

\section{Figure 16}

Damage in middle panels of transducer $\mathrm{C} 15$

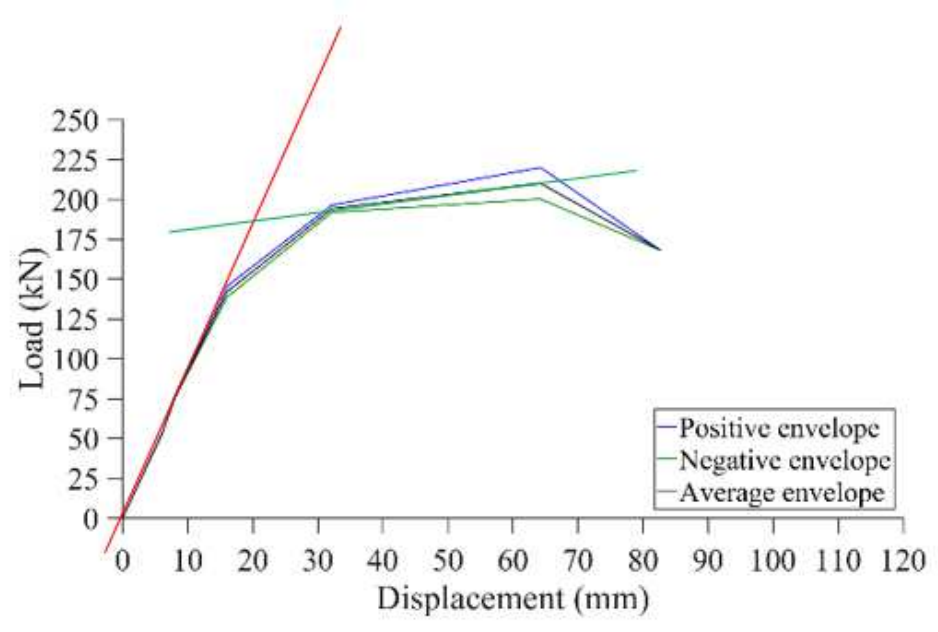

(a)

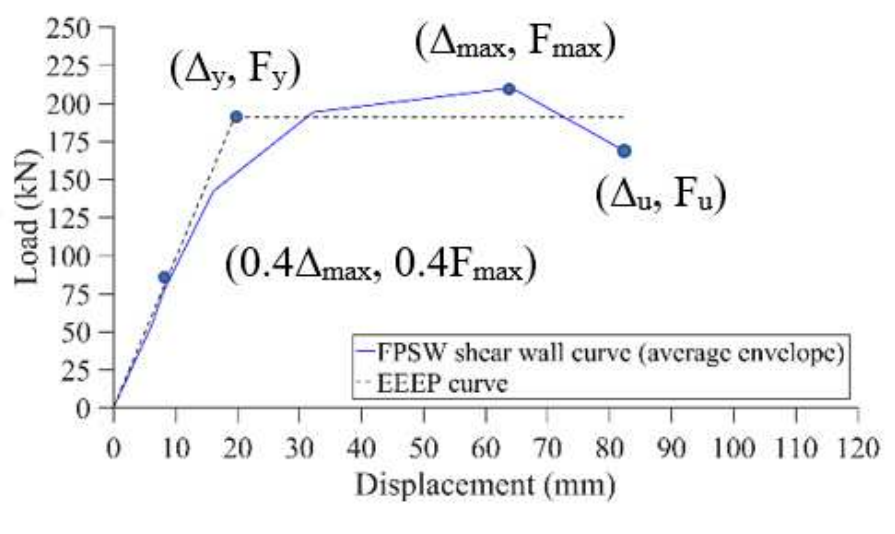

(b)

\section{Figure 17}

(a) Average, positive and negative envelope of CLT-steel wall (FPSW) using EN 12512 methodology; (b) Method design of CLT-steel wall according to ASTM E2126. 




Figure 18

Illustration of a loop for damping calculation. 


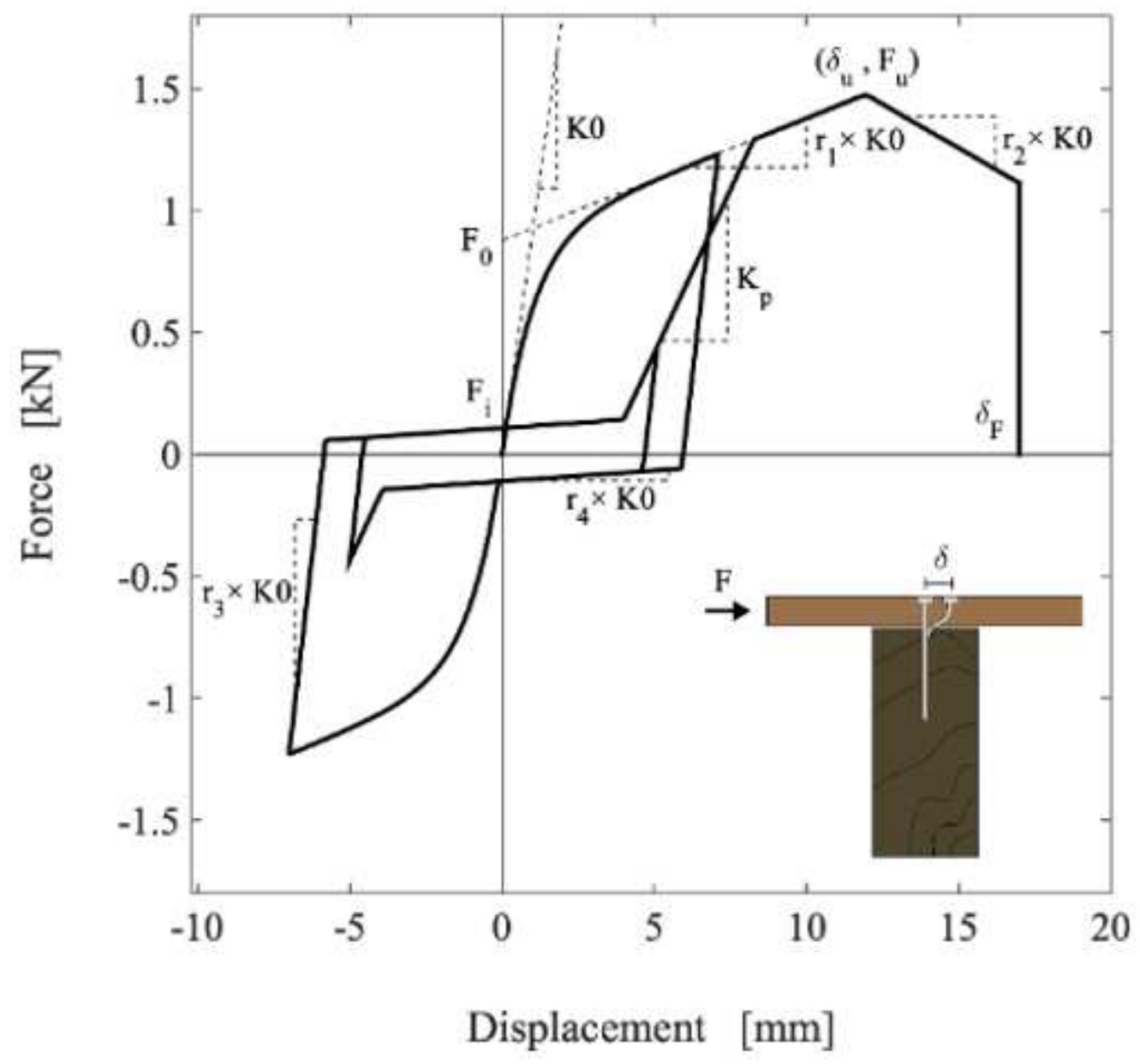

Figure 19

Illustration of the parameters used for modelling the hysteretic response of the modified Stewart hysteretic model (MSTEW) proposed by Folz et al. (2002), based on Estrella et al. (2020). 


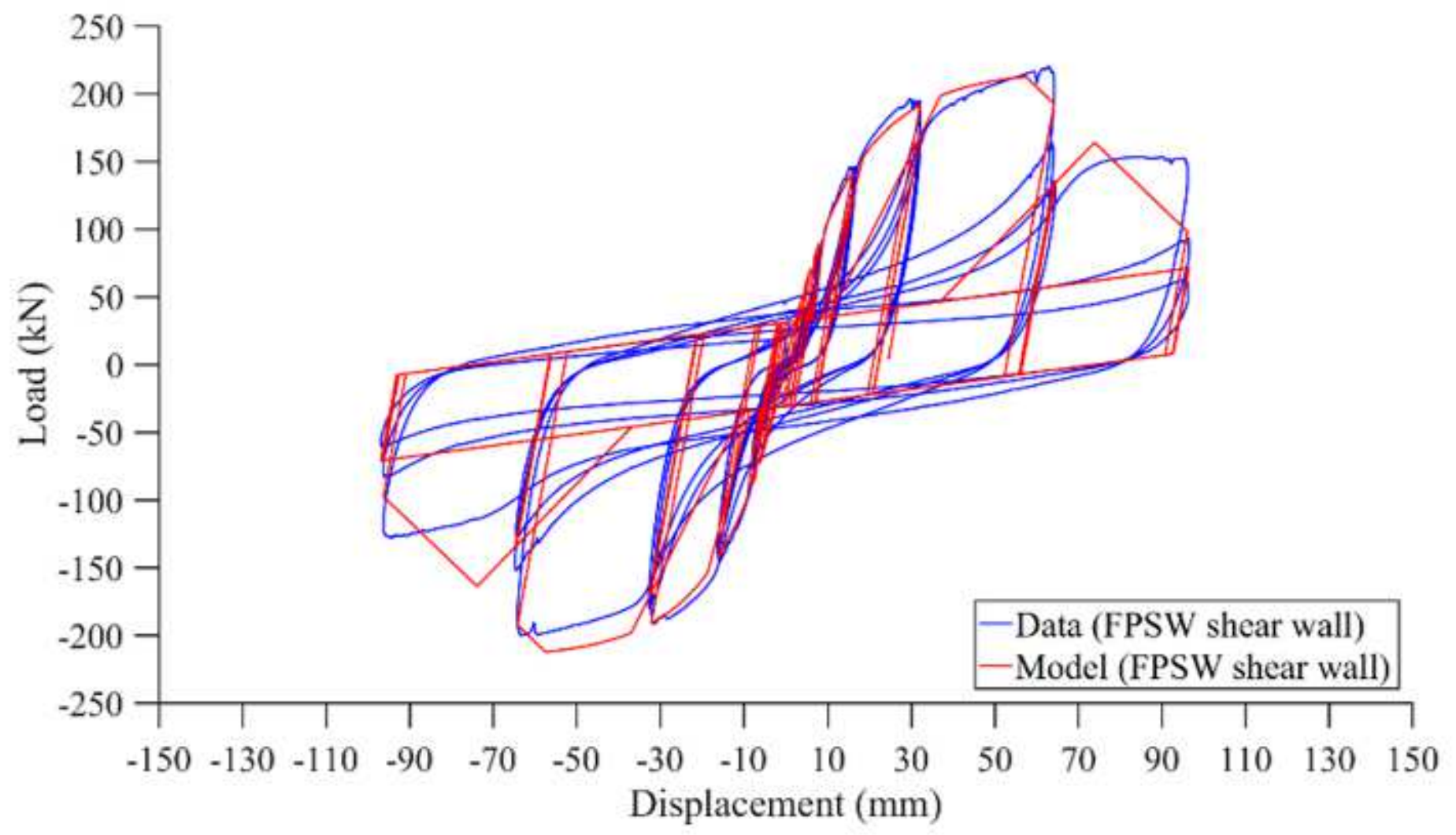

Figure 20

Full detail of the cyclic hysteretic curve and corresponding numerical MSTEW fit of the FPSW wall (CLTsteel).
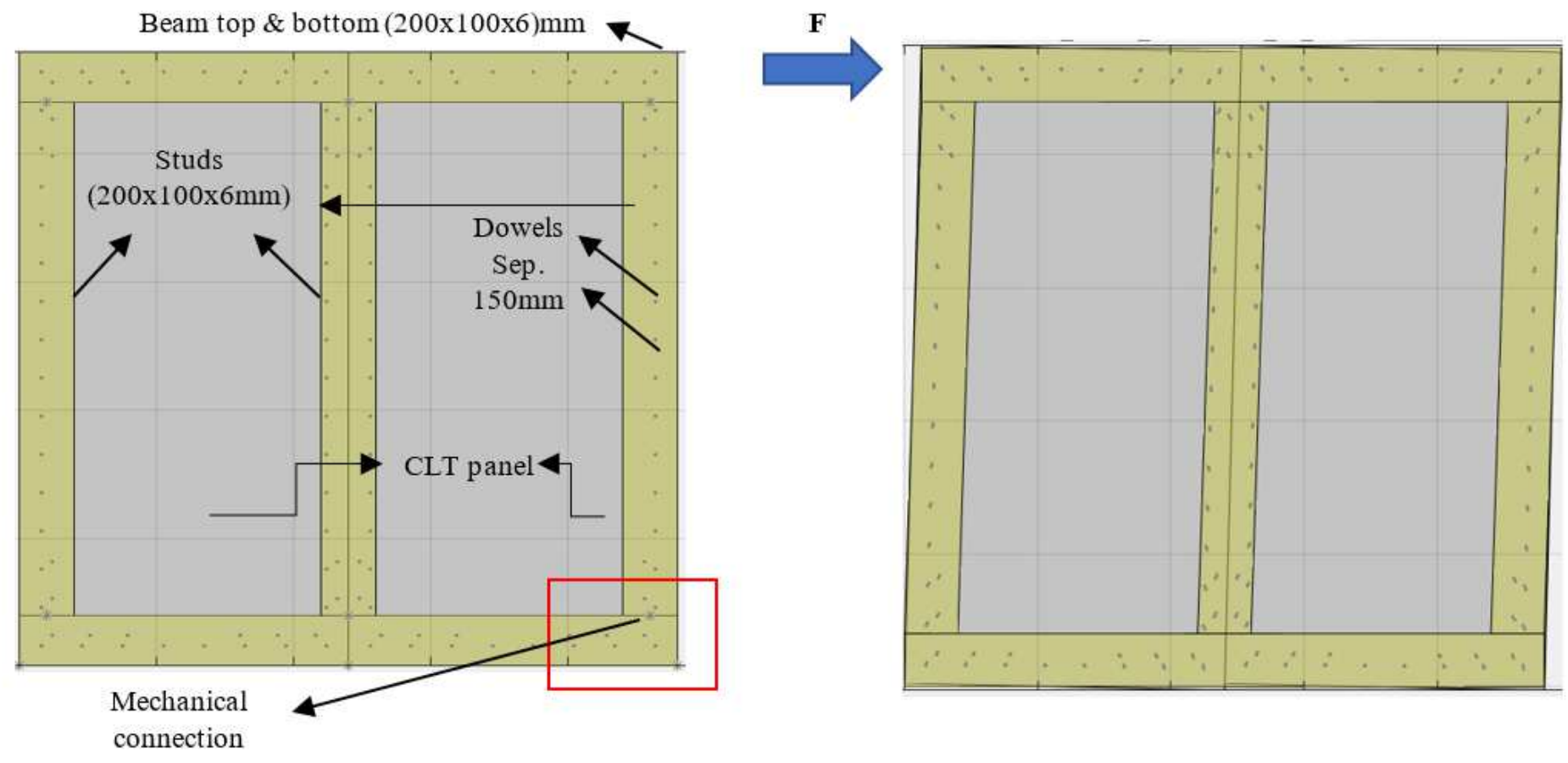
Figure 21

MCASHEW non-linear model prediction for the FPSW test.

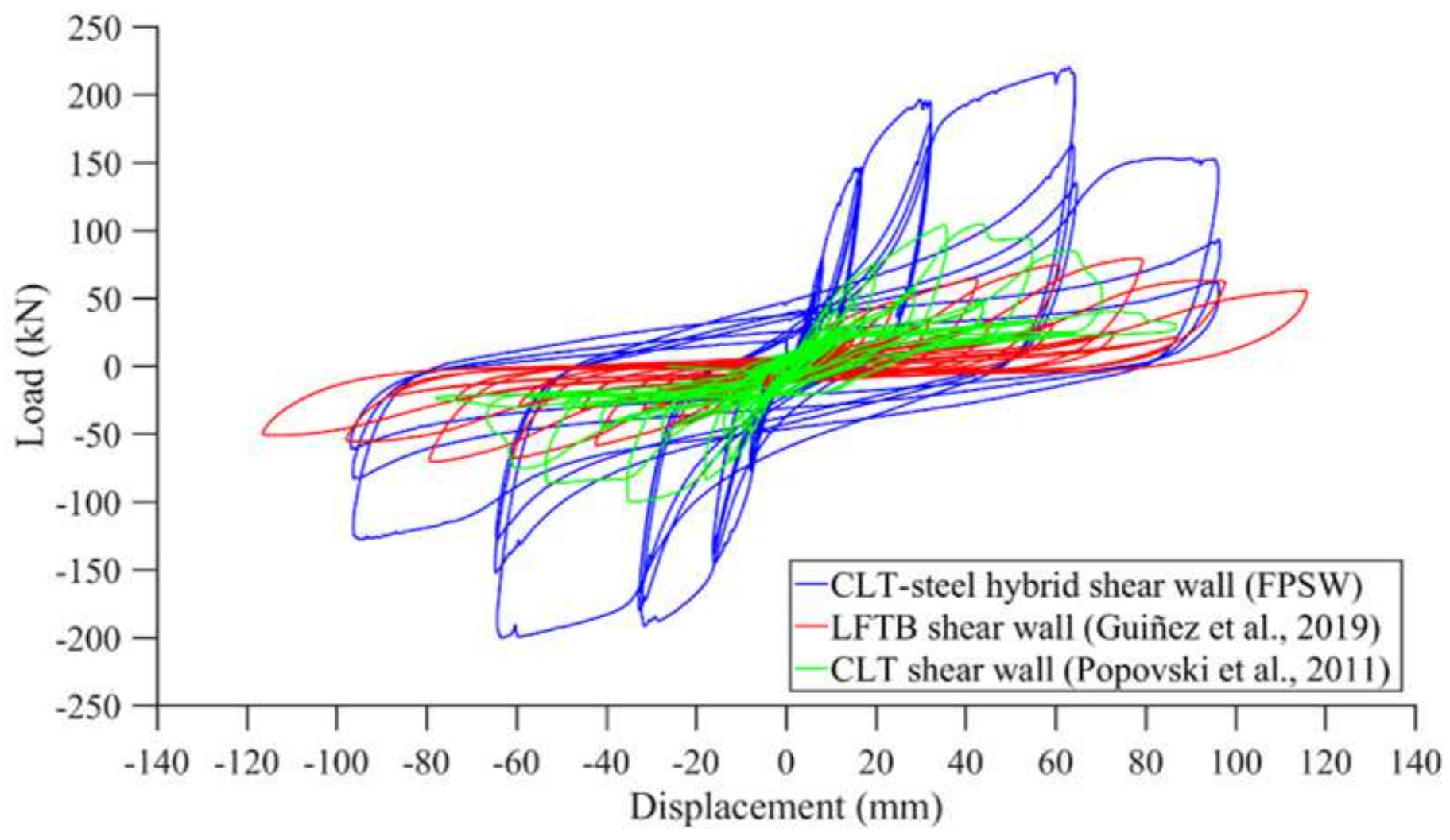

Figure 22

Comparison of cyclic test curves from different wall tests. 


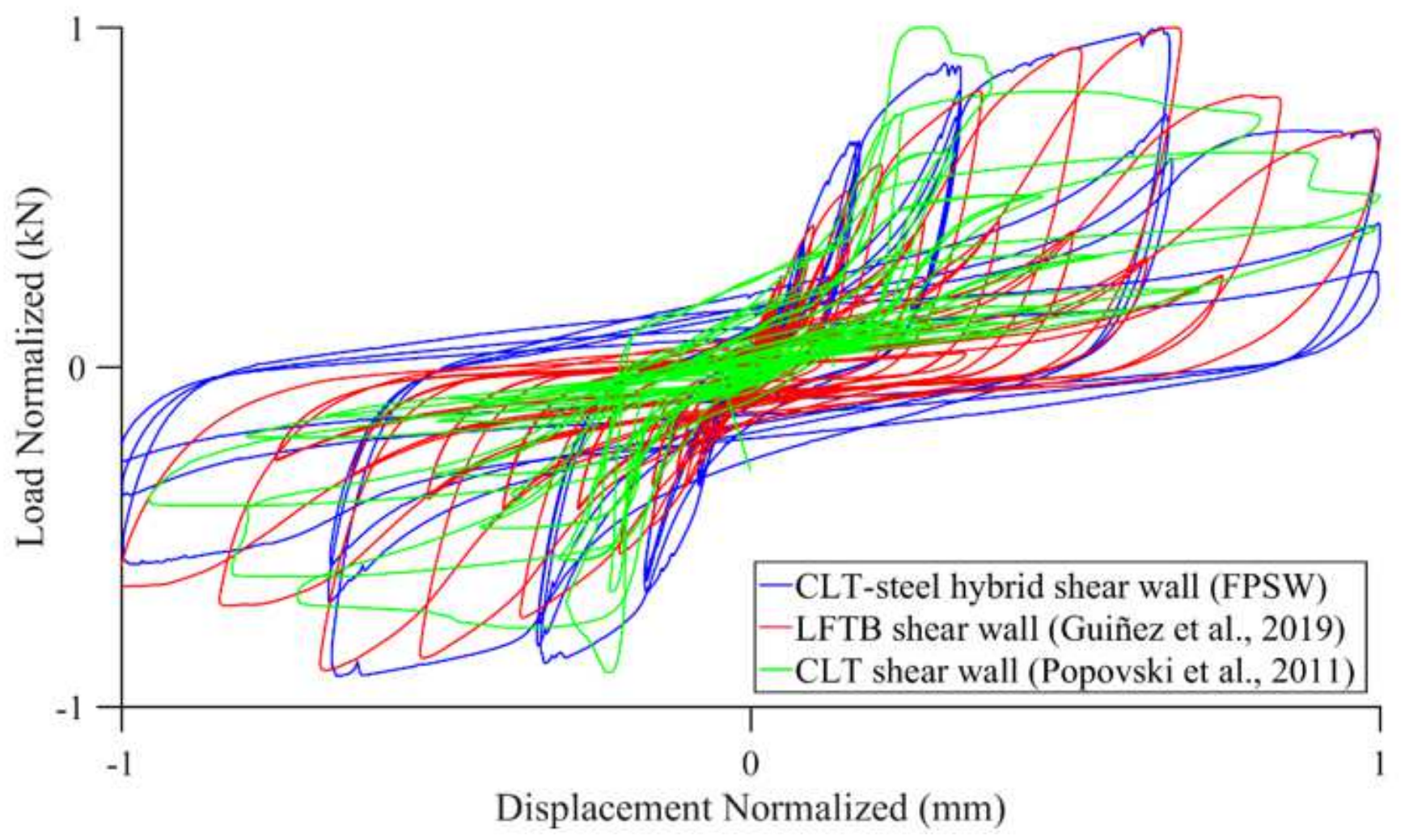

Figure 23

Comparison of cyclic test curves normalized from different wall tests. 

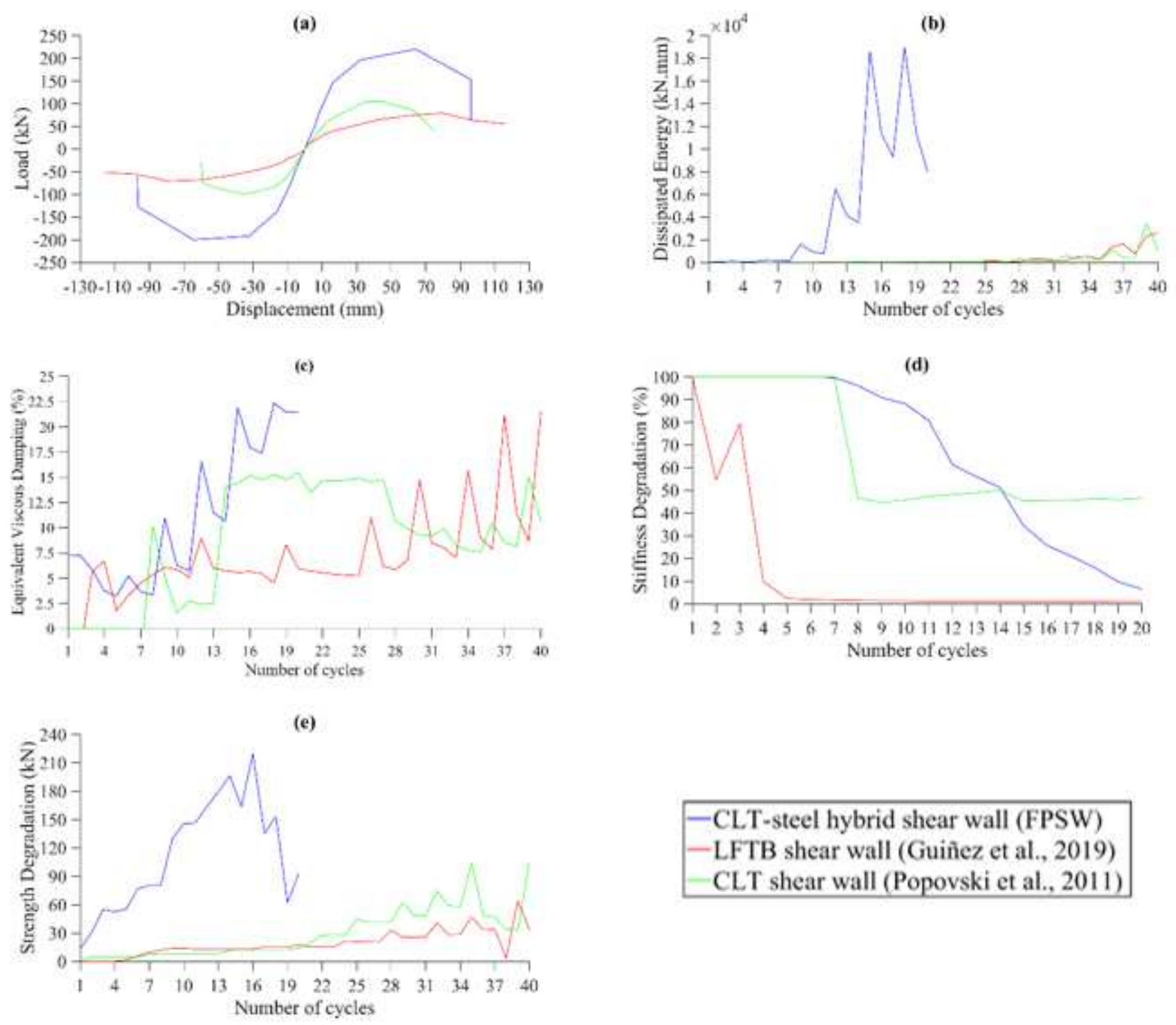

\section{Figure 24}

Comparison of the cyclic performance of the shear walls compared including the innovation CLT-steel wall. (a) hysteresis envelopes; (b) energy dissipation per cycle; (c) equivalent viscous damping per cycle; (d) stiffness degradation per cycle; (e) strength degradation per cycle. 


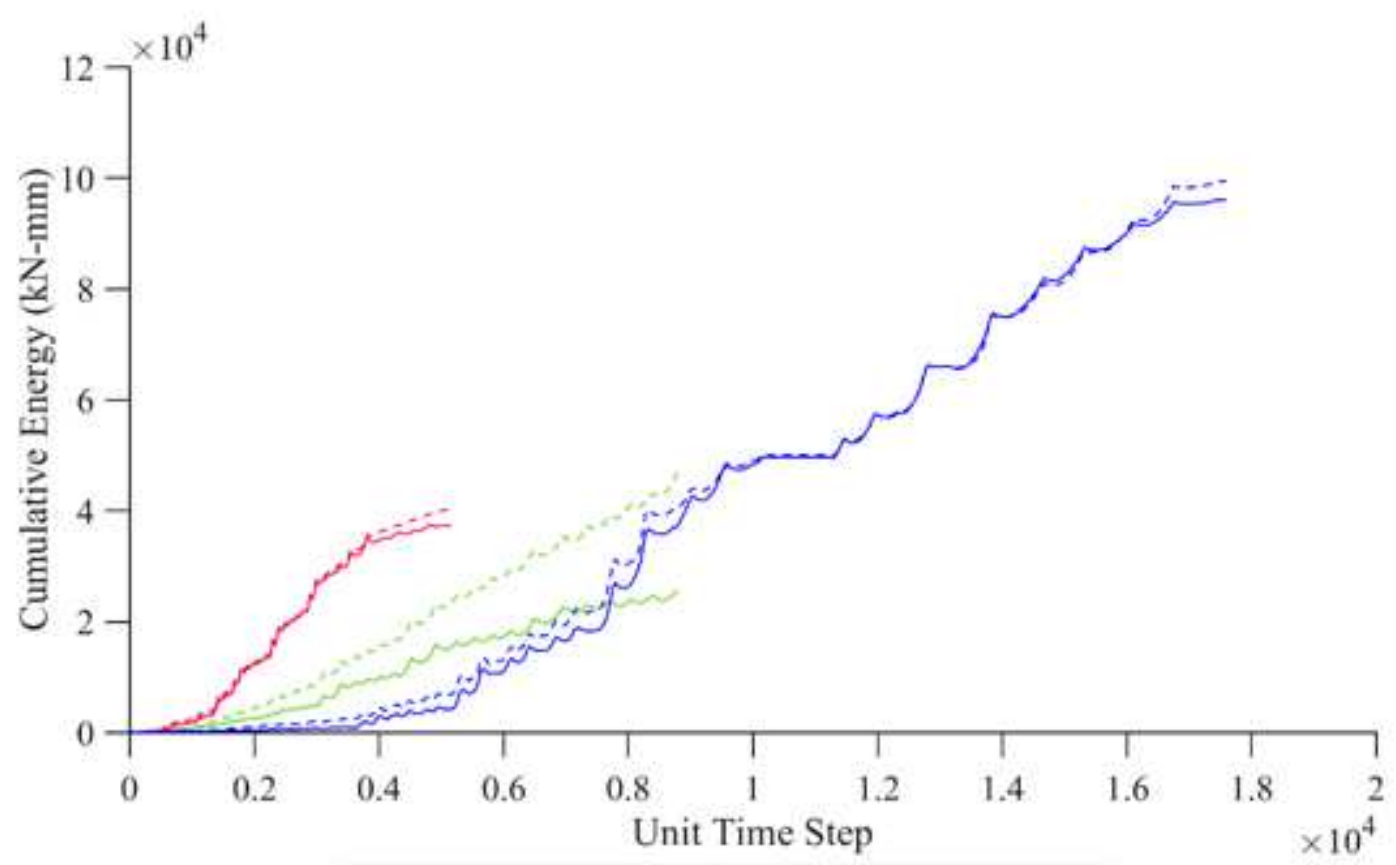

Data CLT shear wall (Popovski et al., 2011)

Model CLT shear wall (Popovski et al., 2011)

-Data LFTB shear wall (Guiñez et al., 2019)

- Model LFTB shear wall (Guiñez et al., 2019)

-Data FPSW shear wall

-- Model FPSW shear wall

Figure 25

Comparison of the cyclic performance of the shear walls' cumulative energy dissipation. 


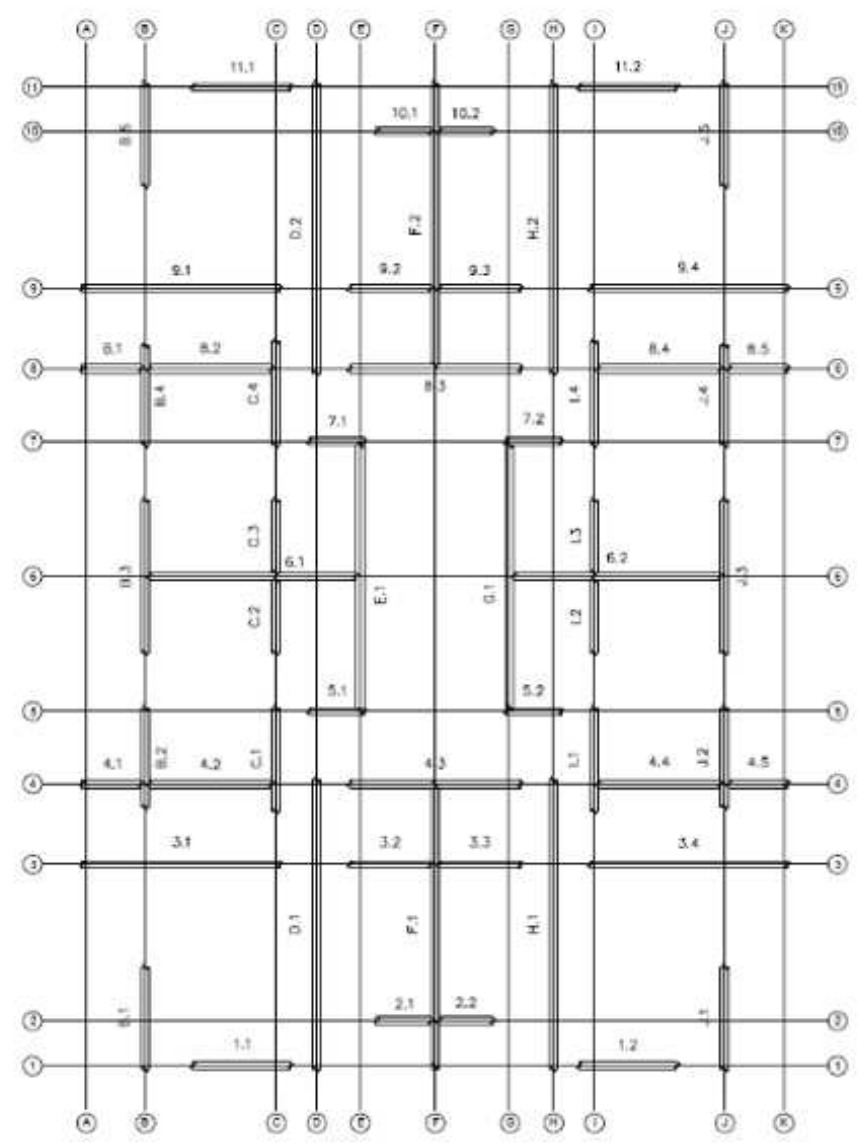

(a)

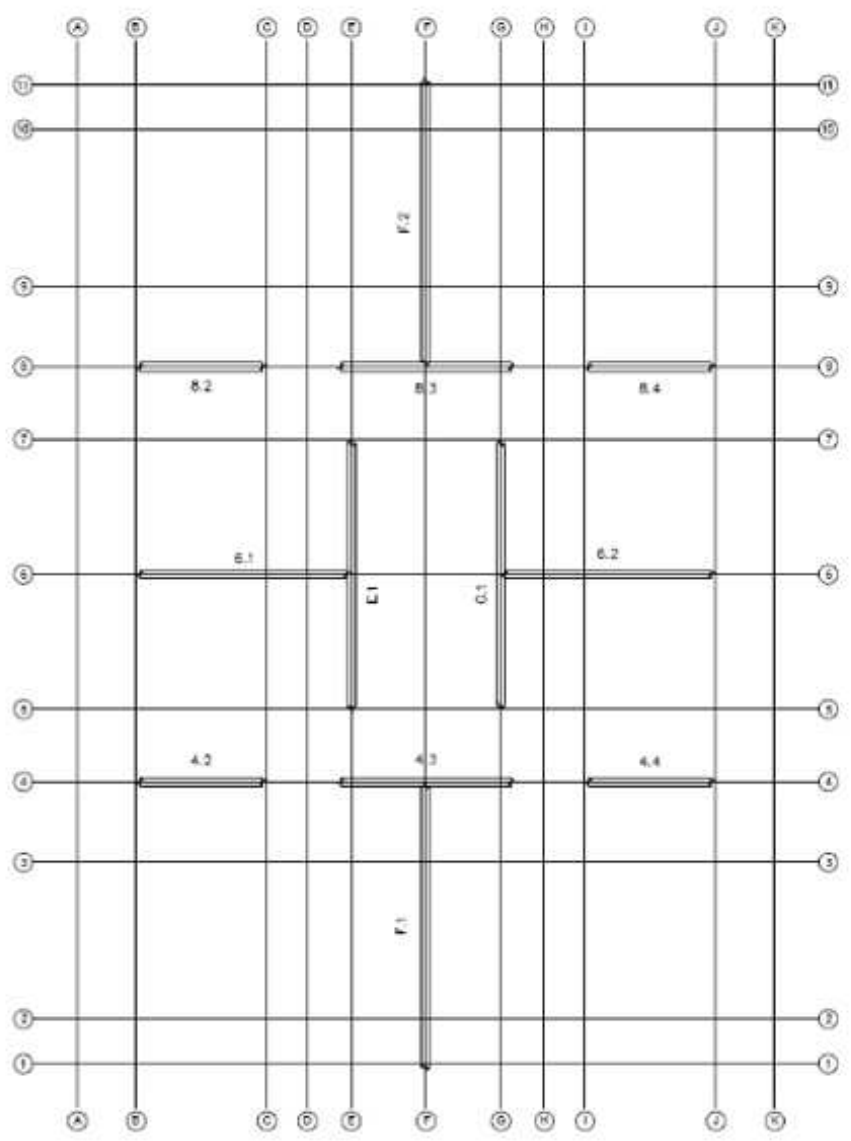

(b)

$-\cdot-$

Figure 26

Floor plan and wall distribution of building: (a) normal frame-platform shear wall (LFTB) density distribution with total walls; (b) FPSW shear wall density distribution with some walls. 

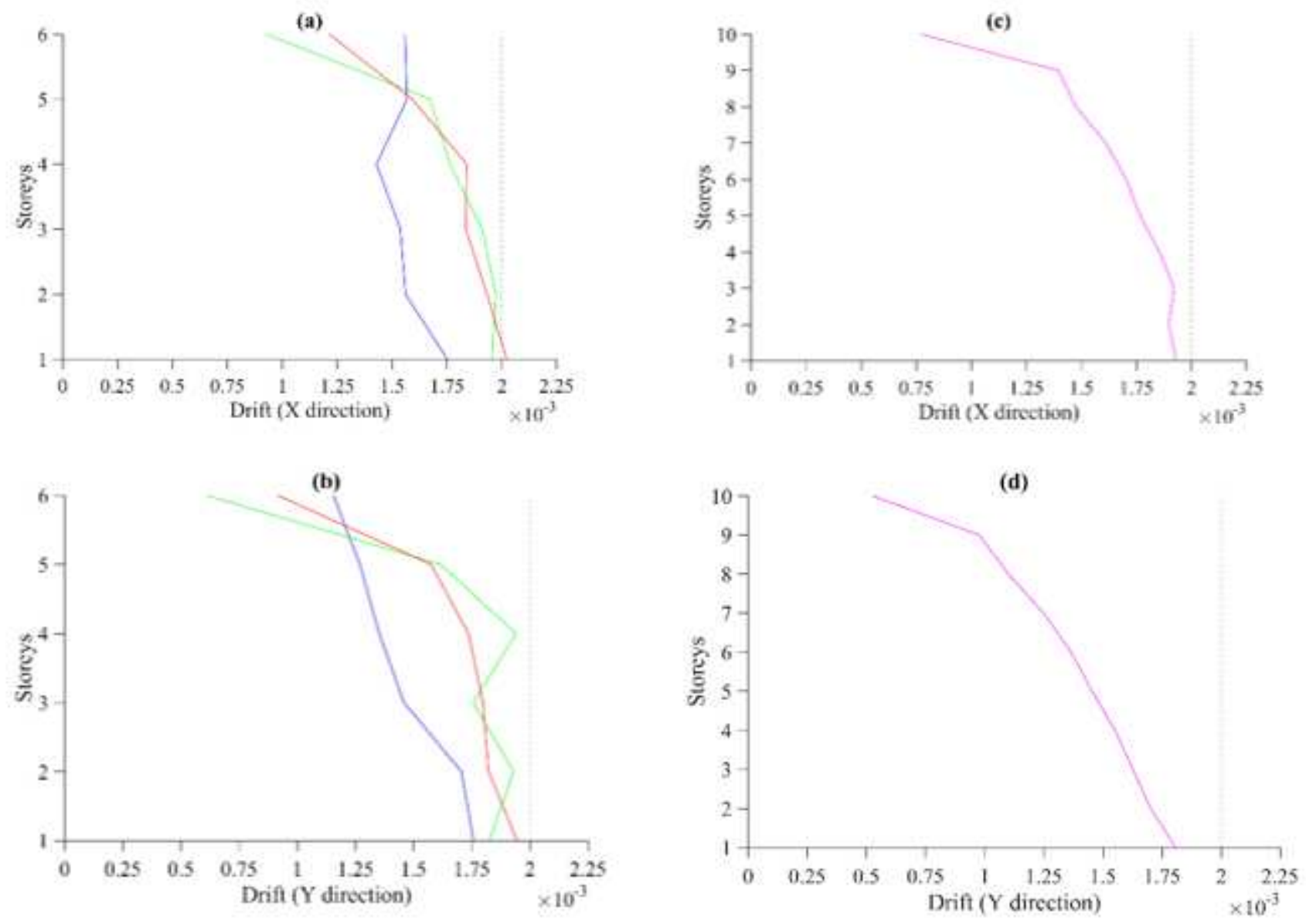

- LFTB building 6 stories (total walls)
-FPSW building 6 stories (total walls)
-FPSW building 6 stories (some walls)
Drift requirement NCH 433

FPSW building 10 stories (total walls) Drift requirement $\mathrm{NCH} 433$

\section{Figure 27}

Drifts limit requirements by (Instituto Nacional de Normalización 2009). 